\title{
AMERICAN SOCIETY OF CIVIL ENGINEERS
}

Founded November 5, 1852

\section{TR A N S A C TIONS}

Paper No. 3360

(Vol 127, 1962, Part I)

\section{RESISTANCE TO FLOW IN ALLUVIAL CHANNELS}

By Daryl B. Simons, ${ }^{1}$ M. ASCE and E. V. Richardson, ${ }^{2}$ A.M. ASCE

With discussion by Messrs. H. A. Einstein; T. Blench; Emmett M. Laursen and Gerald A. Zernial; Dasel E. Hallmark; Thomas Maddock, Jr., and W. B. Langbein; R. Hugh Taylor, Jr., and Norman H. Brooks; Lucien M. Brush, Jr.; and Daryl B. Simons and E. V. Richardson

\section{SYNOPSIS}

This paper presents the initial results of a flume study of alluvial channels. A detailed classification of the regimes of flow, the forms of bed roughness, and the basic concepts pertaining to resistance to flow are discussed.

\section{INTRODUCTION}

The problem of defining roughness in alluvial channels dates back several centuries. The solution of this problem, at least the complete solution, has thus far eluded man. The principal reasons why only limited answers, which in some cases are of questionable value, have been developed is that the scope of the problem is broad, and that there is a great number of variables which influence resistance to flow in alluvial channels. Roughness in alluvial channels is a more complex problem than roughness in rigid channels because the form of the bed is a function of the flow. That is, not only do the alluvial channel roughness elements resist the flow, but they, in turn, are shaped by the flow. Thus far, mostscientists working in this field have been limited by time,

Note.-Published essentially as printed here, in May, 1960, in the Journal of the Hydraulics Division, as Proceedings Paper 2485. Positions and titles given are those in effect when the paper or discussion was approved for publication in Transactions.

1 Hydr. Engr., Geol. Survey, U.S. Dept. of the Interior, Fort Collins, Colo.

2 Hydr. Engr., Geol. Survey, U.S. Dept. of the Interior, Fort Collins, Colo. 


\title{
AMERICAN SOCIETY OF CIVIL ENGINEERS
}

Founded November 5, 1852

\section{TRANSACTIONS}

Paper No. 3360

(Vol 127, 1962, Part I)

\section{RESISTANCE TO FLOW IN ALLUVIAL CHANNELS}

\author{
By Daryl B. Simons, 1 M. ASCE and E. V. Richardson, 2 A. M. ASCE
}

With discussion by Messrs. H. A. Einstein; T. Blench; Emmett M. Laursen and Gerald A. Zernial; Dasel E. Hallmark; Thomas Maddock, Jr., and W. B. Langbein; R. Hugh Taylor, Jr., and Norman H. Brooks; Lucien M. Brush, Jr.; and Daryl B. Simons and E. V. Richardson

\section{SYNOPSIS}

This paper presents the initial results of a flume study of alluvial channels. A detailed classification of the regimes of flow, the forms of bed roughness, and the basic concepts pertaining to resistance to flow are discussed.

\section{INTRODUCTION}

The problem of defining roughness in alluvial channels dates back several centuries. The solution of this problem, at least the complete solution, has thus far eluded man. The principal reasons. why only limited answers, which in some cases are of questionable value, have been developed is that the scope of the problem is broad, and that there is a great number of variables which influence resistance to flow in alluvial channels. Roughness in alluvial channels is a more complex problem than roughness in rigid channels because the form of the bed is a function of the flow. That is, not only do the alluvial channel roughnes elements resist the flow, but they, in turn, are shaped by the flow. Thus far, mostscientistsworking in this field have been limited by time,

Note.-Published essentially as printed here, in May, 1960, in the Journal of the Hydraulics Division, as Proceedings Paper 2485. Positions and titles given are those in effect when the paper or discussion was approved for publication in Transactions.

1 Hydr. Engr., Geol. Survey, U.S. Dept. of the Interior, Fort Collins, Colo.

2 Hydr. Engr., Geol. Survey, U.S. Dept. of the Interior, Fort Collins, Colo. 
facilities, instrumentation needs, and funds. As a result, only small parts of the complete and complex problem have been thoroughly investigated.

\section{THEORY OF FLOW IN ALLUVIAL CHANNELS}

An analysis of flow in alluvial channels is extremely complex because of the many variables involved and the difficulty of measuring them. D. B. Simons, E. V. Richardson and M. L. Albertson discussed ${ }^{3}$ the pertinent variables and important dimensionless parameters related to resistance to flow in alluvial channels, utilizing the principle of dimensional analysis.

Dimensional Analysis. - The equation relating the selected dependent variable $\mathrm{D}$ and the independent variables states that

$$
\mathrm{D}=\phi\left(\mathrm{B}, \mathrm{S}_{\mathrm{fc}}, \mathrm{S}_{\mathrm{fr}}, \mathrm{V}, \mathrm{S}, \rho, \mu, \Delta \gamma, \mathrm{C}_{\mathrm{f}}, \mathrm{d}, \mathrm{w}, \sigma, \Delta \gamma_{\mathrm{S}}\right)
$$

Using $\mathrm{D}, \mathrm{V}$, and $\rho$ as the repeating variables and applying the Pi-theorem

$$
\phi_{1}\left(\frac{B}{D}, S_{f c}, S_{f r}, S, \frac{V d \rho}{\mu}, \frac{V^{2}}{\Delta \gamma D}, C_{f}, \frac{d}{D}, \frac{w}{V}, \sigma, \frac{V^{2}}{\frac{\Delta \gamma_{S} D}{\rho}}\right)=0 \ldots .
$$

The parameters involving $\mu$ and $\Delta \gamma$ are the Reynolds number $R_{e}$ and the Froude number $F_{\mathrm{r}}$, respectively. Since $\Delta_{\gamma} / p \approx \mathrm{g}$ for flow of water in open channels, the Froude number can be expressed in the form

$$
F_{r}=\frac{V}{\sqrt{g D}} \ldots \ldots \ldots \ldots \ldots \ldots
$$

The last term in Eq. 2 can be modified to a drag coefficient $C_{D}$ for the particles. That is,

Eq. 2 can be rewritten as

$$
C_{D}=\frac{d \Delta \gamma_{S}}{\rho w^{2}} \ldots \ldots \ldots \ldots \ldots
$$

$$
\phi_{2}\left(\frac{B}{D}, S_{f c}, S_{f r}, S, R_{e}, F_{r}, C_{f}, \frac{d}{D}, \frac{w}{V}, \sigma, C_{D}\right)=0 \ldots \ldots
$$

This equation can be simplified by noting that:

1. The width-depth ratio is a term which is probably of secondary importance provided $\mathrm{B} / \mathrm{D}>5$. When $\mathrm{B} / \mathrm{D}<5$ the effect of side walls may be appreciable.

2. The relative standard deviation $\sigma$ of the size distribution of the bed material undoubtedly influences flow under certain conditions which must ultimately be determined. However, at this stage of the investigation only one sand has been used, eliminating $\sigma$ as a variable.

3. The shape factors for the channel $S_{f c}$ and $S_{f r}$ may eliminated because the bed is completely alluvial, the cross section is uniformly rectangular except for variation due to bed roughness, and the channel is straight.

Utilizing these simplifications, Eq. 5 reduces to

3 "A Study of Resistance to Flow in Alluvial Channels," by D. B. Simons, E. V. Richardson and M. L. Albertson, U. S. Geol. Survey Water Supply Paper 1948A, 1959. 


$$
\phi_{3}\left(\mathrm{~S}, \mathrm{R}_{\mathrm{e}}, \mathrm{F}_{\mathrm{r}}, \mathrm{C}_{\mathrm{f}}, \frac{\mathrm{d}}{\mathrm{D}}, \frac{\mathrm{w}}{\mathrm{V}}, \mathrm{C}_{\mathrm{D}}\right)=0 \ldots \ldots \ldots
$$

The parameters in Eq. 6 can be modified to other forms in the same manner that the last term in Eq. 2 was modified to a drag coefficient $\mathrm{C}_{\mathrm{D}}$.

\section{EXPERIMENTAL EQUIPMENT AND PROCEDURE}

This study (by the United States Geological Survey (USGS) at the Colorado State University) of roughness in alluvial channels was conducted in a tilting recirculating flume $150 \mathrm{ft}$ long, $8 \mathrm{ft}$ wide, and $2 \mathrm{ft}$ deep (Fig. 1). Any slope between the limits of 0 to $0.013 \mathrm{ft}$ per $\mathrm{ft}$ could be set and discharge could be varied from $2 \mathrm{cfs}$ to $21 \mathrm{cfs}$.

A sand bed $0.7 \mathrm{ft}$ deep was placed in the flume. The sand was a natural river sand obtained from a commercial sand and gravel company located on the Cache La Poudre River. The median fall diameter of the sand, as determined using the visual accumulation size analysis method ${ }^{4}$ was $0.45 \mathrm{~mm}$.

The size distribution plotted as a straight line on log-normal probability paper (Hazen, Whipple and Fuller) with a slope of 1.60 .

Forty-five runs completed with this sand form the basis of this report. These runs ranged from the condition of no sediment movement to antidune flow. To the writers' knowledge, this is the first set of data, excluding that by G. K. Gilbert, 5 which covers such a broad range of flow conditions.

General Procedure. - The general procedure followed for each run involved recirculating a given discharge of the water-sediment mixture in the flume at a given slope until equilibrium conditions were established.

Slope selection was accomplished in a general sense. In any flow system where discharge, depth, and slope can be varied, only two of the three variables can be considered as independent. In a natural stream the discharge and slope are normally independent with depth dependent. In the flume the discharge was independent, slope was independent within limits, and depth was dependent. The slope was preset at the beginning of a run by adjusting the tail gate. Such adjustment indirectly influenced the depth as a dependent variable. Generally, and especially at the flatter slopes (0.0014 to 0.006), the slope of the water surface was adjusted parallel with the bed. With the development of bed configuration, the slope and depth adjusted to the new condition of bed roughness. Thus, for these experiments the slope and depth are a function of $\mathrm{Q}$ and the roughness which develops for that regime of flow. The non-uniformity of flow caused by a change in bed roughness was eliminated by continuing the run until the bed slope and the slope of the water surface again became parallel to each other by natural adjustment of the sand bed.

In the tranquil flow regime the slope of each run was adjusted at the beginning by first setting an M1 backwater curve, and then by alternately adjusting the tailgate and measuring the water surface slope until it reached the desired value. For the flat slopes $(0.00014$ to 0.0006$)$, the bed was carefully screeded to the desired slope before the run. With the steep slopes the bed was only raked to remove the dunes from the previous run before starting the new run

4 "Visual Accumulation Tube for Size Analysis of Sand," by B. D. Colby and R. P. Christensen, Proceedings, ASCE, Vol. 82, No. HY 3, June, 1956.

5 « Transportation of Debris by Running Water," by G. K. Gilbert, U. S. Geol. Survey Prof. Paper 86, 1914. 


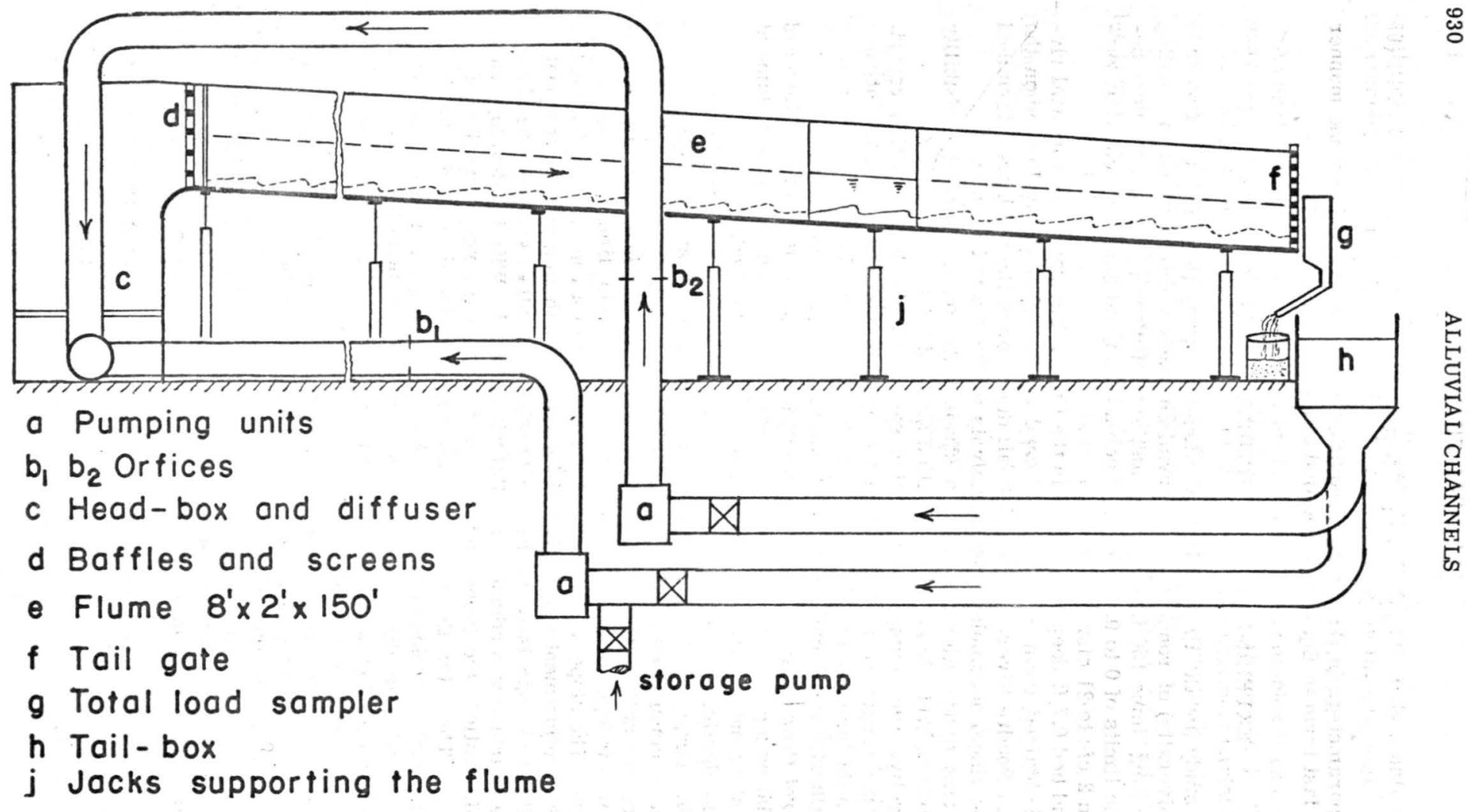

FIG. 1. -SCHEMATIC DIAGRAM OF THE FLUME 
because the increased sand movement assisted in obtaining equilibrium conditions quickly. In the rapid-flow regime the slope was changed by altering the bed control at the lower end of the flume and sediment movement quickly established equilibrium conditions.

Equilibrium flow was considered to be established if:

1. The same bed configuration existed over the full length of the flume, excluding the section influenced by entrance conditions.

2 . The water surface slope remained essentially constant with respect to time $(\partial S / \partial t=0)$.

The period of time required to establish equilibrium conditions varied with the slope and the discharge. Some runs with flat slopes required 3 and 4 days to achieve equilibrium, whereas, for runs with steep slopes, equilibrium was established in 2 or $3 \mathrm{hr}$ 。 Every run involved continuous flume operation until it was completed. Whether or not equilibrium conditions were established was based on the measured data and the judgement of the experimenter. To assure the achievement of equilibrium conditions, most of the experiments were continued longer than the required time as indicated by measurements.

After equilibrium conditions were established, water-surface slope, discharge, water temperature, depth, velocity profiles, total sediment concentration, and suspended sediment concentration were measured. Water-surface slope was measured with a Lory point gage and precision level by determining water-surface elevations every $5 \mathrm{ft}$ along the flume. Discharge was measured with calibrated orifice meters. Depth was determined by subtracting mean bed elevation from mean water surface elevation. Velocity profiles were measured at three verticals with a calibrated Prandtl pitot tube. Total sediment concentration was measured by traversing with a width-depth integrating sampler through the nappe at the downstream end of the flume. Suspended sediment concentration was measured with a DH-48 hand sampler. After the run was completed and the flume drained, a profile of the bed configuration was obtained and bed material was sampled. The basic data are presented in Table 1.

\section{OBSERVED FLOW PHENOMENA}

The form of bed roughness in alluvial channels is a function of the sediment characteristics and the characteristics of the flow. That is, the bed configuration can be changed by altering either discharge (which affects the depth), slope, temperature, or the median diameter or size distribution of the bed material. In the flume experiments the bed material was not changed and the slope, temperature, and depth were varied. Under these conditions the following forms of bed roughness were observed.

Tranquil flow regime, $\mathrm{Fr}_{\mathrm{r}}<1$

1. Plane bed without movement.

2. Ripples.

3. Dunes with ripples superposed.

4. Dunes.

5. Transition from dunes to plane bed.

Rapid flow regime, $\mathrm{F}_{\mathrm{r}}>1$

6. Plane bed and water surface.

7. Standing waves.

8. Antidunes. 
TARLE 1.-BASIC VARIABLES FOR $0.45 \mathrm{~mm}$ BED MATERIAL

\begin{tabular}{|c|c|c|c|c|c|c|c|}
\hline $\begin{array}{l}\text { Run } \\
\text { No. }\end{array}$ & $\begin{array}{c}\mathrm{Sx} 10^{2} \\
\mathrm{ft} / \mathrm{ft}\end{array}$ & $\begin{array}{l}\mathrm{Q} \\
\mathrm{cfs}\end{array}$ & $\begin{array}{l}\mathrm{D}, \\
\mathrm{ft}\end{array}$ & $\begin{array}{l}\text { V, } \\
\text { fps }\end{array}$ & $\mathrm{T}$ & $\begin{array}{l}\mathrm{C}_{\mathrm{T}}, \\
\mathrm{ppm}\end{array}$ & $\begin{array}{l}\text { Form of Bed } \\
\text { Roughness }\end{array}$ \\
\hline 14 & .015 & 3.94 & 0.61 & 0.81 & 10.2 & -- & Plane \\
\hline 17 & .016 & 6.22 & 0.98 & 0.80 & 12.0 & 1 & Ripples \\
\hline 16 & .017 & 5.11 & 0.81 & 0.79 & 12.0 & 2 & Ripples \\
\hline 13 & .019 & 1.84 & 0.35 & 0.65 & 9.0 & -- & Plane \\
\hline 15 & .023 & 5.07 & 0.80 & 0.79 & 11.0 & 1 & Ripples \\
\hline 18 & .031 & 3.62 & 0.58 & 0.78 & 11.3 & 1 & Ripples \\
\hline 2 & .036 & 7.90 & 0.82 & 1.20 & 11.0 & 94 & Ripples \\
\hline 3 & .039 & 7.90 & 0.85 & 1.16 & 11.5 & 101 & Ripples \\
\hline 9 & .040 & 3.84 & 0.55 & 0.88 & 12.0 & 2 & Ripples \\
\hline 1 & .042 & 7.85 & 0.80 & 1.23 & 9.0 & 23 & Ripples \\
\hline 5 & .047 & 7.93 & 0.75 & 1.32 & 11.0 & 26 & Ripples \\
\hline 11 & .049 & 1.95 & 0.35 & 0.70 & 11.5 & 4 & Ripples \\
\hline 4 & .057 & 7.94 & 0.69 & 1.44 & 10.0 & 92 & Dunes \\
\hline 8 & .060 & 3.83 & 0.51 & 0.93 & 12.0 & 8 & Ripples \\
\hline 7 & .078 & 7.98 & 0.70 & 1.43 & 11.5 & 268 & Dunes \\
\hline 10 & .088 & 1.95 & 0.33 & 0.75 & 10.5 & 20 & Ripples \\
\hline 6 & .088 & 3.90 & 0.46 & 1.07 & 9.5 & 42 & Ripples \\
\hline 12 & .106 & 1.95 & 0.29 & 0.85 & 11.7 & 1 & Ripples \\
\hline 19 & .112 & 4.24 & 0.41 & 1.30 & 18.0 & 208 & Dunes \\
\hline 21 & .114 & 12.12 & 0.96 & 1.58 & 16.0 & 641 & Dunes \\
\hline 22 & .124 & 13.54 & 1.00 & 1.70 & 15.7 & 710 & Dunes \\
\hline 25 & .189 & 4.91 & 0.42 & 1.47 & 17.0 & 378 & Dunes \\
\hline 20 & .193 & 8.14 & 0.61 & 1.68 & 16.4 & 508 & Dunes \\
\hline 23 & .247 & 13.34 & 0.65 & 2.57 & 16.0 & 856 & Dunes \\
\hline 24 & .289 & 8.73 & 0.62 & 1.76 & 17.0 & 1200 & Dunes \\
\hline 40 & .301 & 21.41 & 0.81 & 3.32 & 19.0 & 2460 & Dunes \\
\hline 39 & .364 & 20.64 & 0.55 & 4.71 & 19.0 & 3960 & Transition \\
\hline 26 & .366 & 14.45 & 0.34 & 5.38 & 17.0 & 4580 & Transition \\
\hline 28 & .366 & 11.19 & 0.40 & 3.52 & 16.0 & 4230 & Transition \\
\hline 29 & .369 & 4.54 & 0.30 & 1.89 & 17.4 & 1850 & Transition \\
\hline 31 & .432 & 14.85 & 0.44 & 4.24 & 17.5 & 4750 & Transition \\
\hline 27 & .436 & 7.91 & 0.33 & 2.99 & 18.0 & 4100 & Transition \\
\hline 36 & .446 & 3.15 & 0.19 & 2.04 & 19.0 & 1370 & Transition \\
\hline 41 & .466 & 21.62 & 0.54 & 5.05 & 18.7 & 4340 & Transition \\
\hline 30 & .492 & 5.33 & 0.27 & 2.47 & 17.2 & 3550 & Transition \\
\hline 35 & .494 & 5.58 & 0.25 & 2.80 & 17.0 & 4610 & Transition \\
\hline 34 & .546 & 8.44 & 0.28 & 3.73 & 17.5 & 5690 & Transition \\
\hline 33 & .607 & 10.02 & 0.27 & 4.60 & 16.0 & 6810 & Transition \\
\hline 38 & .619 & 21.38 & 0.50 & 5.38 & 19.0 & 6230 & Transition \\
\hline 37 & .620 & 18.87 & 0.43 & 5.54 & 18.5 & 5570 & Transition \\
\hline 32 & .656 & 14.96 & 0.37 & 5.03 & 18.0 & 6180 & Antidune \\
\hline 45 & .862 & 5.58 & 0.28 & 2.50 & 18.9 & 9630 & Anticlune \\
\hline 44 & .898 & 10.83 & 0.28 & 4.78 & 19.4 & 15,100 & Antidune \\
\hline 42 & .986 & 13.43 & 0.31 & 5.36 & 20.0 & 11,400 & Antidune \\
\hline 43 & 1.01 & 21.42 & 0.43 & 6.18 & 18.5 & 11,500 & Antidune \\
\hline
\end{tabular}




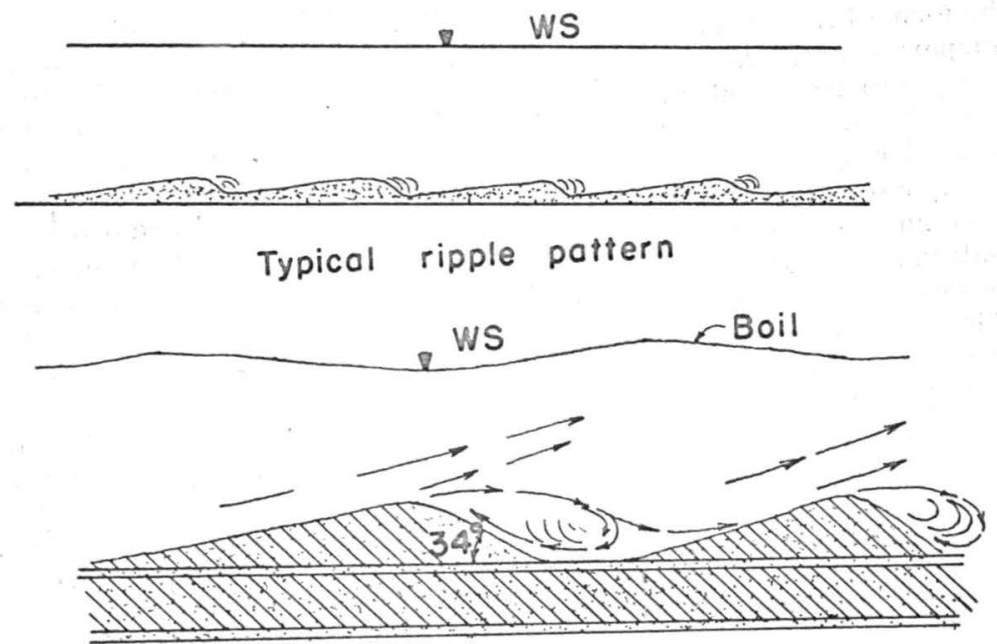

Typical dune pattern

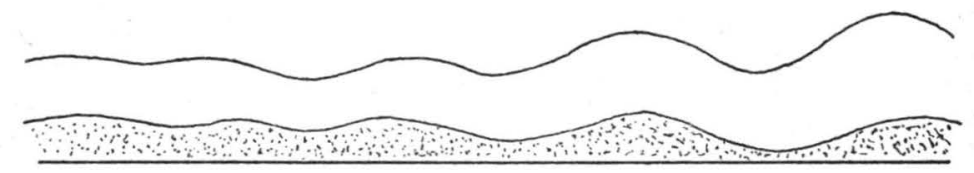

Typical standing waves

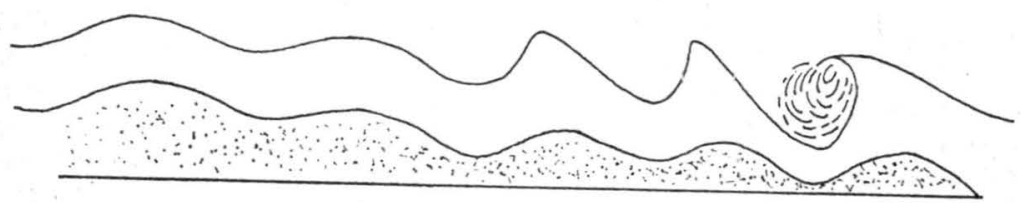

Typical antidune pottern

FIG, 2.-MAJOR FORMS OF BED ROUGENESS 
The major forms of bed roughness are sketched in Fig。 2 .

Slope and bed material were the dominant factors which determined the for $m$ of bed configuration. Although, when slope and bed material remained constant, the form of the bed could be changed by varying depth (changing Q) or changing temperature. However, changing depth or temperature did not change flow from tranquil to rapid unless the slope for a given bed material was close to the critical slope. That is, for a given bed material, a small slope and a dune-bed form of roughness, it was impossible to change to standing waves by changing depth or temperature. With a given depth, temperature, and bed material, all bed formscan be observed by changing slope. This last statement must be qualified because with shallow depths three-dimensional flow and multiple bed roughness forms will occur. It is also possible to have a size of bed material which will not produce some of the bed forms regardless of the depth, slope, or water temperature.

With a given bed material, the change from one bed form to another is not necessarily abrupt. Neither does a particular form occur at the same slope (depth and temperature held constant) nor the same depth (slope and temperature held constant) if the process is reversed. That is, the change from ripples to dunes can occur at a different slope (depth and temperature held constant) than the change from dunes to ripples. This gradual change and/or hysteresis effect results in a transition from one bed form to another. This transition is of major importance when the bed form changes from dunes to plane bed or vice versa. Changes in bed form occur in many natural rivers as a result of a change in discharge. This change will occur if the slope of the energy grade line is close to the critical slope so that a change in $Q$ can cause a change in bed form. For example, the change from dunes at low stage to plane bed at high stage. When this change in bed form occurs there will be a break in the discharge rating curve for that stream. Because there is a hysteresis effect in the transition from dunes to plane bed or plane bed to dunes, the stage where the break in the rating curve occurs depends on whether the stage is rising or falling and also on the rate of change of discharge.

It is important to note that the velocity of the flow in an alluvial channel is not zero at the bed. The velocity of the water through the bed, even though slow, is important, especially when considering seepage force, which is a force or form drag exerted by the liquid on the sand grains within the bed. The magnitude of the seepage force per unit of volume of bed material is equal to the hydraulic gradient of the flow and it acts in the direction of flow. When the magnitude of the seepage force is equal in magnitude and opposite in direction to the submerged weight of a unit volume of bed material (inflow condition), the effective weight of the bed material tends toward zero. Conversely, if the seepage force and submerged weight of bed material act in the same direction (outflow condition), the effective weight of the bed material increased. The direction of flow in the bed canvary from vertically upward to vertically downward depending on bed configuration, direction of flow in the bed, water table condition and regime of flow. The velocity of flow in the bed is largest with the dune-bed form of roughness because the porosity of the material is relatively large due to the relatively loose packing of the bed material resulting from the dune activity, and it is smallest in the rapid flow regime where the bed material is more closely packed. In the flume, as a result of the floor, the velocity of the flow through the bed was probably smaller than in most natural streams with deep sand beds; consequently, the seepage force was smaller. In a natural stream the velocity has vertical components because of inflow to, or 
outflow from the bed. The rate of inflow or outflow, which depends on the position of the water table of the surrounding area, can cause large seepage forces. These forces may have a considerable local effect on the form of bed roughness and transport of sediment.

Tranquil Flow Regime.

Plane Bed Without Movement. - With the plane bed, and no movement of bed material, the bed was soft and easily disturbed. The word plane is used to emphasize that the bed was not hydraulically smooth. For a hydraulically smooth rigid bed $d / \sigma^{\prime}$ (the ratio of median diameter of bed material to the thickness of the laminar sublayer) must be less than 0.25 . The minimum $d / \sigma^{\prime}$ for the flume runs was 0.40 . Obviously, it is possible to obtain a hydraulically smooth boundary without bed movement by decreasing the slope or the depth. However, a smooth bed or a plane bed without sediment movement in itself has little practical significance. The important factor to consider is the shear at which movement of bed material will begin as the slope or depth or both are increased. It was interesting to note that the shear at which movement began with this bed material was not the shear at which the hydraulically smooth boundary became hydraulically rough. That is, the thickness of the laminar sublayer decreased beyond the shear corresponding to the transition before movement began. It must be remembered that the bed material was nonuniform and computations were based on a median diameter of the material.

Movement of bed material began with a slope of 0.00015 when the depth was increased (by increasing Q) from 0.61 to $0.71 \mathrm{ft}$ the $\left(\mathrm{d} / \sigma^{\prime}\right)$ - value at the beginning of movement of the bed material was between 0.48 and 0.53 . The Manning $\mathrm{n}$ for no bed material movement was approximately 0.015 , and $\mathrm{C} / \sqrt{\mathrm{g}}$ varied between 14.0 and 15.0 .

When $d / \sigma^{\prime}$ approached 0.53 movement of the material began and ripples started to form. The ripples first formed at the upstream end of the flume and at any small depression or ridge on the bed, and then continued to develop in a downstream direction from these points of minor disturbance until the bed was covered. As ripples formed on the bed, the slope and depth in the flume increased from 0.00015 and 0.71 to 0.00023 and 0.80 respectively. The Manning $\mathrm{n}$ increased from 0.015 to 0.022 and $\mathrm{C} / \sqrt{\mathrm{g}}$ decreased from 15.0 to 10.3 .

Ripples started to form when movement began. Other investigators have reported movement with a plane bed without the formation of ripples. Whether this movement without ripples is a physical fact or the result of the experimental procedure and equipment is unknown. Possibly, movement without ripples results if a sorted bed material is used. The material used in these experiments was unsorted. The width-depth ratio also may be important.

Ripples. - The form of the ripples is illustrated in Fig。 2, and a photograph of typical ripple formation is shown in Fig。3. For all ripple runs the height of the ripples was less than $0.10 \mathrm{ft}$ and their longitudinal spacing was less than $2.0 \mathrm{ft}$. Their length-height ratio $\mathrm{L} / \mathrm{h}$ varied from 10 to 20 。 The ratio of depth of flow to ripple height ranged from 4 to 24 , Manning $\mathrm{n}$ ranged from 0.019 to 0.027 , and $C / \sqrt{\mathrm{g}}$ ranged from 7.8 to 12.4 . The upper limit of $n$-values, and the lower limit of $\mathrm{C} / \sqrt{\mathrm{g}}$, in general, were associated with the shallow depths.

There was little or no suspended sediment movement with the ripple bed form. The water was sufficiently clear so that the bed was visible at all times. The total sediment load ranged from $1 \mathrm{ppm}$ to $101 \mathrm{ppm}$ and the sediment moved in more or less continuous contact with the bed by rolling up over the crest of the ripples and coming to rest on their downstream face. This sediment did not move again until it became exposed in the upstream part of the ripple as 


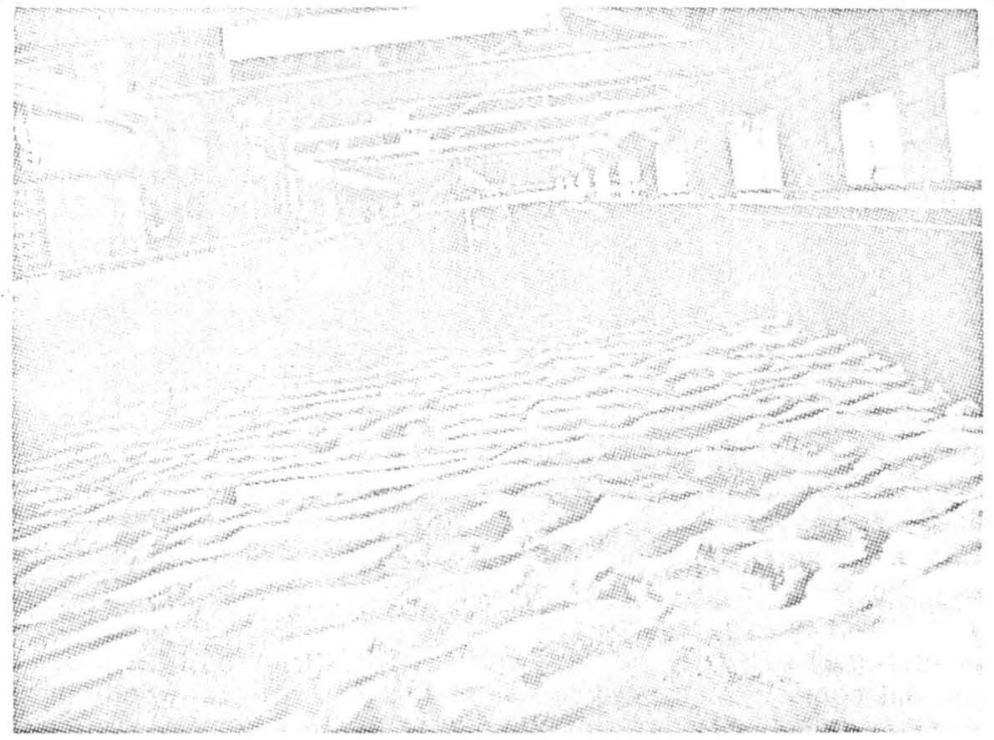

FIG. 3.-VWW OF RIPPLE CONTEURATION, LOOKING UPSTREAM. WATETH-STRFACE SLOPH S $=0.000403$.

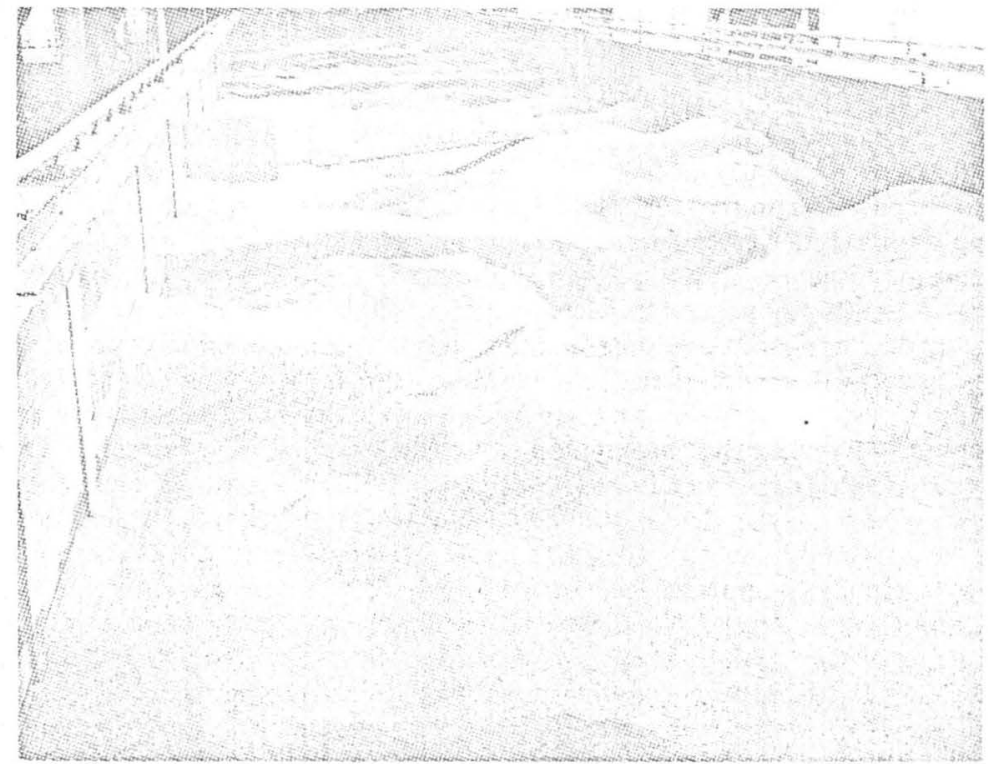

FIG. 4.-VHW OF DUNE CONETGURPTLN, LOOKNG UPSTREAM. WATEIR-SURTACE SLOPL $3=0.00280$, 
the ripple migrated downstream. Thus, the movement of the sediment particles took place in steps. The length of the step and time interval between steps depended on the length of the ripple and ripple velocity.

With ripples, the bed was soft but not as soft as with dunes. The water surface was very smooth with little visible difference from the water surface for the plane bed without sediment movement. The separation zone downstream from the crest of the ripple caused little jet impingement on the downstream ripple. The reverse flow in the trough moved only the finest particles, and the turbulence was small at the interface between the main current and the separation zone.

When the slope and/or depth were increased beyond a certain limit the ripples were modified to dunes. Because of the difference in relative roughness and resistance to flow it is necessary to treat the two forms of bed roughness separately. Compare the ripples shown in Fig. 3 with the dunes in Fig. 4.

The bed changed from the ripple pattern to a dune pattern when the slope and/or depth were changed such that $\mathrm{d} / \mathrm{\sigma}^{\prime}$ was approximately 1.0 , and the Froude number was approximately 0.28 . The change was abrupt, and the dunes established themselves over the full length of the flume in a few hours. To change from dunes to ripples (Q constant), it was necessary to decrease the slope and increase depth from the values at which ripples changed to dunes. With the reduced transport capacity caused by the change in slope and depth. considerable time was required for the flow to convert completely a dune configuration to ripples. However, ripples superposed themselves on the backs of the dunes in a short time.

Dunes. - The form of dunes is illustrated in Fig. 2, and a photograph of typical dunes is shown in Fig. 4. Considering all dune runs, the dunes ranged in average height from $0.15 \mathrm{ft}$ to $0.52 \mathrm{ft}$ and in length from $4.0 \mathrm{ft}$ to $7.5 \mathrm{ft}$. The length to height ratio $\mathrm{L} / \mathrm{h}$ varied from 14 to 28 . The ratio of depth of flow to dune height $\mathrm{D} / \mathrm{h}$ ranged from 1 to 5 . Froude numbers varied from 0.38 to 0.60 fixing the upper limit of the unmodified dune bed form. Manning's n varied from 0.018 to 0.035 , although observing the bed, much larger values of Manning $\mathrm{n}$ would have been expected (Fig. 4). The reason for small n-values is that with a large flume, as with a natural stream, the dunes form in a pattern that allows part of the flow to sideslip or bypass the dune. Sideslippage or meandering of the flow around the dunes was very obvious when a smaller discharge was run over a dune bed formed by a larger discharge.

Dunes move downstream as a result of sediment toppling over the crest and accumulating on the downstream face of the dune. The larger the amplitude $\mathrm{h}$ of the dune, the more sediment is stored in the dune and the smaller the dune velocity for a constant transport rate. Considering a particular run, dunes with small amplitude and with their inherent high velocity overtake the larger dunes. This results in a much larger dune and decreases the dune velocity. Velocity of the dunes varied from $0.02 \mathrm{fpm}$ to $0.70 \mathrm{fpm}$. The large dune velocities were associated with relatively steep slopes and shallow depths. Conversely, the small dune velocities were associated with relatively flat slopes and deep depths. By knowing the average amplitude and velocity of ripples and dunes, the bed load transport can be estimated. 6

The $(\mathrm{L} / \mathrm{h})$-ratios for dunes and ripples were similar. The ratios varied from 10 to 24 for ripples and 14 to 28 for dunes. This indicates that there is

6 "A Study of the Effect of Fine Sediment on Flow in Alluvial Channels," by D. B. Simons and E. V. Richardson, U. S. Geol. Survey Water Supply Paper 1948B, 1959. 
a correlation between dune height and dune length for a given sediment. That is, if the amplitude of the dune or ripple increases with a change in slope or depth, the length also increases. The variation in the $(\mathrm{L} / \mathrm{h})$-ratios may be the result of the randomness of the dune configuration-which makes it difficult to obtain true average length and amplitude. Some of the variation in $\mathrm{L} / \mathrm{h}$ may result from including the separation zone in measured lengths of the dunes. Whereas the true length of the dune may only extend from the end of the separation zone to the next crest downstream, the measured length, as used, was from crest to crest. The magnitude of the separation zone increased as slope increased until the transition region was reachedwhere the dunes began to wash out.

The ratio of depth of flow to dune height (relative roughness) $D / h$ was different for ripples than for dunes. Ripples have a larger $(D / h)$-ratio than dunes. This parameter may help explain why the $n$-values are smaller for ripples than for dunes. Also with the ripple and dune-bed forms, the largest $n$ values occurred with the smallest $(D / h)$-values.

It appears from the flume data which is for essentially two-dimensional flow that maximum dune height is limited by the depth of flow。 That is, dunes will only grow until their crests are within a certain relative distance of the water surface. Possibly, this phenomenon does notoccur in three-dimensional flow. Also, with a given slope and a continuous increase in depth the dune height may reach some maximum value for that size of sediment and water temperature, and increasing the depth beyond this limiting depth will not increase the dune height. If this is true then the shear at which dune height becomes independent of depth must be determined to predict accurately the resistance to flow in an alluvial channel. This shear may be a function of the width of the channel. If dune height becomes independent of depth, the n-values may decrease with increasing stage. That is, $h / D$ the relative roughness will decrease。

With dunes, the bed was very soft and fluid and there was considerable segregation of the bed material. The surface of the upstream slopes and crests of the dunes, which had a negative slope of approximately $2^{\circ}$ to $4^{\circ}$, consisted of the fine and coarse material moving downstream. The slopes of the upstream faces were practically the same as those of the upstream faces of the ripples. Ripples formed on the upstream faces of the dunes at the smaller slopes. At large slopes, the ripples on the dunes were not apparent. The downstream face, which had a positive slope between $31^{\circ}$ and $39^{\circ}$, largely consisted of the coarse fraction of the bed material. The coarse fraction was the material which could not be swept into suspension at the crest and avalanched down the fore slope. It was deposition by avalanching which caused the dune bed to be so soft and fluid. The material was deposited by the force of gravity and had relatively large voids. If it had been deposited by the dynamic force of the fluid, it would have been packed into place, with relatively small voids ratio. R. A。 Bagnolic observed 7 and explained the same phenomena with wind-blown dunes. The troughs of the duries contained a horizontal layer $1 / 8 \mathrm{in}$. to $2 \mathrm{in.}$ thick of the fine fraction of the material. Part of the fines in the trough came from the sediment which was swept over the crest and part came from the lower part of the upstream face of the adjacent downstream dune where the main current overrode the separation zone and impinged on the bed (Fig. 2). As the water-

7 "The Physics of Blown Sand and Desert Dunes," by R. A. Bagnold, Methuen and Co., London, 1941, pp. 238-240. 
surface slope was increased, with the dune form of bed roughness, the toe of each dune was blasted and eaten away by the high velocity water that impinged on it. The erosion provided a source of additional fine material which was deposited in the trough by the reverse flow in the separation zone.

The slopes of the downstream faces of the dunes, which varied from $31^{\circ}$ to $39^{\circ}$ and averaged $34^{\circ}$, were clearly defined by lines formed by the dark-colored particles as the dune moved downstream (Fig. 2). The angle of repose in air for dry non-cohesive $1 \mathrm{~mm}$ sand (the bed material in the flume was $95 \%$ finer than $1 \mathrm{~mm}$ ) varies from $29^{\circ}$ to $32^{\circ}$ depending on angularity of the particles. 8 It is probable that the angle of the forward face of the dune was greater than the angle of repose of dry bed material in air as a result of pressure on the fore-plane of the dune in the separation zone and the reverse flow in the trough moving up of the face of the dune. This was verified by the fact that as the velocity of flow was reduced to zero in the flume, the downstream face of the dune slumped to a smaller angle of inclination.

With the dune-bed form of roughness, the water surface was uneven and turbulent and the water surface was lower over the troughs than over the crests of the dunes. This was the result of the acceleration and deceleration of the flow as it contracted over the crest and expanded over the trough. This was illustrated for rigid boundaries by $\mathrm{H}_{\circ}$ Rouse. 9 The degree of roughness (turbulence) of the water surface increased as the bed roughness increased. The roughest water surface observed with dunes occured when there were large water surface boils. The water surface in the boils was approximately $0.1 \mathrm{ft}$ higher than the surrounding water surface. However, the roughness of the water surface was not great enough to affect the accuracy of the water surface slope measurements. The turbulence created at the interface between the main flow and the flow in the separation zone dissipated considerable energy and normally the disturbance caused by the interference was visible at the water surface downstream. With the dune-bed form, the suspended sediment concentration, the intensity of the turbulence, the relative roughness, and the velocity of the reverse flow in the trough increased as the slope increased. Along with the dunes, potholes formed which had a depth equal to the height of the dunes. These potholes, as well as the dunes, caused boils on the water surface that were evident downstream from the dunes. The potholes and boils moved downstream in front of the dunes at the velocity of the dunes. Normally from ten to twenty potholes and boils were evident in the full length of the flume with this type of bed roughness. The pothole appeared to develop as a result of the increased strength of the secondary circulation in the separation zone. The combination of the velocity in the direction of flow and the secondary circulation caused a vertical circulation similar to a whirlwind. This rotating motion scoured out additional material at a point in the separation zone and produced a pothole. The existence of these potholes was indicated by the formation of very strong boils which visibly transported considerable suspended sediment upward to the water surface.

The segregation of material by the formation and movement of dunes means that a large number of bed material samples must be obtained and analyzed before the size distribution can be established with confidence. With the flume

8 "Theory and Design of Stable Channels in Alluvial Materials," by D. B. Simons, Ph. D. Dissertation, Dept. of Civ. Engrg., Colo. State Univ., Fort Collins, Colo., 1957.

9 "Elementary Mechanics of Fluids," by H. Rouse, John Wiley and Sons, New York, N. Y., 1946, pp. 135 and 139. 
material, sixty samples were needed before another sample would not alter the median diameter a significant amount. Segregation should have some value, though, because in the field $\left(\mathrm{F}_{\mathbf{r}}<0.6\right)$, it might be possible to determine the characteristics of the bed roughness by core sampling the bed.

Transition, Dunes to Standing Waves. - The change from dunes to standing waves was complex, and the form of the bed roughness was erratic. The transition occurred when the depth and/or slope were changed so that $d / \sigma^{\prime}>2$ and $0.6<\mathrm{F}_{\mathrm{r}}<1.0$.

With dunes, the maximum Froude number was 0.60. Runs with a Froude number between 0.6 and 1.0 displayed a multiple roughness, that is, a bed form between dunes and standing waves which consisted of washed-out dunes and sand bars. The washed-out dunes and sand bars were $20 \mathrm{ft}$ to $30 \mathrm{ft}$ in length and had $(\mathrm{L}<\mathrm{h})$-ratios between 30 and 50 .

It is logical that the upper limit of the Froude number, with the dune-bed form, is considerably less than 1.0 . The change in roughness, and consequently, the change in resistance to flow and the dissipation of energy were large when the bed changed from the undulating form to dunes, whereas the change in energy from a change in the Froude number was small when $F_{r} \approx 1$. Thus, the velocity and depth were changed considerably when the bed form changed and small Froude numbers resulted. Conversely, the change from dunes to rapid flow resulted in smaller loss of energy because of the reduced roughness, which caused larger velocities, small depths, and larger Froude number.

There was a hysteresis effect in the change of bed roughness from dunes to standing waves and back to dunes. The value of slope and/or depth for the change depended on the bed configuration prior to the change. If the bed was covered with dunes, a slope of 0.0035 was perhaps required before the dune configuration was destroyed. If the bed was standing waves, a slope of about 0.0025 was required before dunes were formed. This hysteresis effect may have resulted because the energy changed as the bed form changed from dunes to standing waves or standing waves to dunes; that is, potential energy changed to kinetic energy when the form changed from dunes to standing waves, and kinetic energy changed to potential energy when the form of roughness changed from standing waves to dunes. The changes in energy resulted from the large changes in roughness associated with the changes in bed form. Dunes had nvalues which ranged from 0.018 to 0.035 , whereas the standing waves had $n$ values which ranged from 0.010 to 0.015 .

The fact that a typical dune pattern did not occur with this bed material, and a Froude number equal to or greater than 0.60 is important, especially if the phenomenon holds true for other bed materials. The bed form for $0.6<\mathrm{Fr}_{\mathrm{r}}<1.0$ was washed out dunes with rather large $(\mathrm{L} / \mathrm{h})$-values. The Manning $n$-values were 0.018 and 0.021 respectively; these $n$-values are smaller than $n$-values for dunes, but are larger than rapid flow n-values. With dunes, it seems that the magnitude of Manning $\mathrm{n}$ is related to both spacing and amplitude of the sand waves.

Some runs had distinctly different types of flow occuring side by side. This was probably because discharges which were too small with respect to slope were used which produced three-dimensional flow. This same phenomena was also observed in the antidune range when the discharge was decreased below a given value. With three-dimensional flow, the n-values ranged from 0.014 to 0.023 , whereas with standing waves, the $n$-values were approximately 0.012 。

Three-dimensional flow probably resulted because, in the experiments, discharge and slope were controlled and with the steeper slopes the small 
discharges set up conditions favorable for three-dimensional flow. Other experimenters may have experienced this flow condition because of the limited discharge capacity of their flume system which caused large width to depth ratios to develop when slope was increased. With the dune bed form, the smallest discharge used was sufficient to insure two-dimensional flow. Presumably, however, by further decreasing the discharge, three-dimensional flow could develop.

Rapid Flow Regime. - With rapid flow, $\mathrm{F}_{\mathrm{r}}>1.0$, three forms of sand bed and water surfaces were observed: plane, standing waves, and antidunes.

Plane Bed and Plane Water Surface.-A completely plane bed and plane water surface, for the full length of the flume was only produced once in the total sequence of runs. It was anticipated from existing literature that this would be the type of bed configuration following dunes. However, for this sand, such was not the case. Based on recent tests in which a fine sand was used, it is apparent that the development of a plane bed is intimately related to size of bed material. With fine sand as a bed material plane bed runs are a common phenomenon, and they develop at $\mathrm{F}_{\mathrm{r}}<1$ in the tranquil flow regime.

Standing Waves. - The water surface consisted of symmetrical standing waves of small amplitude. The standing waves formed and gradually disappeared, and unlike antidunes they had no tendency to break or migrate upstream. The forms of bed roughness observed with standing waves, in the order of increasing slope, were:

(a) a diagonal dune pattern cross-laced like a shoestring.

(b) a plane bed.

(c) a symetrical undulating sand wave similar in form to those observed in the antidune regime.

The standing waves formed when Froude number was approximately 1.0; the undulating sand wave bed developed when $1.2<\mathrm{Fr}_{\mathrm{r}}<1.3$. The Manning $\mathrm{n}$ for standing waves was relatively small, ranging from 0.012 to 0.015 . The water surface waves were roughly 1.5 times as high as the corresponding sand waves. Concurrent profiles of the sand bed waves and the water surface waves are illustrated in Fig. 7.

Antidunes. - When the Froude number, which was computed on the basis of average velocity and average depth, was greater than 1.3 , and $d / \sigma^{\prime}$ was greater than 3.0, antidunes formed.

Antidunes are defined as a train of symmetrical sand waves which are in phase with a corresponding train of symmetrical water surface waves. Both trains of waves move upstream, grow in height, then break (Figs, 5 and 6) causing a cyclical fluctuation of the water surface waves and the sand waves. The waves built up from a plane bed with a plane water surface. They grew and moved upstream until one or two of the waves became unstable and broke. Normally, when one wave broke other waves broke immediately thereafter for a distance of 1 or 2 waves upstream and 4 or 5 waves downstream. That is, depending on discharge and slope, from 1 to 8 waves at a spacing of $1 \mathrm{ft}$ to $6 \mathrm{ft}$ usually broke within a short time interval. The chain reaction that followed the breaking of the first wave was apparently triggered by the action of the first wave which broke.

While making concurrent measurements of the bed and water surface in the troughs and crests of antidunes, it was observed that the antidunes became unstable and broke whenever the water surface in the trough of the wave train was approximately the same elevation as the crest of the downstream bed 


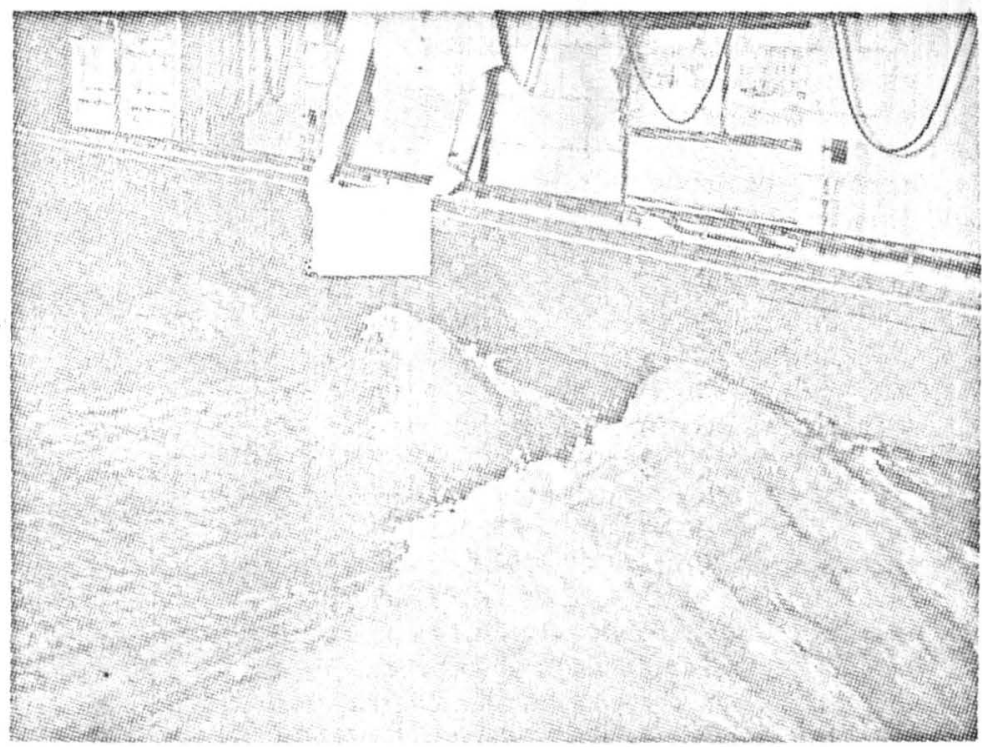

FIG, 5,-ANTIDUNE WAVE AT POINT OF BREAKING LOOKING UPSTREAM.

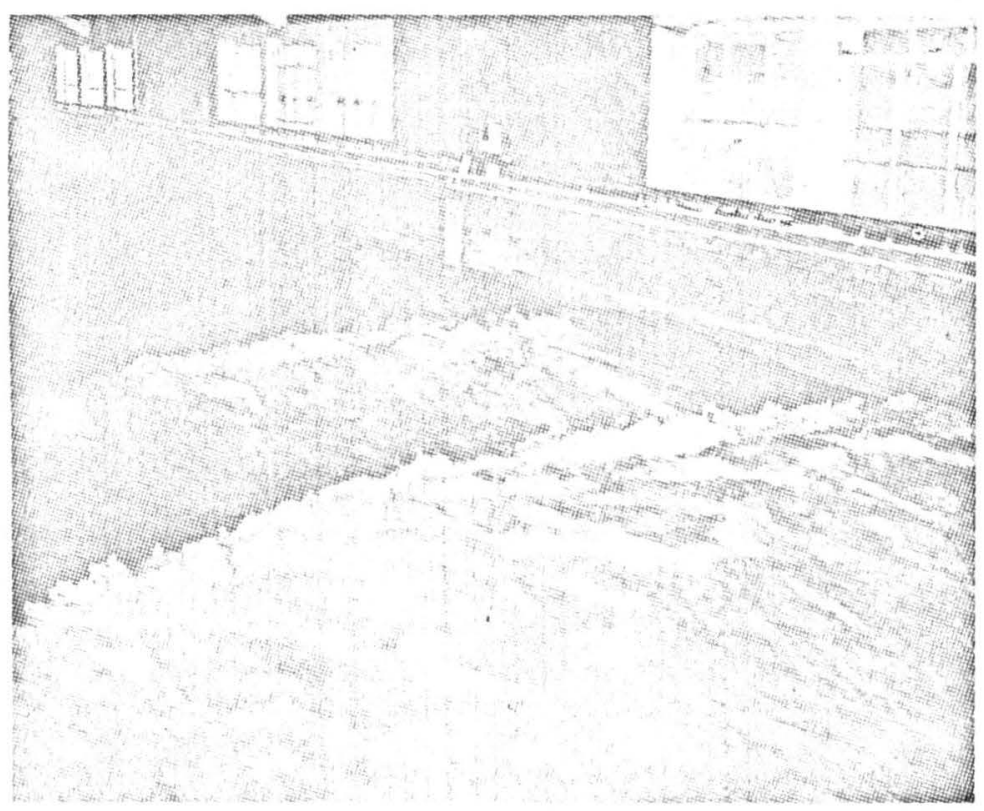

FIG. 6. - ANTIDUNE WAVE AFTER BREAKING. 

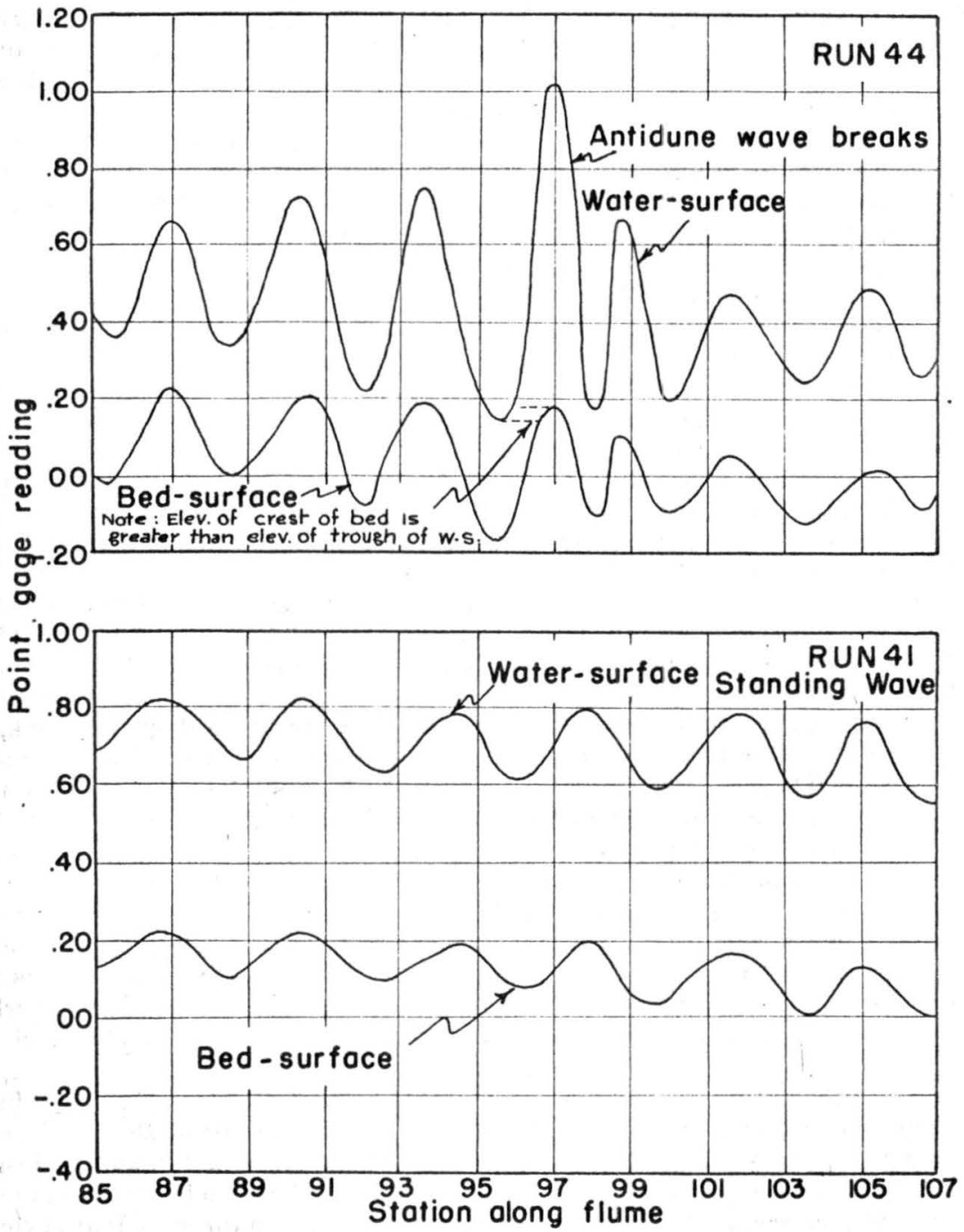

FIG. 7.-THE ACTUAL WATER SURFACE AND BED CONFIGURATION FOR RUNS 44 AND 41 
wave (Fig. 7). The measurements also indicated that the water waves were 1.7 times larger in amplitude than the corresponding sand waves. The total height of the water surface waves from trough to crest was from 1.0 to 1.5 times the average depth. When the waves started to break their heights were about twice the average depth. The breaking of the waves was very spectacular. There was considerable turbulence, dissipation of energy, and mixing of the flow. When waves broke they sounded like the surf in the ocean and there is probably some resemblance to the breaking ocean wave.

When the antidunes were building up the bed was very firm and there was no separation between the flow and bed. However, when the antidune broke, the crests of the sand waves became soft and fluid and seemed almost to explode. When the waves broke, the flow was very turbulent, there was separation, and considerable sediment was thrown into suspension。 Total load concentrations were very large and ranged from $4,240 \mathrm{ppm}$ to $15,000 \mathrm{ppm}$. It appeared that the upstream movement of the antidunes resulted from scour on the downstream side of the sand wave and deposition on the upstream side of the wave-consequently, the wave moved upstream.

Except for one run, which was considered three-dimensional, there was only one train of waves in the cross section. The train of waves was located off center at about the left $1 / 3$-point in the cross section. In subsequent runs, however, two trains of waves symmetrically located at the flume were observed several times. The wave trains were not continuous throughout the entire length of the flume. That is, a train of antidunes would either build up, break in a $20 \mathrm{ft}$ to $40 \mathrm{ft}$ length of flume, then build up in another $20 \mathrm{ft}$ to $40 \mathrm{ft}$ reach, or they would build up and break in two or three discontinuous lengths of the flume. The building up and breaking in the different reaches of the flume could be in phase or out of phase.

The period of time it took for one antidune wave to build up and break, and the number of antidune waves which built up at one time, varied with the slope and the discharge. The antidune run with the flattest slope had only one train of 6 to 8 antidune waves which would build up and break at a given time. This train of waves which was about $40 \mathrm{ft}$ long, would perhaps build up in the lower section, then in the middle or upper sections, and again at some other position in a random manne- Normally, about two complete cycles occurred every hour-a cycle includes starting with a plane surface, the building up of waves, the breaking of the waves, and back to a plane surface. For other runs with the steepest slopes there were three or four reaches in the flume in which the train of waves built up and broke both in phase and out of phase, almost continuously.

When the antidunes broke, a considerable amount of water was stored in the flume. Based on observations at the glass-walled section of the flume, when an antidune broke the water in the crest moved upstream, the water close to the bed almost ceased to move until the wave vanished, and shortly thereafter normal flow was restored. With the large slopes, when three or four series of antidune waves in the train would build up and break simultaneously, water was stored in the flume to such an extent that the pumps would surge. In the extreme case, antidune waves would build up and break in phase with the surging of the pumps. This caused the discharge to fluctuate and the antidune activity to increase. Consequently, throughout the full length of the flume so much water was stored in the flume that the tail-water level in the tailbox dropped until the pumps lost their prime. To reduce the surging of the pumps, the level of the water in the sump was raised and excess water was continuously added 
to the sump to replace that stored in the flume. When the antidunes were not breaking the surplus of water was discharged through an overflow at the top of the sump.

The storage of water caused by the breaking of the antidune waves probably accounts for the surging discharge that is sometimes observed in alluvial streams with steep slopes. That is, with antidunes water is stored and released in the upper reaches of the stream in a random haphazard manner, but as the flow travels downstream the fluctuation in discharge caused the antidunes to break in a more systematic pattern until surges develop which cause the antidunes to form and break at regular time intervals. Some streams that surge are Muddy Creek in Wyoming and Medano Creek in the Great Sane Dune National Monument, Colo.

Antidune flow using this bed material, hydraulically speaking, was very efficient. The Manning $\mathrm{n}$ ranged from 0.010 to 0.013 . Even though considerable energy was dissipated when the antidunes broke, the period of time and length of flume over which the antidunes broke was small in comparison with the total time and total flume length. This explains the small $\mathrm{n}$-values. It was observed that, as slope was increased antidune activity increased, the dissipation of energy increased, the discharge coefficient $\mathrm{C} / \sqrt{\mathrm{g}}$ decreased, and Manning $\mathrm{n}$ increased.

Surface velocities, obtained by timing floats along a center line of a train of antidune waves (when they were not breaking) and along a nearby parallel line where the water surface was smooth, showed that the surface velocity was greater in the train of waves. The velocity of flow in the trough of the antidunes was considerably greater than that in the crest. It is possible that the antidunes break when the velocity decreases and depth increases over the crest because the wave height increases until a Froude number less than 1.0 results.

\section{ANALYSIS OF DATA}

It should be borne in mind that the relations presented are based on only one group of flume data, and that the size and gradation of bed material remained constant except as altered by miscellaneous sorting which may or may not have been significant. That is, $d$ and $\sigma$ were constant and $w$ varied only because of temperature changes.

Variation of Velocity With Depth. - The variation of velocity with depth and inter relationships of these two variables with the six major forms of bed roughness are given in Fig. 8. Lines of equal Froude number have been superposed on the figure to illustrate the wide scope of the data. Velocities range from those for no movement of bed material to those far in excess of the critical velocity, from $0.65 \mathrm{fps}$ to $6.2 \mathrm{fps}$. Note that the transition roughness includes those runs in which bed roughness was somewhere between dunes and the roughnesses associated with rapid flow (washed out dunes or transition). Data representing runs of this type plot just below the critical velocity curve. The lines dividing the plot into forms of bed roughness are based on the observed roughness and the Froude number.

Variation of Resistance to Flow. - Considering the complete range of conditions investigated the Manning $\mathrm{n}$ ranged from 0.008 to 0.035 . These $n$-values have been corrected for side wall effect in accordance with the procedure presented by $H_{\circ}$ A. Einstein。 10 The magnitude of $n$ increased as the slope in-

10 "River Channel Roughness," by H.A. Einstein and N. L. Barbarossa, ProceedingsSeparate No. 78, ASCE, Vol. 77, July, 1951. 


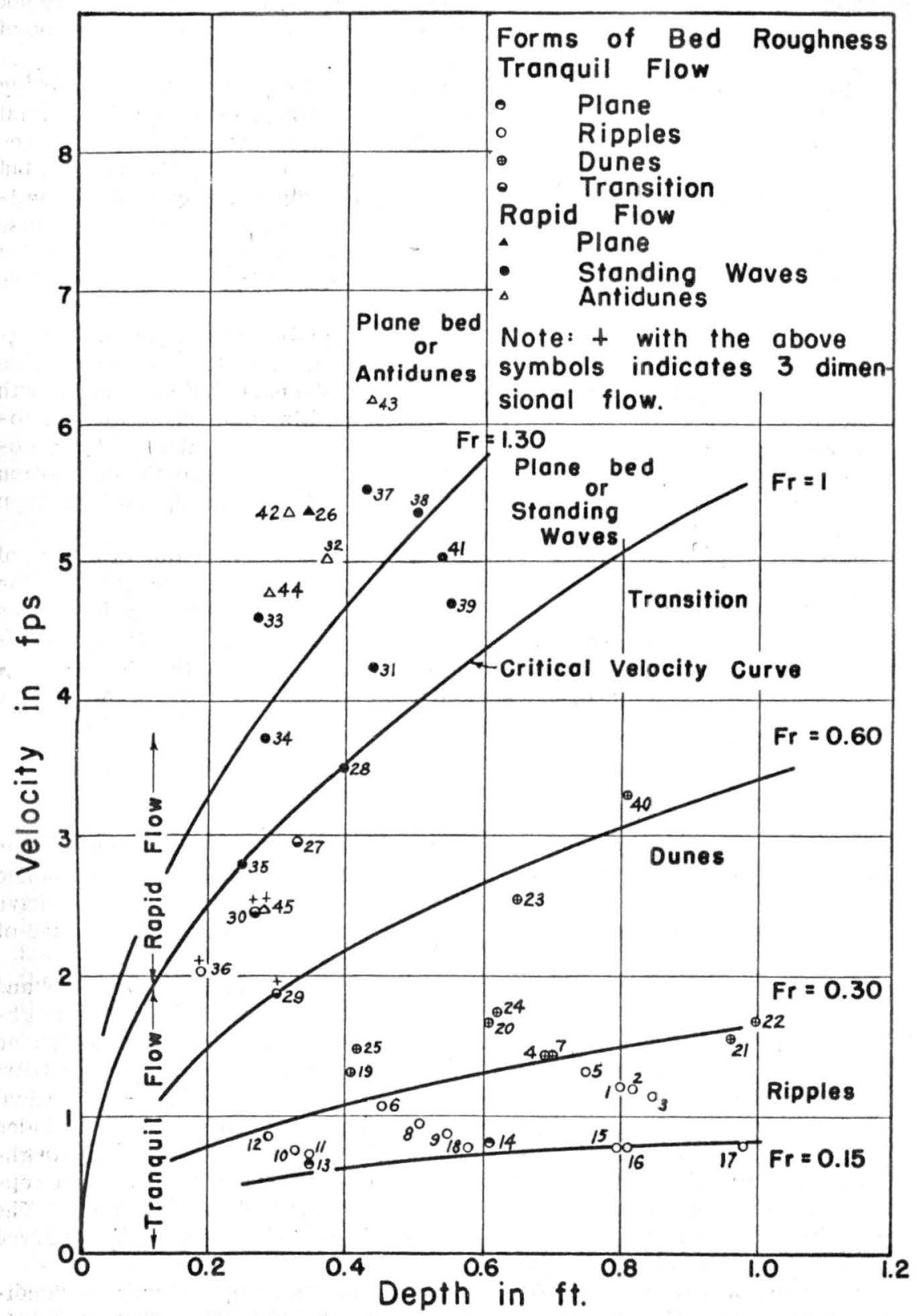

FIG. 8. - VARLATION OF VELOCITY V WITH DEPTH D 
creased and the depth remained constant, until the regime of flow shifted from the tranquil regime to the rapid regime; with rapid flow n-values decreased in magnitude quite suddenly to approximately 0.012 .

In the tranquil flow regime the Manning $\mathrm{n}$ was 0.015 for the plane bed and no bed material movement, ranged from 0.019 to 0.027 for ripples, and from 0.020 to 0.035 for dunes. In the transition from tranquil flow to rapid flow the resistance to flow was also in transition. It shifted with small changes in depth and slope from a large resistance, which was slightly smaller than the resistance for dunes to a small resistance, which was slightly larger than the resistance for rapid flow. With dunes, the magnitude of the resistance to flow is dependent on the spacing and amplitude of the dunes.

In the rapid flow regime, Manning $\mathrm{n}$ ranged from 0.0078 to 0.015 . The fact that resistance to flow is much smaller than for dunes can be attributed to the change in bed roughness. Dunes have a large separation zone with large form drag, whereas the symmetrical sand waves had little or no separation zone, only the form drag of the particles. Possibly some of the decrease in Manning n can be attributed to the movement of large quantities of sediment as bed load and not entirely to the elimination of the dunes. In the rapid flow regime insufficient turbulence was created to hold large quantities of sediment in suspension. Consequently, the sediment load which was carried in suspension with dunes was carried near the bed. This large concentration near the bed, in turn, markedly changed the properties of the fluid-sediment mixture. The fluid was not homogeneous and a sort of stratified flow resulted which inhibited mixing and reduced the effective bed roughness to extremely small values. The flow had some similarity to plug flow in pipes. During the single run for which $\mathrm{n}=$ 0.0078 , the bed was plane and the resistance caused by the standing waves was not effective. Under these conditions the plug-flow phenomenon was even more pronounced.

Variation of Tractive Force and Total Sediment Load.-Fig. 9 was obtained by plotting the tractive $T 0$, which has been calculated by

$$
\tau_{0}=\gamma \mathrm{RS} \ldots \ldots \ldots \ldots \ldots \ldots \ldots
$$

against the total sediment load concentration. Although there is appreciable scatter, a trend definitely exists. The magnitude of total load $\mathrm{C}_{\mathrm{T}}$ increases as the tractive force $\tau_{0}$ increases. In Fig. 9 each run has been symbolized in accordance with its form of bed roughness. There is a discontinuity between the tranquil-flow data and the rapid-flow data because of the relatively large tractive force associated with runs with large dunes.

The deviation of the runs with dunes from the general trend resulted from an increase in shear $\tau_{0}$, due to the extreme size of the dunes, without a corresponding increase in concentration $\mathrm{C}_{\mathrm{T}}$. It is significant to note that a sudden decrease in $\tau_{0}$ occurred at about $\mathrm{C}_{\mathrm{T}}=2,000 \mathrm{ppm}$ as the bed changed from dunes to plane bed or standing waves. This was caused by a reduction in roughness, which also decreased the ability of the flow to transport sediment. Consequently, $\mathrm{C}_{\mathrm{T}}$ was cut in half from tun 40 to run 36 , beyond which point $\mathrm{C}_{\mathrm{T}}$, in the transition regime steadily increased. No discontinuity occurred at the change from ripples to dunes or from standing waves to antidunes. There was, however, considerable scatter in the rapid flow regime, which shows that other variables are needed to define the phenomenon more completely.

Various Relationships. - The relationship between $\mathrm{V}_{*} \mathrm{~d} / \nu,\left(\mathrm{V} \tau_{0}\right) /\left(\mathrm{V}_{*} \Delta \gamma_{\mathrm{s}} \mathrm{d}\right)$ and the form of bed roughness was investigated for both regimes of flow (Fig. 10). It is of importance to note the precision with which the relation 


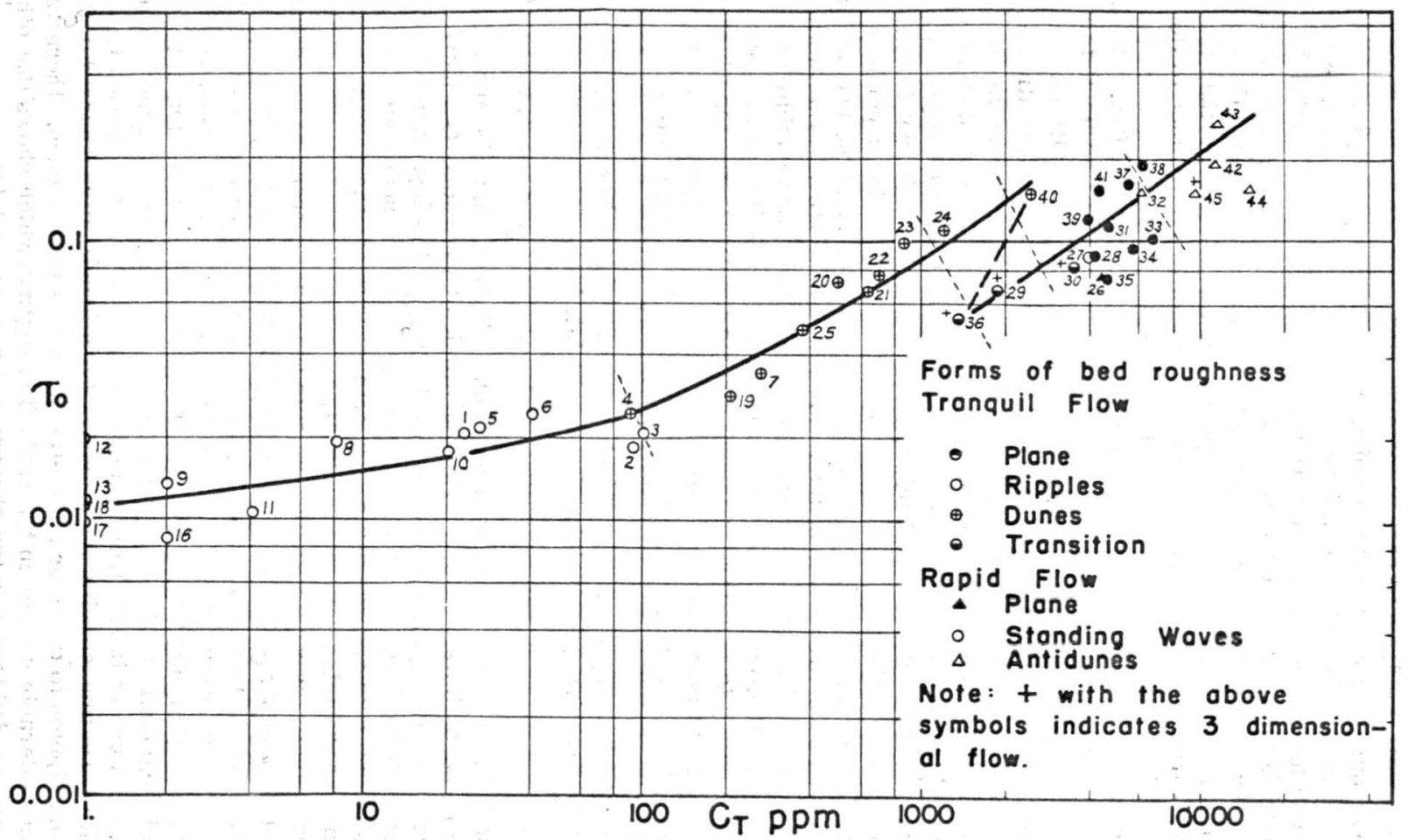

蛋

FIG. 9.-VARIATION OF $\tau_{0}$ AND C $\mathrm{T}_{\mathrm{T}}$ PPM 


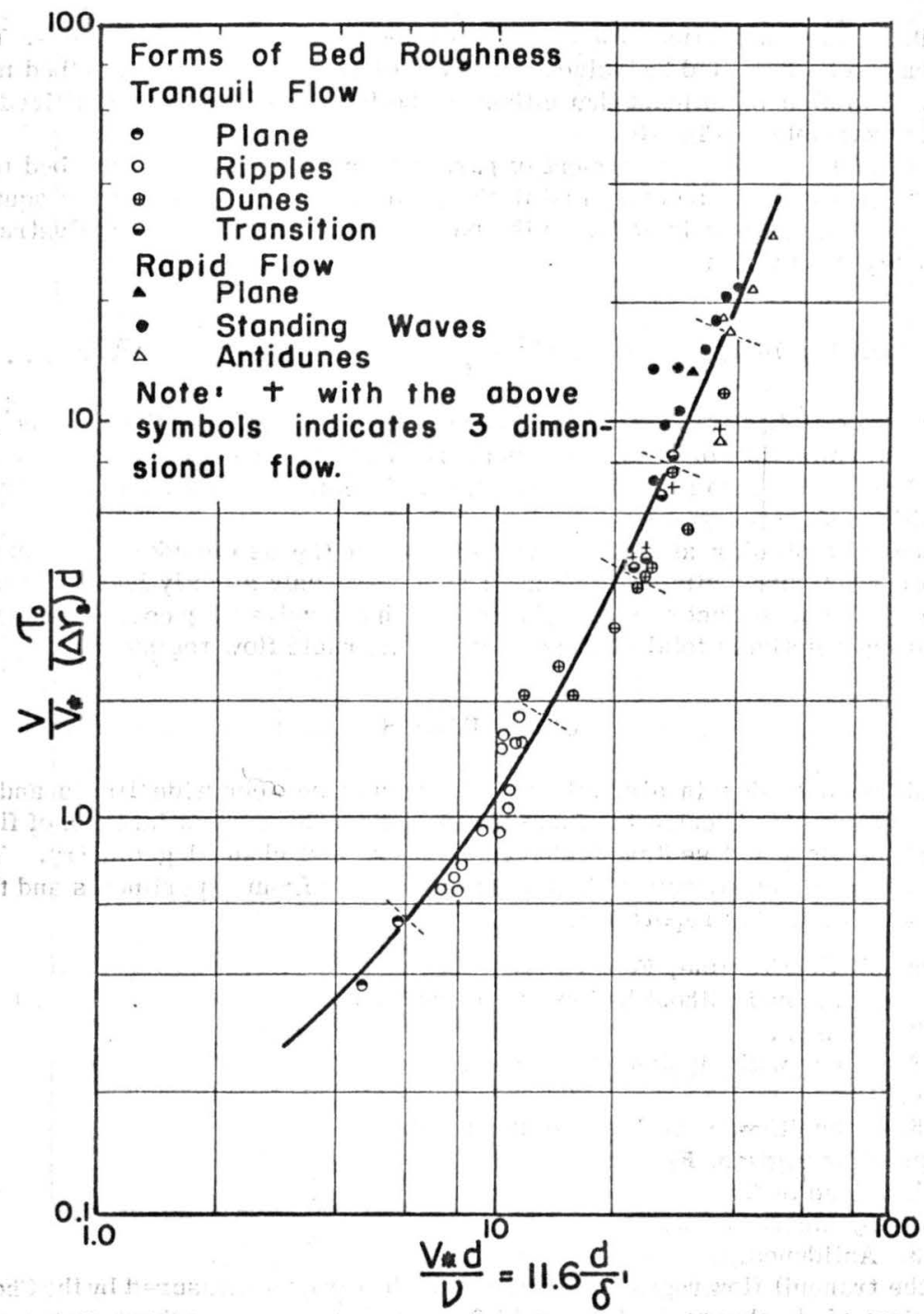

FIG, 10. -VARIATION OF $\frac{\mathrm{V}}{\mathrm{V} *} \frac{\tau_{0}}{\left(\Delta \gamma_{\mathrm{s}}\right) \mathrm{d}}$ WITH $\frac{\mathrm{V} * \mathrm{~d}}{\nu}$ 


$$
\frac{\mathrm{V}}{\mathrm{V}_{*}} \frac{\tau_{0}}{\Delta \gamma_{\mathrm{s}} \mathrm{d}}=\frac{\phi\left(\mathrm{V}_{*} \mathrm{~d}\right)}{\nu} \ldots \ldots \ldots \ldots
$$

describes and systematically groups the various forms of bed roughness. The relation can be modified to include the effect of size and gradation of bed material. It is also significant that either or both $\mathrm{Fr}$ and $\mathrm{C}_{\mathrm{T}}$ can be utilized as the third variable in Fig. 10.

Additional study and adjustment of parameters showed that for the bed material used, $\mathrm{C} / \sqrt{\mathrm{g}}$ can be computed if the product of a constant and the square of the Froude number is added to the parameter $\mathrm{w} \mathrm{d} \mathrm{S} / \nu$. This is illustrated in Fig. 11, from which

$$
\mathrm{V}=0.90 \times 10^{-6}\left[\frac{\mathrm{wd} \mathrm{S}}{\nu} \times 10^{2}+\frac{5 \mathrm{~V}^{2}}{\mathrm{~g} \mathrm{D}}\right] 1.85 \frac{\Delta \gamma_{\mathrm{S}} \mathrm{S}^{-2}}{\gamma} \sqrt{\mathrm{gDE}} \ldots
$$

The form of bed roughness plots very well as a third variable except for minor intermingling of ripple and dune runs at the arbitrarily selected dividing line. It is also possible to utilize total sediment load as a third variable with useful accuracy.

Based on a similar approach, but using $\mathrm{R}_{e}$ or $\mathrm{C}_{\mathrm{T}}$ as the additive term instead of $F_{r}$, figures similar to Fig. 11 which are only slightly less accurate can be obtained. In fact a figure of this type that involves $\mathrm{C}_{\mathrm{T}}$ could be used to estimate qualitatively total sediment load in the rapid flow regime.

\section{CONCLUSIONS}

Resistance to flow in alluvial channels varies between wide limits and is extremely'complex because the form of the bed roughness is a function of fluid properties, flow and sediment characteristics, and channel geometry. The major forms of bed roughness that were determined from experiments and that are discussed in this report are:

Tranquil flow regime, $\mathrm{F}_{\mathrm{r}}<1$.

1. Plane bed without bed material movement.

2. Ripples.

3. Dunes with ripples superposed.

4. Dunes。

5. Transition from dunes to plane bed.

Rapid flow regime, $\mathrm{Fr}_{\mathrm{r}}>1$.

1. Plane bed.

2. Symmetrical standing waves.

3. Antidunes.

In the tranquil flow regime the resistance to flow, as measured by the Chezy coefficient of discharge $\mathrm{C} / \sqrt{\mathrm{g}}$, was 14.0 for the plane bed without movement, varied from 7.8 to 12.4 for ripples, and from 7.4 to 12.8 for dunes. The large $\mathrm{C} / \sqrt{\mathrm{g}}$ values for the ripples or dunes were associated with the deepest depths, and hence, the smallest relative roughness.

In the rapid flow regime $\mathrm{C} / \sqrt{\mathrm{g}}$ varied from 13.9 to 27.0 . The largest $\mathrm{C} / \sqrt{\mathrm{g}}$ value occurred with a plane bed and plane water surface. Stancing waves, in general, had larger values of $\mathrm{C} / \sqrt{\mathrm{g}}$ than antidunes. This resulted from the dissipation of energy by the breaking waves. The value of $\mathrm{C} / \sqrt{\mathrm{g}}$ could be reduced further for antidune flow but for the fact that the period of time and length of 


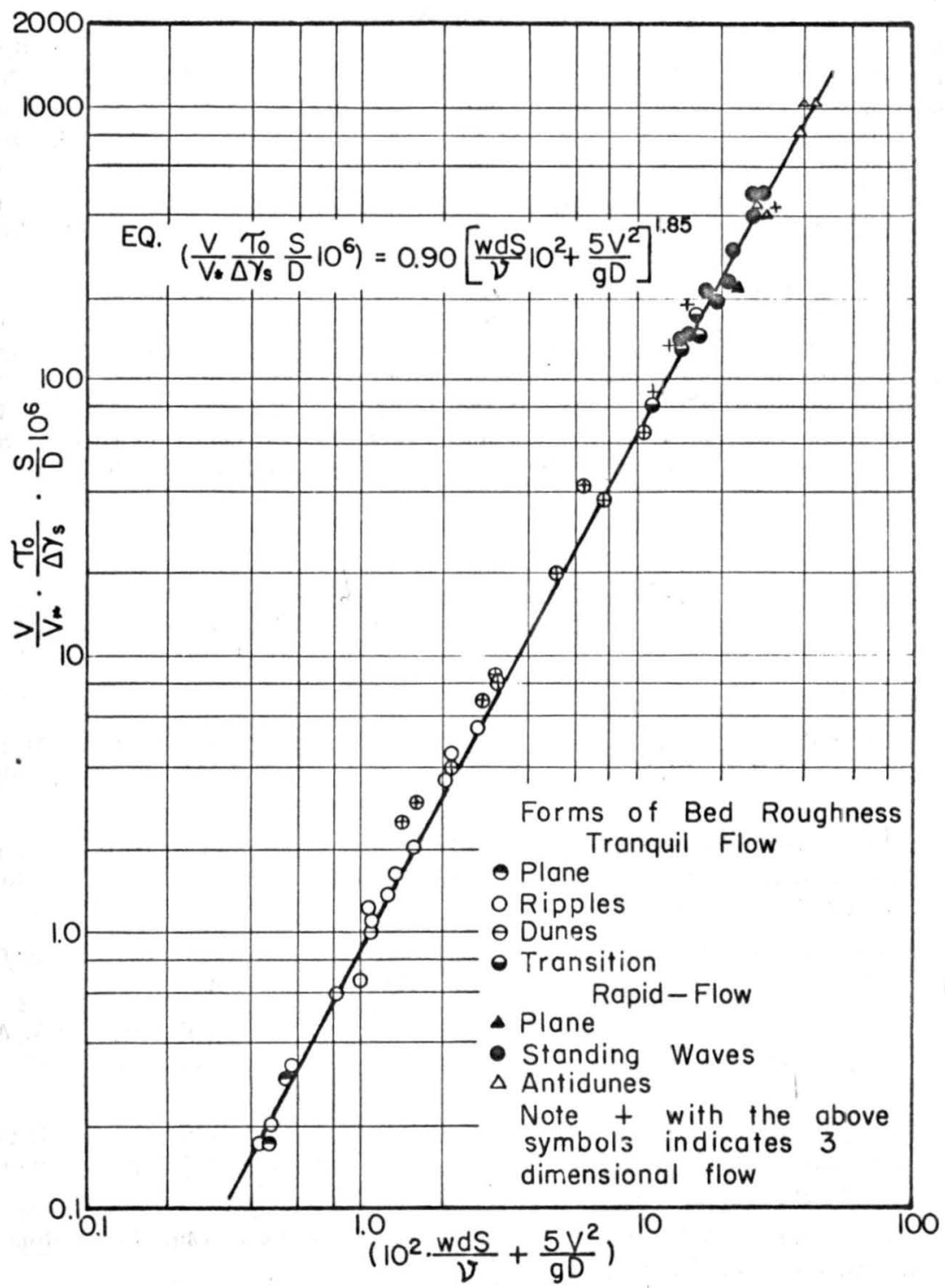

FIG. 11.-VARLATION OF $\left(\frac{\mathrm{V}}{\overline{\mathrm{V}}_{*}} \frac{\tau_{0}}{\Delta \overline{\gamma^{-} \mathrm{s}}} \frac{\mathrm{S}}{\mathrm{D}}\right) 10^{6}$ WITH $\left(\frac{\mathrm{wdS}}{\nu} 10^{2}+\frac{5 \mathrm{~V}^{2}}{\mathrm{gD}}\right)$ 
flume occupied by breaking waves was small in comparison with the total time and length of flume.

It was observed that with the bed material and the flume used in the experiments, dunes started to wash out and resistance to flow decreased when $\mathrm{F}_{\mathrm{r}}>0.6$. In the transition from dunes to plane bed $\mathrm{C} / \sqrt{\mathrm{g}}$ varied from 10.0 to 14.1 . The magnitude of $\mathrm{C} / \sqrt{\mathrm{g}}$ increased as the percentage of the bed which was covered with dunes decreased. Also, there was a hysteresis when the dure bed changed to standing waves which depended on the form of the bed prior to the change. That is, with discharge constant, a larger slope was required to change from a dune bed to a standing wave bed than was required to change from standing wave bed to dune bed.

For certain size gradations of bed material, if the slope of the energy grade line is close to critical slope, a change in stage causes dunes to change to plane bed or standing waves or vice versa. This phenomenon occurs in many natural streams and produces a discontinuity in the stage discharge relation. However, because of the hysteresis that is associated with such a change in bed form, the stage at which the discontinuity develops depends on whether the stage is rising or falling and on the rate of change of discharge with time.

\section{APPENDIX I. -ADDITIONAL REFERENCES}

1. "Mechanics of Ripple Formation," Discussion by M. L. Albertson, D. B. Simons and E. V. Richardson, Proceedings, ASCE, Vol. 84, No. HY1, February, 1958.

2. "A Study of Sediment Transport in Alluvial Channels," by J. R. Barton and P. N. Lin, Dept. of Civ. Engrg., Colo. State Univ., Fort Collins, Colo., No. 55JRB2, 1955, p. 43 .

3. "Mechanics of Streams with Movable Beds of Fine Sand," by Norman H. Brooks, Transactions, ASCE, Vol。123, 1958, pp. 526-549.

4. "Study of Transportation of Fine Sediments by Flowing Water," by A. A. Kalinske and C. H. Hsia, Studies in Engrg., Bulletin No. 29, State Univ. of Iowa, 1945.

5. "Some Factors Affecting the Stability of Canals Constructed in Coarse Granular Materials," by E. W. Lane and E. J. Carlson, Internatl. Hydr. Convention Proceedings, Minneapolis, Minn., 1953, pp. 37-48.

6. "Mechanics of Sediment-Ripple Formation," by H. K. Liu, Proceedings, ASCE, Vol. 83, No. Hy2, April, 1957. 


\section{APPENDIX II. -NOTATION}

The following symbols have been adopted for use in this paper:

Symbols

$$
\text { B }
$$

$\mathrm{C} / \sqrt{\mathrm{g}}=$ Chezy coefficient of discharge in dimensionless form which is equivalent to $\mathrm{V} / \mathrm{V}_{*}$.

$\begin{array}{ll}C_{D} & =\text { Drag coefficient for the particle } \\ C_{T} & =\text { Concentration of total load }\end{array}$

\section{Dimensions Units}

L

ft

$\begin{array}{ll}0 & -- \\ 0 & -- \\ \text { ppm } & 0 \\ \text { ppm } & 0 \\ \text { L } & \mathrm{ft} \\ \text { L } & \mathrm{ft} \\ 0 & -- \\ \text { L } & \mathrm{ft} \\ 0 & -- \\ \text { L } & \mathrm{ft}\end{array}$

$\mathrm{L}^{1 / 6} \quad \mathrm{ft}^{1 / 6}$

$=$ Mannings coefficient of roughness

$=$ Mannings coefficient of roughness (Einstein)

$=$ Discharge of water-sediment mixture

$=$ Reynolds number

$=$ Shape factor of the channel cross section

= Shape factor for the reach of the stream 0

$\mathrm{S}=\begin{aligned} & \text { Slope of energy gradient equal to water } \\ & \text { surface slope in steady, uniform flow }\end{aligned}$

$\begin{aligned} \mathrm{fr}= & \begin{array}{l}\text { Slope of energy gradient equal to water } \\ \text { surface slope in steady, uniform flow }\end{array}\end{aligned}$

$\mathrm{t}=$ Time

0

$\mathrm{L}^{1 / 6} \quad \mathrm{ft}^{1 / 6}$

$\mathrm{L}^{3 / \mathrm{T}}$

cfs

$$
0
$$

(1)$$
0
$$

$\mathrm{L} / \mathrm{T}$

$\mathrm{ft} / \mathrm{sec}$

$\mathrm{L} / \mathrm{T}$

$\mathrm{ft} / \mathrm{sec}$

$\mathrm{L} / \mathrm{T}$

$\mathrm{ft} / \mathrm{sec}$

$\mathrm{F} / \mathrm{L}^{3}$

$\mathrm{lbs} / \mathrm{ft}^{3}$

$F / L^{3}$

$1 \mathrm{bs} / \mathrm{ft}^{3}$

$\mathrm{F} / \mathrm{L}^{3} \quad \mathrm{lbs} / \mathrm{ft}^{3}$ 


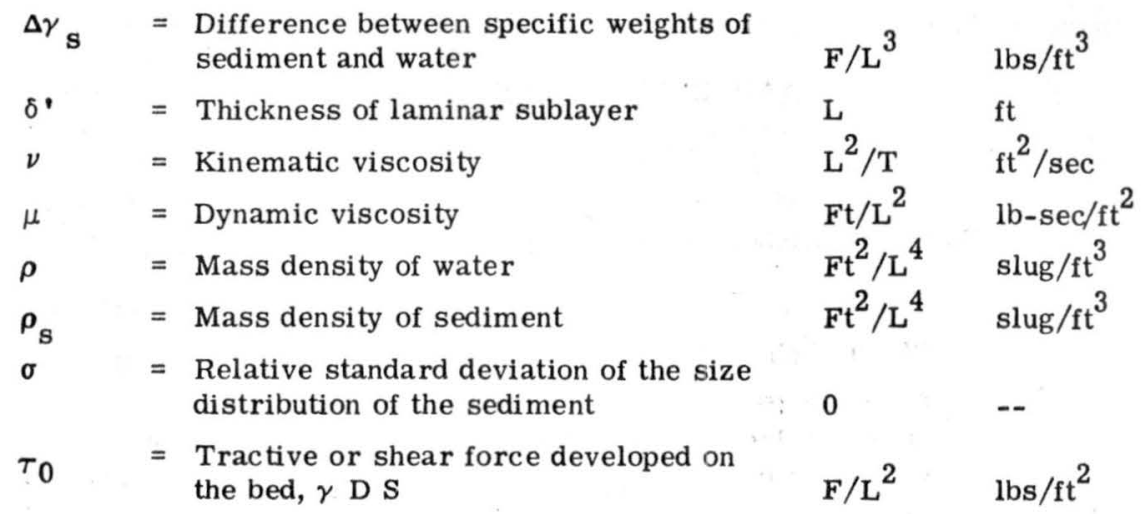

\section{DISCUSSION}

H. A. EINSTEIN, ${ }^{11}$ F. ASCE.-This paper is very valuable for the experimental data given, as well as for the excellent description of the various bed formations.

As far as the analysis of the data is concerned, it is most gratifying to see that the change of roughness is related to the geometry of the bed, but not to the "work spent on moving the sediment," one of the early concepts which has helped much to obscure the facts.

The experiments cover a large range of sediment rate and of slope values. They reach up into Froude numbers above critical and indicate that no particular changes occur in the friction law at that point. The water depth covers a rather small range. Only one sediment mixture was used.

In their analysis, the authors appear to use exclusively their own experimental results. If they had used these results to check previousiy proposed theories of friction along sediment beds, the paper would have been extremely valuable in its analysis. Unfortunately, that was not done. Instead, they developed a new relationship as given by Eq. 9 and in Fig. 11. This relationship is composed of rather complicated combinations of the variables and definitely needs an explanation.

This relationship in question is given in Fig. 11 in the form:

$$
\frac{\mathrm{V}}{\mathrm{V}_{*}} \frac{\tau_{\mathrm{o}}}{\Delta \gamma_{\mathrm{s}}} \frac{\mathrm{S}}{\mathrm{D}}=\mathrm{f}\left(\frac{\mathrm{w} \mathrm{d} \mathrm{S}}{\nu} 100+5 \frac{\mathrm{V}^{2}}{\mathrm{~g} \mathrm{D}}\right) \ldots \ldots \ldots
$$

in which the nomenclature is the same as that of the original paper and $\mathrm{V}$ is the average flow velocity; $\mathrm{V}_{*}=\sqrt{\tau_{\mathrm{O}} / \rho}=\sqrt{\mathrm{S} \mathrm{D} g}$ the shear velocity along the bed; $\tau_{0}$ is the shear stress at the bed; $\Delta \gamma_{S}$ is the specific weight of the sediment under water; $\mathrm{S}$ is the slope; $\mathrm{D}$ represents the water depth; $\mathrm{w}$ is the settling velocity of the sediment (average); $d$ denotes the diameter of the sediment (average); $v$ is the kinematic viscosity; g represents the density of the fluid;

11 Prof., Mech. Engrg., Univ. of Calif., Berkeley, Calif. 
and $\mathrm{f}$ is a function. Of these variables, $\Delta \gamma_{\mathrm{S}}, \rho, \mathrm{w}$, and d are constants for the entire set of experiments. Thus, Eq. 10 may be rewritten in the following form collecting all constants in brackets

$$
\left[\frac{\mathrm{g} \rho}{\Delta \gamma_{\mathrm{s}}}\right]\left(\frac{\mathrm{V}}{\mathrm{V}_{*}}\right) \mathrm{S}^{2}=\mathrm{f}\left\{\mathrm{S}\left([100 \mathrm{wd}] \frac{1}{v}+[5]\left(\frac{\mathrm{V}}{\mathrm{V}_{*}}\right)^{2}\right)\right\} \ldots
$$

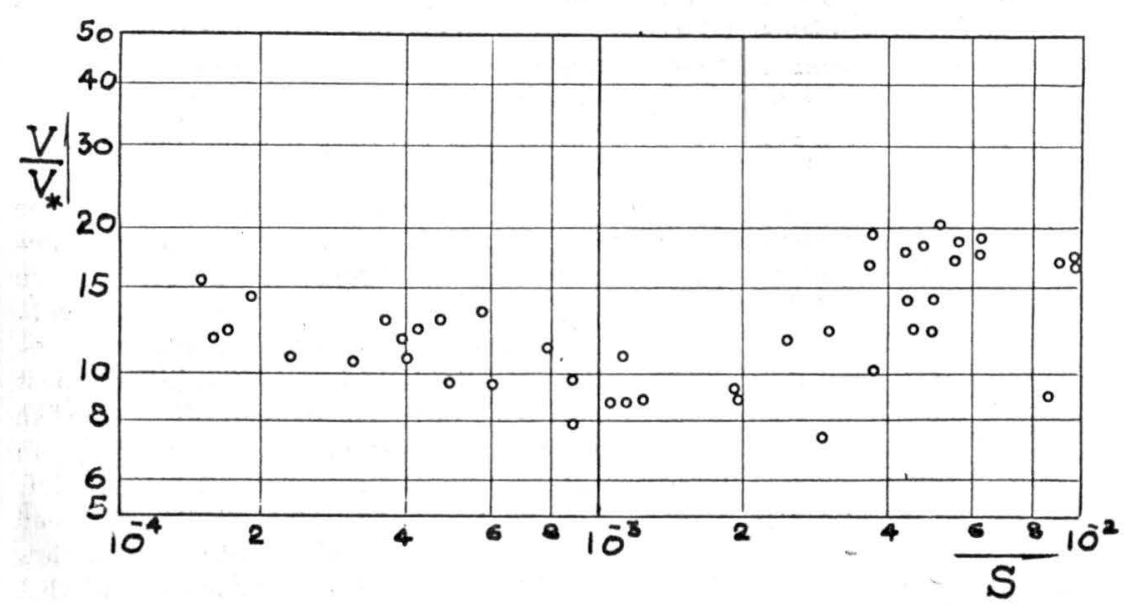

FIG. $12,-\frac{\mathrm{V}}{\mathrm{V}_{*}}$ AS A FUNCTION OF S

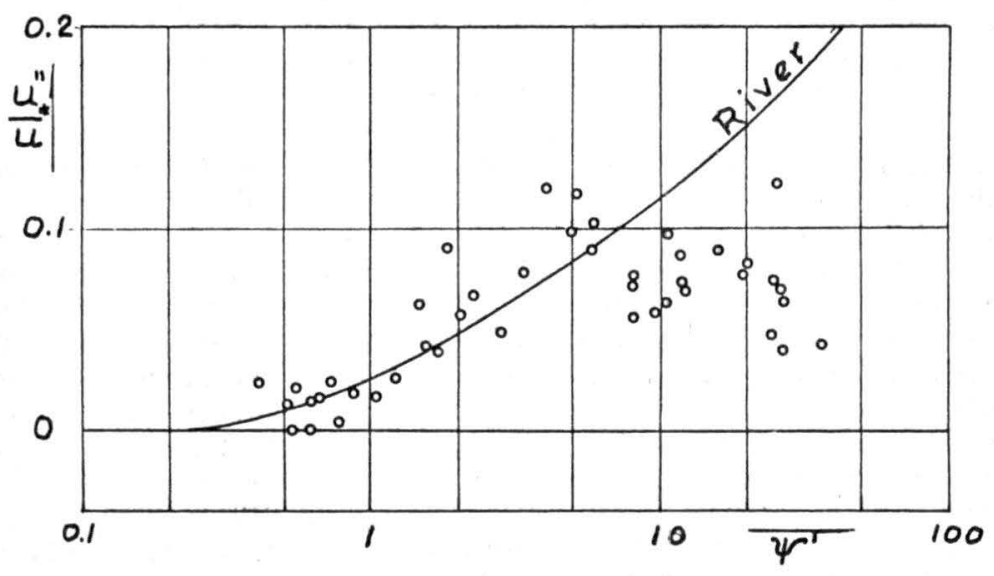

FIG. 13. $-\frac{\mathrm{u}^{n}}{\mathrm{u}}$ AS A FUNCTION OF $\psi$

With all the brackets constant for the range of the experiments, this is a relationship between $\left(\mathrm{V} / \mathrm{V}_{*}\right), \mathrm{S}$ and $\nu_{0} \mathrm{~A}$ check of the range of temperatures shows 
that $\nu$ stays between the values of $1.03 \times 10^{-5}$ and $1.22 \times 10^{-5}$. This represents a $\pm 10 \%$ maximum deviation from an average value, which is well within the scatter of the points in Fig. 11. For the sake of that discussion $v$ may thus be assumed to be constant, too. Eqs. 10 and 11 are, therefore, a relationship between $\left(\mathrm{V} / \mathrm{V}_{*}\right)$ and $\mathrm{S}$. The values of $\left(\mathrm{V} / \mathrm{V}_{*}\right)$ were thus computed for all experiments and plotted against the slope $\mathrm{S}$ in Fig。12. It is seen there that this relationship is very weak with a minimum of $\left(\mathrm{V} / \mathrm{V}_{*}\right)$ near $\mathrm{S}=10^{-3}$, with a slow increase towards $S=10^{-4}$ and a more abrupt increase towards $S=10^{-2}$. The entire change of an average line is about from 9 to 18 , or by a factor 2. This factor may be responsible for the slight deviation of the curve of Fig. 11 in the original paper from a slope 2. Otherwise, that curve is nothing but a plot of $\mathrm{S}^{2}$ against $\mathrm{S}$ as is easily seen from Eq. 11 .

In their analysis, the authors refer to another paper ${ }^{10}$ If they had used the entire procedure proposed in that paper, they would have found that their results (except Run 26, which appears to be far out of line) follow the river curve reasonably well for $\Psi^{\prime}-$ values below 10 . (See Fig. 13). For higher $\Psi^{\prime}$ - values, $u_{*}^{\prime \prime} / \mathrm{u}$ deviate systematically from the river curve towards zero. This deviation is characteristic for all flume flows with coarser sediment than about $0.5 \mathrm{~mm}$. It may be mentioned that the plotting of $u_{*}^{\prime \prime} / \mathrm{u}$, instead of $\mathrm{u} / \mathrm{u}_{*}^{\prime \prime}$ as in the original paper, has been used here as it tends to emphasize the range in which the bar resistance is important rather than the range where it fades out. Fig. 13 shows a rather large scatter of the points which may be easily explained by the difficulty of defining and measuring the exact location of the bed in view of its large irregularities. It must be kept in mind, furthermore, that that method of analysis accumulates all accidental errors of the entire measurement into a part of the energy dissipation.

If the authors had been satisfied with checking the applicability of their measurements to various existing theories and formulas, they would have done the difficult field of river hydraulics a much better service than by trying to derive from the rather limited amount of information a new relationship which does not seem to have much physical significance.

T. BLENCH, 12 F. ASCE. - To see this starting attempt to repeat the outstanding work of Gilbert (5) with large equipment in the engineering department of a University is indeed a pleasure. To the "principal reasons why only limited answers ..... have been developed" (Introduction) for the matter in hand the writer would add the lack of science instruction in schools followed by engineering curricula that also ignore basic science infavour of manipulation of uncritically accepted formulas; these added reasons seem necessary to explain the almost complete failure of engineers to study the information Gilbert collected and presented. The continued demonstration of transport phenomena in college, and the progressive measurement and critical analysis of quantities relevant to sediment-bearing flow in and beyond the Gilbert range in flumes, as the authors obviously intend, should help to inject a scientific outlook into engineering instruction and advance engineering information; extension to field

12 Prof, of Civ. Engrg., Univ, of Alberta, and Pres., T. Blench \& Associates, Cons. Hydr, Engrs., Edmonton, Alta., Canada.

13 "Regime Formulas for Bed-Load Transport," by T. Blench, Proceedings, IAHR, 1955 .

14 "Regime Analysis of Laboratory Data on Bed-Load Transport," by T. Blench and R. Bryan Erb, La Houille Blanche, No. 2, 1957. 
observations will yield even more. The writer offers his congratulations and would like to profer some comments from his own experiences and analysis of Gilbert data 13,14 in the hope that they may be useful.

Experimental Equipment and Procedure

Recirculation of Sand. - The writer, after finding that the relatively modern method of circulating water and sediment saves time in qualitative work and produces very realistic river behavior even with "steady" discharge, has reverted to direct injection for exact quantitative purposes. First, steady pumping of sediment-laden flow is very difficult, and second, even with steady pumping there seems to be atendency for oscillation of sediment charge withperiods that may run from hours to days depending on the type of experiment. These oscillations seem largely responsible for the realistic sediment behavior of river models with steady discharge. The initiation of oscillation, in a flume, appears to arise from a disturbance, or error of adjustment, causing a backwater effect; then sediment either deposits or is removed from the downstream end and results in a starvation or excess of sediment supply at the upstream one. The consequent degradation or accretion that moves down the flume takes a relatively long time to travel, so the oscillations are of long period. In special experiments now in hand at the University of Alberta ${ }^{15}$ where bed-load is about $20 \%$ by weight of the water flow, the pulsation of sediment-flow is rapid and clearly visible - presumably associated with the pump behavior. Oscillating discharge causes enhanced scatter of plotted points and might cause bias.

Measurement of Bed-Load Charge.-A special cause of scatter of the authors' plotted data, which the writer finds rather more than he expected from his own experiments, field canal observations, and regime analysis of Gilbert 13,14 might be the method of measuring charge. Charge (weight discharge of sediment divided by weight discharge of liquid) is not measurable generally by concentration found in a grab sample (weight of sediment found in such a sample divided by weight of water in it) unless the sediment moves at fluid speed. ${ }^{16}$ An interesting analogue from physical chemistry is of anions and cations flowing in opposite directions between the poles of a battery; obviously, if a sample of their concentration showed them in the ratio of $\mathrm{x} / \mathrm{y}$ this would not prove they moved in the same direction with discharge ratio $\mathrm{x} / \mathrm{y}$. Recent work at the University of Alberta ${ }^{15}$ has shown discordance between charge measured from concentration and directly by collecting and analysing the watersediment complex volume that is diverted for a considerable time into a tank. Perhaps the methods of measurement of charge, even in a nappe, merit check against a case where sediment is injected at a known charge rate.

Measurement of Depth. - The writer once had bed profiles observed in a glass-sided flume ${ }^{17}$ with results that condensed to "... the mean of the mean depths observed on each side of the test reach differed by a very small, but statistically significant, amount from the mean found from that mean and the mean depth along the centerline in the small flume. Also the mean depth taken from the sides, by planimetering the bed-wave profiles, did not differ signifi-

15 Flume transport research under R. W. Ansley, M. Sc., sponsored by Cities Service Athabasca, Inc., 1960.

16 "Regime Behavior of Canals and Rivers," by T. Blench, Butterworths Scientific Publications, Washington 14, D. C., 1957.

17 Note on Studies of Bed-Movement in Flumes, 1949-51, Report of September, 1951 by T. Blench, to National Research Council (Canada) re Fraser River Model (Available Department of Civil Engineering, University of British Columbia). 
cantly, on an average, from that given by averaging the two extreme depths of each of the planimetered profiles ..." Perhaps the mean bed elevation might be quite accurately found by smoothing out the dunes after a run.

Use of Orifice Meters.-It is possible that an orifice meter calibrated for clean water reads incorrectly for sediment-laden flow because (1) the kinetic energy correction factors at the measuring sections are different, (2) the sediment deposits against the orifice plate.

Natural River Sand.-Sand obtained from a river is not necessarily natural river sand; it may be a mix obtained from a dredging pile. Work at the University of British Columbia ${ }^{17}$ showed that a mix of natural sands used in flume experiments alters during running and tends to become natural with a median diameter that may be different from that of the mix. The writer's observations 18 show that a natural river sand plots fairly straight between the $1 \%$ and $99 \%$ limits on log normal paper and has about $1 \%$ coarser than twice median size and $1 \%$ finer than half median size. Repeated observations over several years at the University of Alberta have shown that a natural sand used in a river tray does not change its constitution. Presumably an unnatural sand will split into bed and suspended load in different proportions at different discharges and cause considerable errors in assessing bed-load and what it would do in water free from suspensions.

Observed Flow Phenomena

Time of Development of Regime.-The writer agrees about the long time required for establishment of a new steady regime in sand-bearing flumes after even a small change in a factor such as bed-load charge. In flume experiments 17 aimed at relating bed-factor to charge (for designing a model) the mean depth, after a change, was plotted at intervals of several hours for periods of several days and was found to change asymptotically from some three to four inches and oscillate slightly about its limit; the results indicated that three days was a fair steadying time. The matter is important in measuring bed-factor, $F_{b}=$ $V^{2} / D$, since discharge is usually known exactly, so $F_{b}$ varies inversely as the cube of $\mathrm{D}$.

Absence of Ripples or Dunes at Low Charges.-On page 81 is the statement "Other investigators have reported movement with a plane bed without formation of ripples..” This phenomenon is under investigation now at the University of Alberta ${ }^{19}$ with $1 \mathrm{~mm}$ gravel. At discharge intensities such as in the present paper small charge flow is duneless, and if dunes have been previously induced they gradually vanish; but at higher charges in the subcritical range dunes form and persist. The behavior is important practically because, although a sand model can reproduce qualitative gravel river behavior 20 it is quantitatively imperfect. (Gravel may be defined as material have settlement velocity proportional to the square root of sediment size, so $1 \mathrm{~mm}$ is a convenient lower size limit (with some margin). In the sand range, less than somewhat smaller than $1 \mathrm{~mm}$, settlement velocity does not follow a fixed index law; the index increases progressively from $1 / 2$ till size is about $0.1 \mathrm{~mm}$, af-

18 “Normal Distribution Found in Sample of River-Bed Sand," Civil Engineering, Febbruary, 1952, with replies to discussion February, 1953.

19 Research at University of Alberta by A. N. Varzelioti under auspices of Alberta Government Highways Department (Bridge Branch) and Alberta Research Council, 1960. re certain river erosion problems.

20 "Regime Behavior of Canals and Rivers," by T. Blench, Butterworths Scientific Publications, London, England, and Toronto, Canada, 1957, Chapter 8. 
ter which it remains fixed at 2). The quantitative advantages of using a small gravel to represent the material of a gravel river are considerable, so the practical question arises whether, in a small model, somefactor like Reynold's Number in terms of depth, or relative grain size 21 becomes important and prevents the model from behaving like the prototype. Unfortunately, Gilbert's notes on the appearance of dunes seem rather vague on whether they were absent in certain cases, or he did not verify, and his charges were mostly higher than those that affect engineering practice. The authors are paying attention to the engineering range of charges up to some 400 parts per million - so it is hoped that they will consider investigating this problem of gravel behavior and perhaps carry it to the field, aided by sonic sounding, 22 as an extension of their related paper 23 (Excessive saltation in a gravel river confuses sonic records).

Seepage Flow。-The effect of seepage flow, page 80, certainly deserves the attention given it . The writer has noted, in glass-sided flumes, that the phenomenon related to Figs. 5, 6 can be associated with piping failure of the bed due to formation of a hydraulic jump.

The Shock Antidune.-Sponsored research 15 being carried out at the University of Alberta by R.W. Ansley M.Sc. has recently shown an interesting new phenomenon that might be named the "shock antidune." With about $20 \%$ by weight sand bed-load (in supercritical flow) in a flume insertion of the hand causes a hydraulic jump and load deposits rapidly in its subcritical portion. The jump moves slowly upstream with sand continuing to deposit. Removal of the hand then lets a clear backwater curve form down the downstream side of the deposit. Erosion of this downstream side proceeds more slowly than deposition occurs just downstream of the jump, so a gradually lengthening super antidune combined with hydraulic jump (or "shock-wave") moves slowly upstream.

Ripples and Dunes.-Laboratory workers usually find the need for distinguishing between ripples and dunes, but the writer has not felt the need in canal practice since, even with very small charges, the bed-wave patterns observed during closure seem to be fairly described as dunes; also analysis of transport data do not seem to indicate that the change from ripples to dunes is associated with a discontinuity of formula such as Fig. 9 shows for the change from dunes to sheet flow (of course, data usually scatter considerably so may hide an effect). The question arises, in connection with the comments on "absence of ripples or dunes at low charges," whether ripples may be a small scale phenomenon. Would it be possible, now or later, to extend the authors' helpful descriptions to a detailed quantitative definition of ripples and dunes?

Analysis of Data.-It is a little surprising that the data have been analyzed in terms of "tractive force," which is not, to borrow a thermodynamic term, a function of state, and the rather peculiar concept of a laminar film thickness on a duned bed, when the authors' related paper 23 has found regime theory parameters so rewarding. As all the Gilbert data plus some of L. B. Straub and of the U. S. Waterways Experiments Station have been analyzed, using re-

21 Ibid., See 5, 18 ,

22 "Systematic Changes in the Beds at Alluvial Rivers," by Walter C. Carey and M. Dean Keller, Proceedings, ASCE, Vol.83, No.HY 4, August, 1957, and discussion thereon by T. Blench, Proceedings, ASCE, Vol. 84, No. HY 2, February, 1958.

23 "Uniform Water Conveyance Channels in Alluvial Materials," by Daryl B. Simons and Maurice L. Albertson, Proceedings, ASCE, Vol. 86, No. HY 5, May, 1960, and discussion thereon by T. Blench. 
gime theory methods, the writer 13,14 has re-analyzed Table 1 accordingly and found some interesting agreements with and points arising from the authors' findings:-

(i) Regime slope relation and charge. The regime analysis just mentioned 13,14 led to the following: 24

$$
\mathrm{V}^{2} / \mathrm{gDS}=3.63(1+\mathrm{aC})(\mathrm{Vb} / \nu)^{\frac{1}{4}} \ldots \ldots \ldots \ldots
$$

In this, for Gilbert sand and gravel, and subcritical flow, “a” was found to be $1 / 400$ with $C$ measured in parts per hundred thousand (not per million like $C_{T}$ in the present paper). So, as an alternative to Fig. 9, regime theory would suggest plotting $(\mathrm{Vb} / \nu)^{\frac{1}{4}}$ divided by $\mathrm{V}^{2} / \mathrm{gDS}$ against $\mathrm{C}_{\mathrm{T}}$, and the expectation would be that a practically horizontal line would result (to the log scale) up to $\mathrm{C}_{\mathrm{T}}=100$, with a slight dip up to 1,000 and a discontinuity of slope beyond about

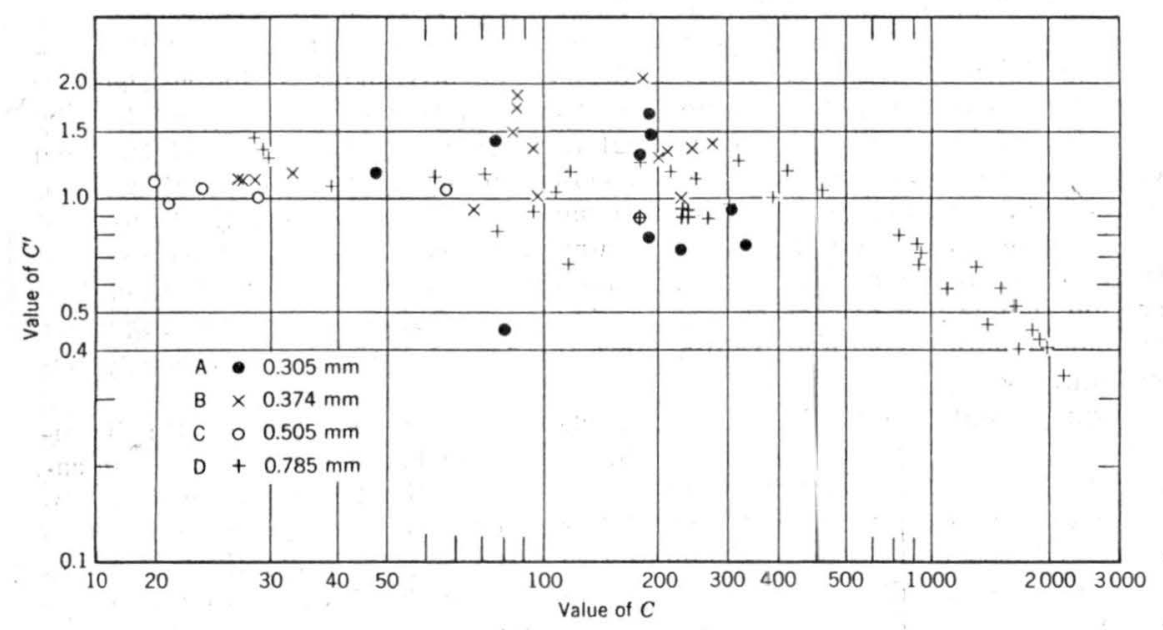

FIG. 14.-CHANGE IN REGIME SLOPE FORMULA WHEN DUNES VANISH

3,000. (Fig. 14 reproduces Fig. 4 of Ref. 13, in support; it tests, on logarithmic scale for convenience of publication, whether equation (12) with " $a$ " $=1 / 400$ does actually fit a good sample of Gilbert data in the subcritical range). The plot, 25 actually of $\mathrm{SQ}^{1 / 12} / \mathrm{F}_{\mathrm{b}} 11 / 12$ gave a horizontal line with the scatter of points comparable with those of Fig. 9 and too much to show the expected dip; it showed a definite change of slope where expected; the scatter of points was more than would have been expected from Gilbert; the discontinuity of slope was as marked as that of $\tau$ in Fig. 9; the position of the line did not agree with the value of 3.63 in equation (12).

24 Discussion by T. Blench of "Uniform Water Conveyance Channels in Alluvial Materials," by Daryl B. Simons and Maurice L. Albertson, Proceedings, ASCE, Vol. 87, No. HY 1, 1961.

25 “Regime Behavior of Canals and Rivers,” by T. Blench, Butterworth's Scientific Publications, Sec. 1.7, Washington, D. C., 1957. 


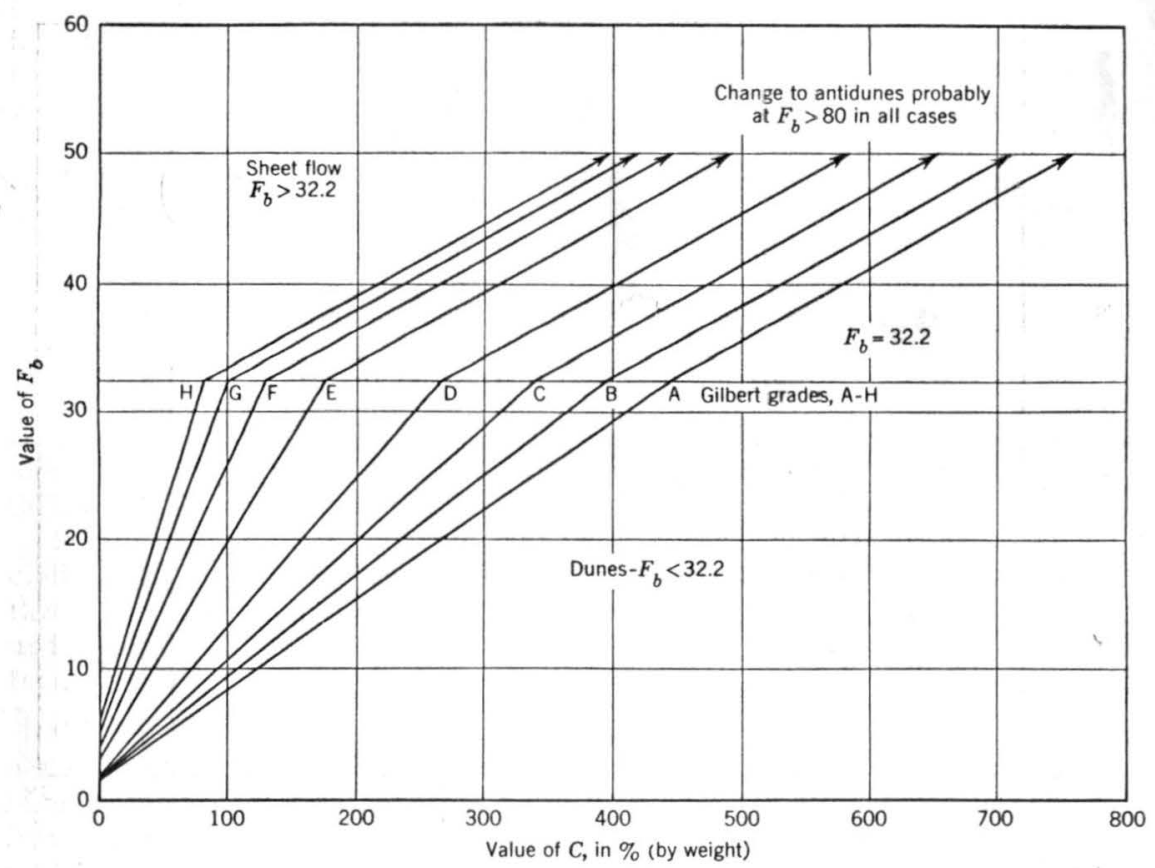

FIG. 15.-PROBABLE TYPE OF BED-FACTOR AGAINST CHARGE RELATION FOR ALL GILBERT SANDS AND GRAVELS

The discontinuity over which the writer and the authors agree is interesting because the well-known transport formula of Meyer-Peter 26 and the bed-load function of Einstein, 27 both resting partially on a selection of Gilbert data and both giving essentially the same relation, 28 are devised to show a continuous relation through ripples, dunes, sheet flow and antidunes. Obviously some reconciliation amongst authorities is desirable, perhaps by further observations.

The disagreement in coefficient between the writer and the authors might be due to measurement methods, see comments under EXPERIMENTAL EQUIPMENT AND PROCEDURE. Possibly a re-plot to Meyer-Peter and Einstein parameters would help by showing whether there was disagreement with their data as well as with those of Gilbert and of major irrigating canals of India. 16

(ii) Bed-factor, $\mathrm{F}_{\mathrm{b}}$, and charge. Regime theory 13,14 would replace Fig. 10 by a simple plot of $\mathrm{V} 2 / \mathrm{D}$ against charge, $\mathrm{C}$, for each bed-material used. Fig. 15 is an idealized key diagram showing the type of relations obtained by doing this for all Gilbert data. Fig. 16 plots the subcritical ripple and dune

26 "Formulas for Bed-Load Transport," by E. Meyer-Peter and R. Muller, Proceedings, I.A.H.R., 1948, p. 39.

27 × Formulas for the Transportation of Bed-Load," by H. A. Einstein, Transactions, ASCE, Vol, 107, 1942, pp. 561-594.

28 "The Present Status of Research of Sediment Transport," by Ning Chien, Transactions, ASCE, Vol. 121, 1956, p. 833, Fig. 5 . 


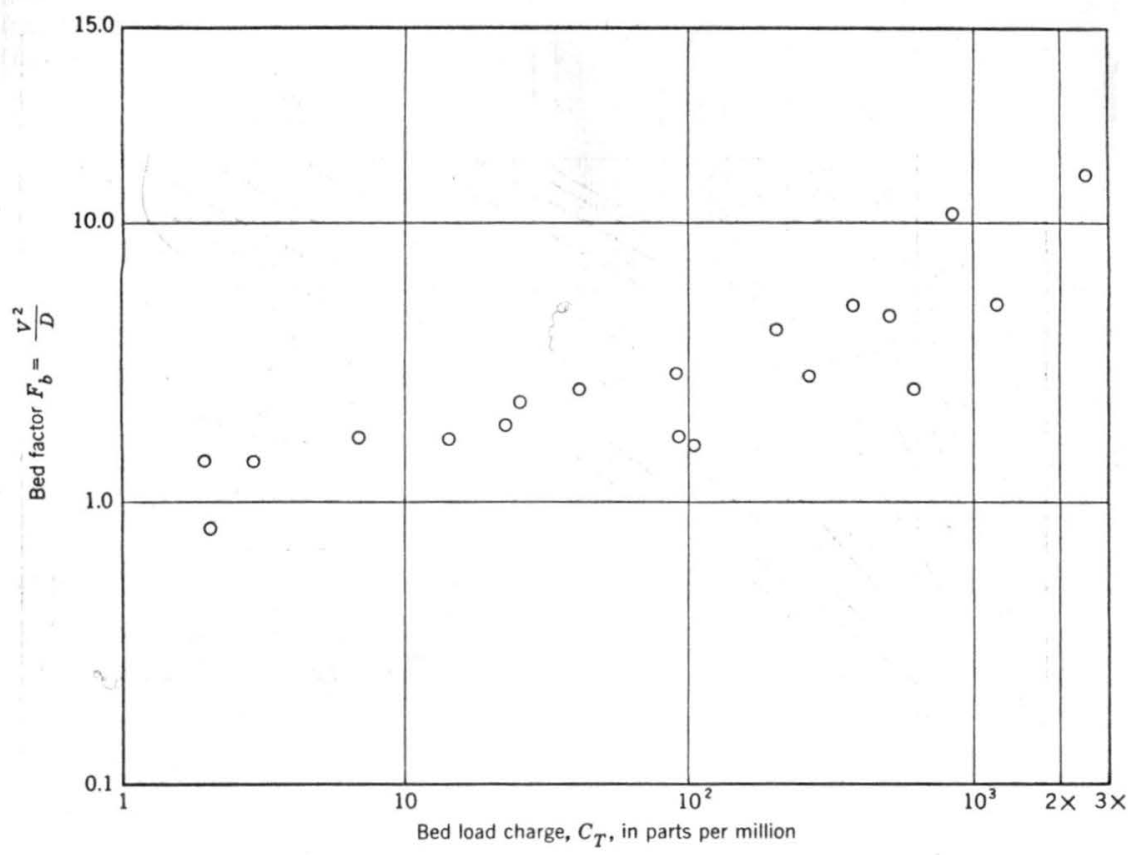

FIG. 16.-BED FACTOR CHARGE RELATION FOR DUNES: TABLE 1

data of Table 1 similarly and yields the kind of relation expected, but the slope of the line is considerably different from expectation from Gilbert and from work done with natural sands of $0.275 \mathrm{~mm}$ and $0.45 \mathrm{~mm}$ at the University of British Columbia。17 Those last experiments, for the small but highly practical range of $\mathrm{C}=$ almost zero to $\mathrm{C}=12$ parts per hundred thousand were fitted by:

$$
F_{b}=1.9 \sqrt{d_{m}}(1+0.135 C) \ldots \ldots \ldots \text { (13) }
$$

in which $d_{m}$ is particle median size in millimeters. As they made lengthy runs at vanishing $C$, the scatter at $C=0$ was small, whereas the points at $C=1$ in Fig. 16 scatter badly. So again the questions raised previously about natural sand and measurement methods come into prominence.

An important agreement about the type of fit to bed-factor data is that, at vanishingly small charge, $\mathrm{V}^{2} / \mathrm{d}$ has a definite value. This contradicts theories that make bed-factor vanish when charge tends to zero. A further important showing is that bed-factor is a "function of state" in that it depends on the bedmaterial and the charge, but not on the discharge of the fluid. This contradicts hydraulics texts that publish tables purporting to give the velocities at which channels moving non-cohesive sediment along their beds will neither silt nor scour; such tables require that the channels of an ideal irrigating system that distributes sediment uniformly should be designed to run all at the same velocity whereas they would run all at the same $\mathrm{V}^{2} / \mathrm{D}$; that is, the large channels would run considerably faster than the small ones. These matters have been discussed in detail elsewhere ${ }^{16}$ 
Need For Research.-Attention is drawn to the specific recommendations for research。 13,14 The Gilbert data, despite their great range and number, do not have uniform coverage and are for artificial sands and gravels. Their analysis 13,14 leads to a selection of specific questions, most of which could be answered in a couple of years by a few co-operating stations with large facilities, supplemented by large scale experiments in the field. A research not mentioned, 13,14 but likely to be fruitful because Canadian and American engineers have demonstrated its simplicity in the field, 22 is into the relation among dune parameters and those of the water-sediment complex and flow。 Although individual dunes and ripples may be impermanent, the average number per unit length, the average heights and the average speeds of progression are definite, and regime theory ${ }^{29}$ indicates that a suitable equivalent roughness height is given by $\left(\nu \mathrm{F}_{\mathrm{S}}\right)^{\frac{1}{2}} \quad \mathrm{~F}_{\mathrm{b}}(1+\mathrm{a} \mathrm{C})^{2}$. Perhaps the authors would consider the feasibility of such a program interms of the canal facilities used for their related work 23 and, of course, their laboratory flume.

Nomenclature.-For several years the writer has adhered to ASCE nomenclature for his publications, including international ones. ${ }^{30}$ It is suggested that the authors might also conform, for example in using a small $d$ for depth and a large D for particle size; no system based on only 26 letters can be perfect.

EMMETT M. LAURSEN, ${ }^{31}$ M. ASCE, and GERALD A. ZERNIAL, 32 A. M. ASCE.-Useful as dimensional analysis and dimensionless parameters can be in many instances, if not used with caution, their use can confuse and embellish rather than clarify and simplify. It seems to the writers that too great a faith in the power of dimensionless parameters has marred this report on an otherwise careful and worthwhile investigation.

Both Figs. 10 and 11 illustrate one of the traps waiting for the unwary, relating something to itself. The parameter of Fig. 10, for example:

can be rewritten as

$$
\frac{\mathrm{V}}{\mathrm{V}_{*}} \frac{\tau_{\mathrm{O}}}{\Delta \gamma_{\mathrm{S}} \mathrm{d}} \text { versus } \frac{\mathrm{V}_{*} \mathrm{~d}}{\nu}
$$

$$
\frac{C}{\sqrt{g}} \frac{\gamma \text { D S }}{\Delta \gamma_{s} d} \text { versus }-\frac{\sqrt{g \text { D S }} d}{\nu}
$$

since $\mathrm{V} / \mathrm{V}_{*}=\mathrm{C} / \sqrt{\mathrm{g}}, \tau_{\mathrm{O}}=\gamma \mathrm{D} \mathrm{S}$, and $\mathrm{V}_{*}=\sqrt{\mathrm{g} \mathrm{D} \mathrm{S}}$. In this form, it is readily apparent that in the ordinate parameter there is a factor $\mathrm{D} \mathrm{S} / \mathrm{d}$ and in the abscissa parameter $\sqrt{\mathrm{D} \mathrm{S} / \mathrm{d}}$, which by themselves would plot as a perfect line on a 2 to 1 slope on log-log paper. The data in Fig. 10 plot in a scatter band with a slight curve approximately a 2 to 1 line. Because most of the range in values of the parameters is due to the range in values of the slope, it can be concluded that the relationship indicated in Fig. 10 is primarily $D S / d=(\sqrt{D ~ S / d})^{2}$.

29 “Regime Behavior of Canals and Rivers," by T. Blench, Butterworth's Scientific Publications, Sec. 1.7, Washington, D. C., 1957.

30 “Civil Engineering Reference Book," Butterworths, London, England, 2nd Edition (under issue 1960). Chapter "Hydraulics of Canals and Rivers of Mobile Boundary," by T. Blench.

31 Assoc. Prof., Civ. Engrg., Michigan State Univ., East Lansing, Mich.

32 Assist. Instr., Dept. of Civ. Engrg., Michigan State Univ., East Lansing, Mich. 
Presumably, the systematic deviation from this line should then be due to the residue of the parameters

$$
\frac{\mathrm{C} \gamma}{\sqrt{\mathrm{g}} \Delta \gamma_{\mathrm{s}}}=\phi_{\mathrm{a}}\left(\frac{\sqrt{\mathrm{g} \mathrm{d}^{3 / 2}}}{\nu}\right) \ldots \ldots \ldots \ldots
$$

and the scatter due to other unincluded factors or to experimental errors.

Similarly, the parameters of Fig. 11

$$
\frac{\mathrm{V}}{\mathrm{V}_{*}} \frac{\tau_{\mathrm{o}}}{\Delta \gamma_{\mathrm{S}} \mathrm{D}} \mathrm{S} \text { versus } 10^{2} \frac{\mathrm{wd} \mathrm{S}}{\nu}+5 \frac{\mathrm{V}^{2}}{\mathrm{~g} \mathrm{D}}
$$

can be rewritten

$$
\frac{\mathrm{C}}{\sqrt{\mathrm{g}}} \frac{\gamma}{\Delta \gamma_{\mathrm{s}}} \mathrm{S}^{2} \text { versus }\left(100 \frac{\mathrm{w} \mathrm{d}}{\nu}+5 \frac{\mathrm{C}^{2}}{\mathrm{~g}}\right) \mathrm{S}
$$

and it is evident that the range of values of $\mathrm{S}$, from 0.00015 to 0.0101 , determines in large measure the manner in which the data plot. In this case, the residue of the parameters are still not completely independent when the S factors are removed.

$$
\frac{\mathrm{C}}{\sqrt{\mathrm{g}}} \frac{\gamma}{\Delta \gamma_{\mathrm{s}}}=\phi_{\mathrm{b}}\left(100 \frac{\mathrm{w} \mathrm{d}}{\gamma}+5 \frac{\mathrm{C}^{2}}{\mathrm{~g}}\right) \ldots \ldots \ldots
$$

It would appear from Eqs. 14 and 15 that the dimensionless Chezy coefficient $\mathrm{C} / \sqrt{\mathrm{g}}$ is related to either $\sqrt{\mathrm{g}} / \mathrm{d}^{3 / 2} / \nu$ or $\mathrm{w} \mathrm{d} / \nu$. These parameters, however, only vary with the temperature insofar as this particular study is concerned. From a plot simply of run number (presumed to be in order of occurrence) against temperature, Fig。17, it might be inferred that the first eighteen runs were made in the winter and the remainder in the summer. Because the conditions for the runs were more or less systematically varied, the runs with rippled beds (and rather small $\mathrm{C} / \sqrt{\mathrm{g}}$ values) happened to be at low temperatures, while the transition and antidune runs (with larger $\mathrm{C} / \sqrt{\mathrm{g}}$ values) happened to be at higher temperature. A suspicion that the apparent temperature effect is really a bed-form effect can hardly be avoided.

That the Chezy coefficient is a function of the bed form, or roughness, is shown in Fig. 18 where $\mathrm{C} / \sqrt{\mathrm{g}}$ is plotted against $2 \mathrm{D} / \mathrm{h}$ 。 The numbers beside each point are values of $\mathrm{L} / \mathrm{h}$ 。 The values of $\mathrm{L}$ and $\mathrm{h}$, the length and height of the dunes and ripples, were obtained from correspondence with the authors and are listed in Table 2. Considering the variety and complexity of bed forms, the relative height and length are not really sufficient to describe completely the geometry. Moreover, the surface texture (particle roughness) and the Reynolds number of the flow might also be expected to be influential in determining the resistance to flow. The data of the $0.18-\mathrm{mm}$ sand used by Barton and $\mathrm{Lin}, 33$ and of the $0.1-\mathrm{mm}$ sand used in some experiments at the Iowa Institute of Hydraulic Research 34 also scatter about the Nikuradse line, Figs. 19 and 20 , but with smaller $\mathrm{L} / \mathrm{h}$ values. Qualitatively, the contribution to the to-

33 "A Study of Sediment Transport in Alluvial Channels," by J. R. Barton and P.-N. Lin, Research Report, Civ. Engrg. Dept., Colorado A and M College, 1955.

34 "The Total Sediment Load of Streams," by E. M. Laursen, Proceedings, ASCE, Vol. 84, No. HY 1, February, 1958. 


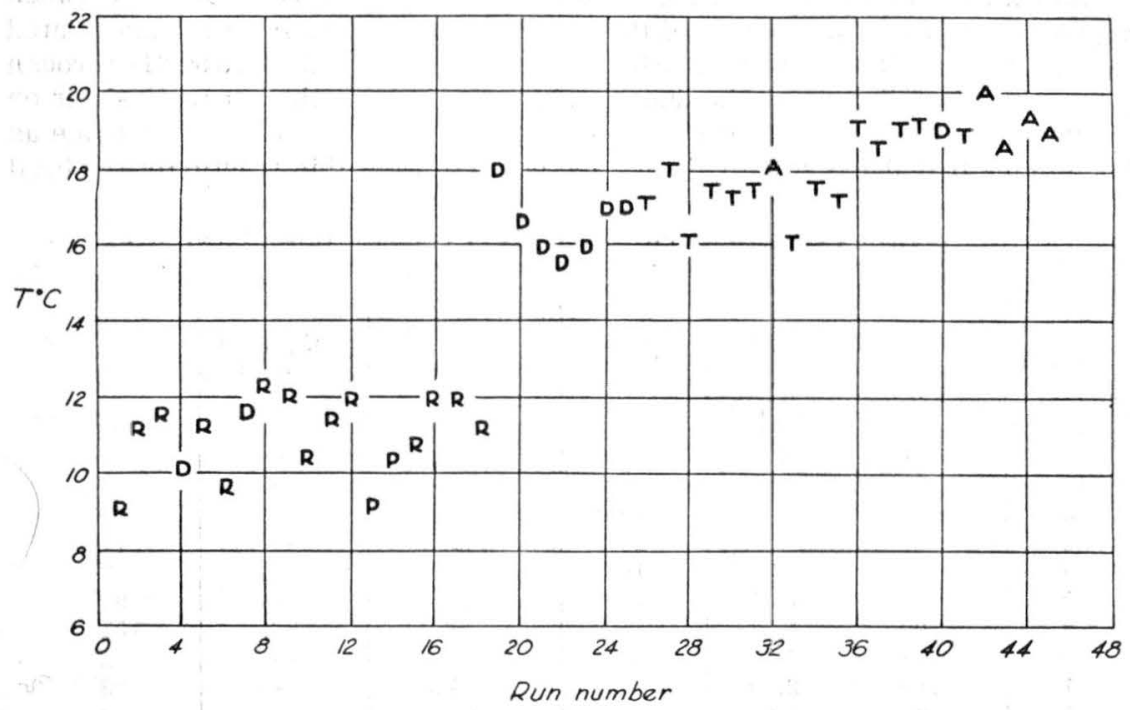

FIG. 17.-TEMPERATURE VERSUS RUN NUMBER

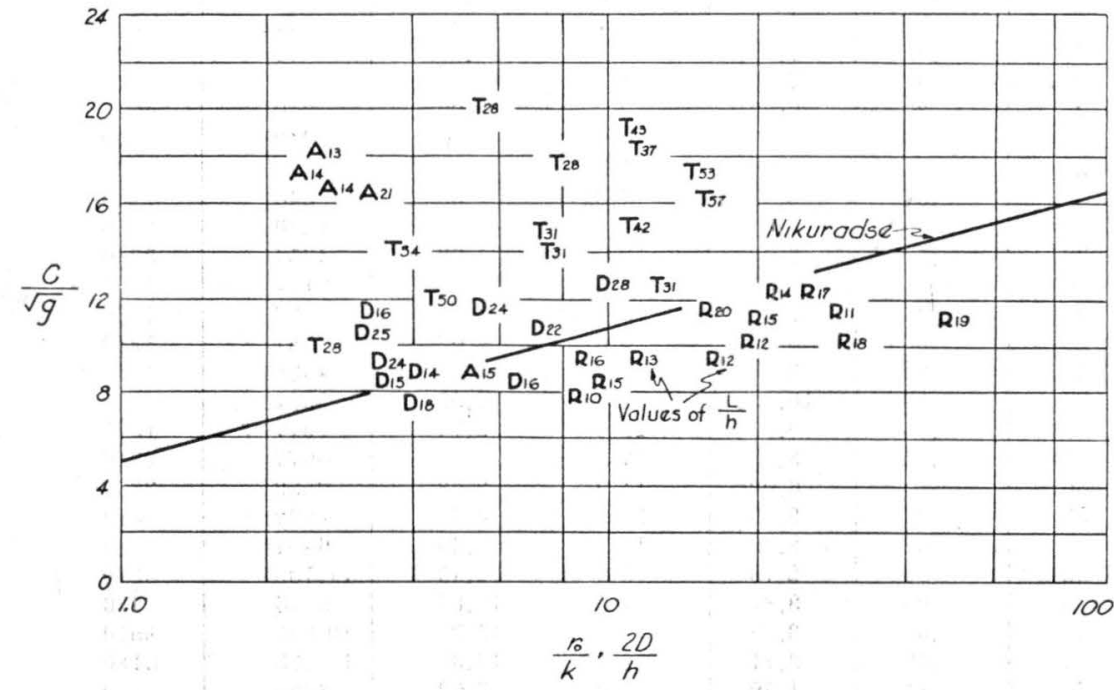

FIG, 18.-RESIST ANCE AND ROUGHNESS, SIMONS AND RICHARDSON 
tal resistance of surface (particle) roughness would seem to be greater the coarser the sand.

As pointed out by the authors, the discontinuity in the relationship between $\tau_{0}$ and $\mathrm{C}_{\mathrm{T}}$ in Fig。 9 is because of the relatively large tractive force associated with the dunes. The total tractive force is transmitted to the bedpartly through a pressure distribution on the dunes and partly through the apparent shear on the sediment particles. If one assumes that the particle shear is the same as for a plane bed at the same velocity and depth of flow, this fraction of the total

TABLE 2,-VALUES OF LENGTH AND HEIGHT OF THE DUNES AND RIPPLES

\begin{tabular}{|c|c|c|c|c|c|c|}
\hline $\begin{array}{l}\text { Run } \\
\text { No. } \\
(1)\end{array}$ & $\begin{array}{c}h \text {, in } \mathrm{ft} \\
\text { (2) }\end{array}$ & $\begin{array}{c}\mathrm{L} \text {, in } \mathrm{ft} \\
\text { (3) }\end{array}$ & $\begin{array}{r}\frac{\mathrm{C}}{\sqrt{\mathrm{g}}} \\
(4)\end{array}$ & $\tau_{0}^{\prime} \times{ }_{\text {in psf }}^{1} \times 0^{2}$, & $\begin{array}{c}\mathrm{C}_{\mathrm{TCm}} \text {, in } \\
(6) \\
\end{array}$ & $\begin{array}{c}\mathrm{C}_{\mathrm{TMm}} \text {, in } \\
\text { (7) }\end{array}$ \\
\hline 14 & -- & --- & 14.9 & 0.294 & --- & --- \\
\hline 17 & 0.04 & 0.77 & 11.2 & .244 & --- & 1 \\
\hline 16 & .06 & .69 & 11.9 & .254 & --- & 2 \\
\hline 13 & --- & --- & 14.0 & .227 & --- & -- \\
\hline 15 & --- & --- & 10.2 & .255 & --- & 1 \\
\hline 18 & .04 & .71 & 10.2 & .276 & --- & 1 \\
\hline 2 & .07 & 1.21 & 12.3 & .585 & --- & 94 \\
\hline 3 & .09 & 1.36 & 11.2 & .539 & 8.2 & 101 \\
\hline 9 & .06 & 0.73 & 10.4 & .359 & -- & 2 \\
\hline 1 & .10 & 2.00 & 11.8 & .625 & --- & 23 \\
\hline 5 & .07 & 1.00 & 12.4 & .729 & --- & 26 \\
\hline 11 & .06 & .80 & 9.4 & .264 & --- & 4 \\
\hline 4 & .15 & 4.16 & 12.8 & .890 & --- & 92 \\
\hline 8 & .06 & .73 & 9.4 & .411 & --- & 8 \\
\hline 7 & .20 & 4.41 & 10.8 & .873 & 70 & 268 \\
\hline 10 & .08 & .83 & 7.7 & .310 & -- & 20 \\
\hline 6 & .10 & 1.56 & 9.3 & .564 & --- & 42 \\
\hline 12 & .06 & .89 & 8.5 & .416 & --- & 1 \\
\hline 19 & .26 & 6.42 & 10.7 & .862 & 97 & 208 \\
\hline 21 & .31 & 4.82 & 8.4 & .962 & 86 & 641 \\
\hline 22 & .52 & 7.50 & 8.5 & 1.09 & 113 & 710 \\
\hline 25 & .26 & 6.29 & 9.2 & 1.09 & 210 & 378 \\
\hline 20 & .36 & 5.37 & 8.6 & 1.26 & 240 & 508 \\
\hline 23 & .41 & 6.60 & 11.3 & 2.89 & 840 & 856 \\
\hline 24 & .31 & 5.51 & 7.31 & 1.38 & 346 & 1200 \\
\hline 40 & .31 & 7.35 & 11.8 & 4.48 & 1200 & 2460 \\
\hline 39 & .10 & 3.68 & 18.6 & 1.03 & 4354 & 3960 \\
\hline 26 & --- & --- & 26.8 & 15.85 & 9171 & 4580 \\
\hline 28 & .05 & 2.57 & 16.2 & 6.38 & 3432 & 4230 \\
\hline 29 & .23 & 6.40 & 10.0 & 2.02 & $9 \varepsilon 7$ & 1850 \\
\hline 31 & .06 & 3.16 & 17.1 & 8.97 & 4998 & 4750 \\
\hline 27 & .19 & 10.22 & 13.9 & 4.92 & 3091 & 4100 \\
\hline 36 & .03 & 0.93 & 12.3 & 2.74 & 1977 & 1370 \\
\hline 41 & .14 & 3.93 & 17.7 & 11.85 & 6077 & 4340 \\
\hline 30 & .12 & 6.02 & 11.9 & 3.58 & 2558 & 3550 \\
\hline 35 & .07 & 2.20 & 14.0 & 4.71 & 3632 & 4610 \\
\hline 34 & .08 & 2.46 & 16.8 & 8.08 & 6451 & 5690 \\
\hline 33 & .10 & 2.76 & 19.9 & 12.40 & 11,798 & 6810 \\
\hline 38 & .09 & 3.81 & 17.0 & 13.85 & 9476 & 6230 \\
\hline 37 & .08 & 3.82 & 18.8 & 15.2 & 10,655 & 5570 \\
\hline 32 & .29 & 3.71 & 18.0 & 13.3 & 11,533 & 6180 \\
\hline 45 & .11 & 1.59 & 9.0 & 3.62 & 3700 & 9630 \\
\hline 44 & .21 & 2.95 & 16.8 & 13.28 & 14,876 & 15,100 \\
\hline 42 & .25 & 3.62 & 17.0 & 16.10 & 18,890 & 11,400 \\
\hline 43 & .27 & 5.81 & 16.5 & 19.17 & 23,500 & 11,500 \\
\hline
\end{tabular}




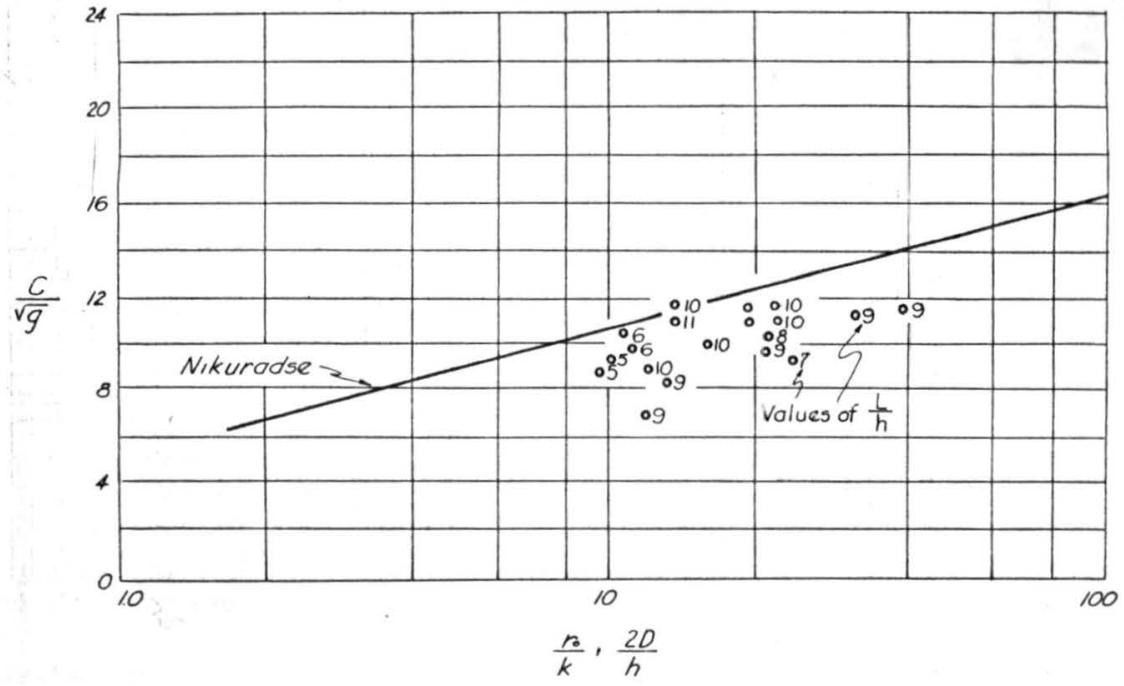

FIG. 19.-RESISTANCE AND ROUGHNESS, BARTON AND LIN

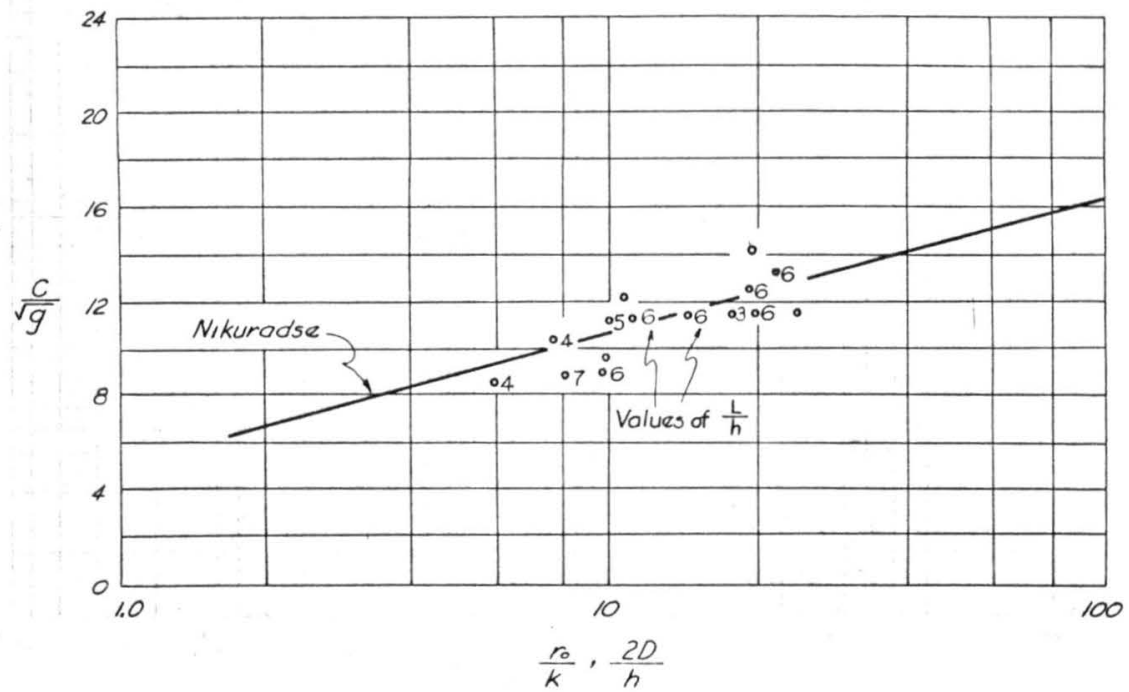

FIG. 20.-RESISTANCE AND ROUGHNESS, LAURSEN AND LIN 


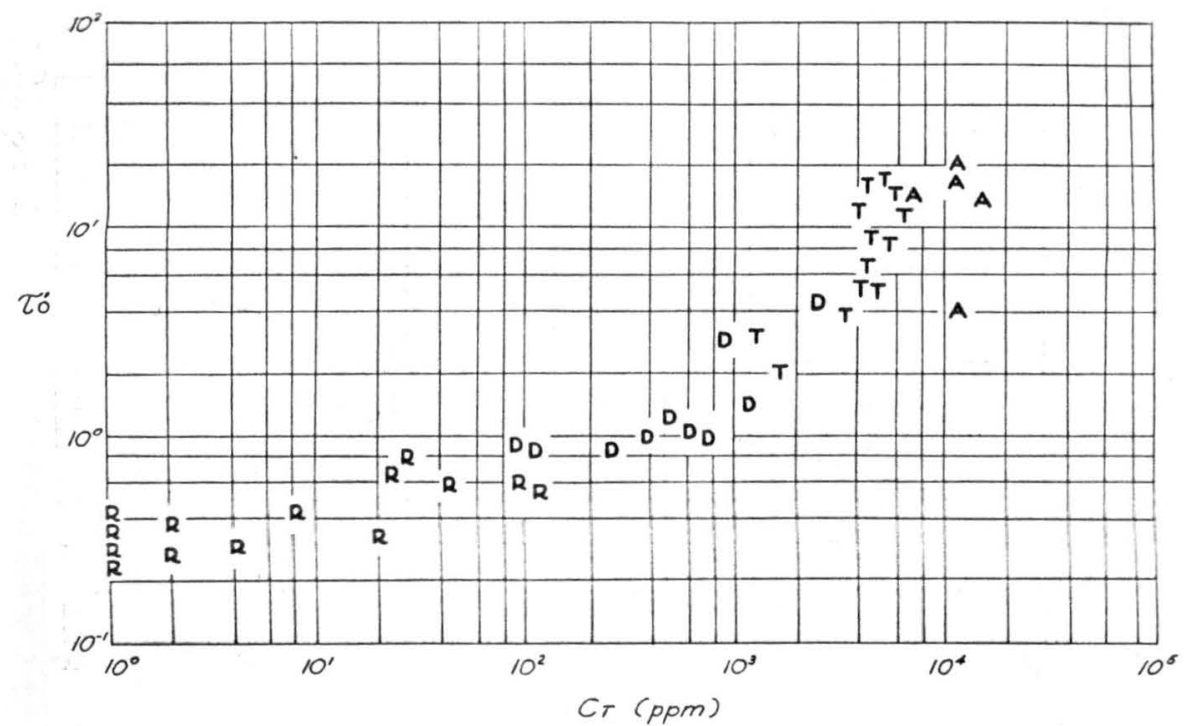

FIG. 21.-CONCENTRATION VERSUS PARTICLE SHEAR

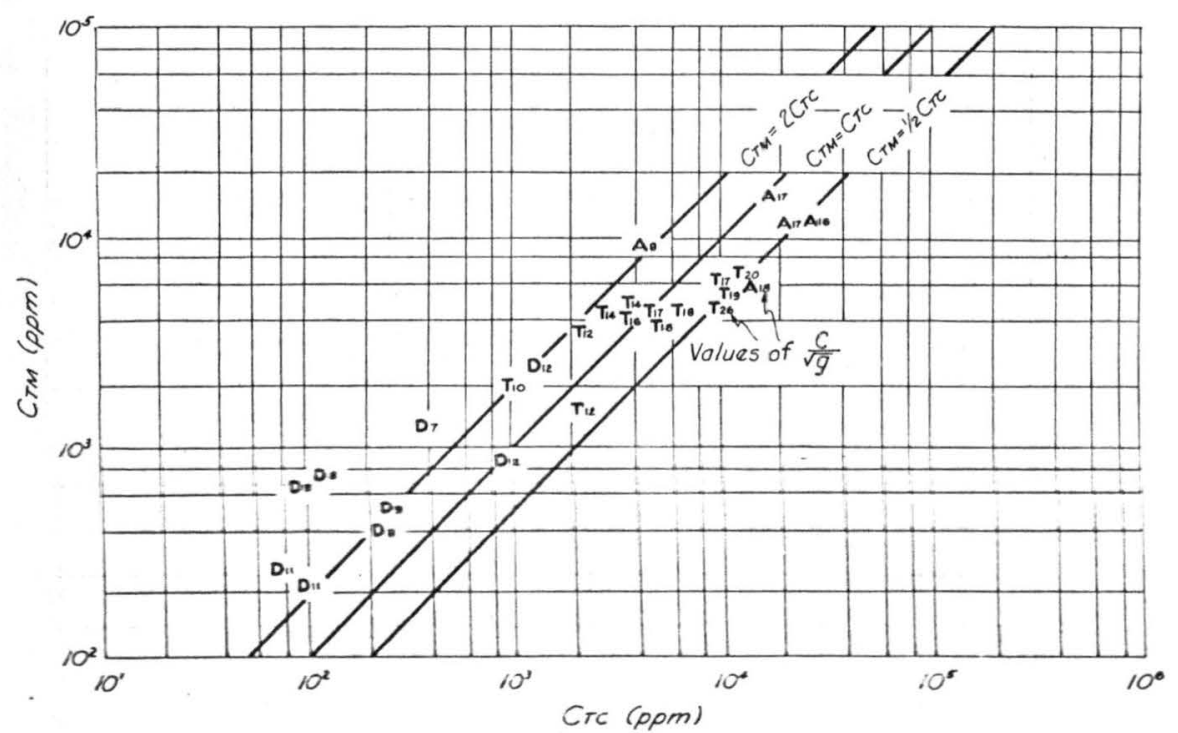

FIG. 22.-COMPARISON OF WEASURED AND COMPTTED CONCENTRATLNS 
shear can be evaluated by the use of Manning's equation and Strickler's evaluation of $n$ as:

$$
\tau_{\mathrm{o}}^{\prime}=\frac{\mathrm{v}^{2} \mathrm{~d}^{1 / 3}}{30 \mathrm{D}^{1 / 3}} \ldots \ldots \ldots \ldots \ldots
$$

The plot in Fig. 21 of this approximation of the particle shear against the concentration eliminates the discontinuity of Fig. 9 .

The use of the particle shear was an integral part of the relationship for computing total sediment load, proposed by one of the writers: 34

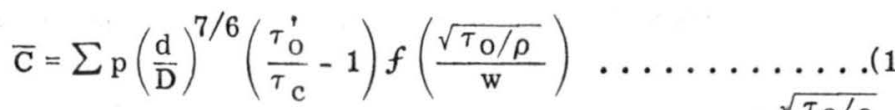

in which $p$ is the fraction of sediment of size $d$, and the function, $f \frac{\sqrt{\tau_{\mathrm{o}} / \rho}}{\mathrm{w}}$ is in a figure presented elsewhere. ${ }^{34}$

Figure 22 shows a comparison between measured total concentration $\left(\mathrm{C}_{\mathrm{TM}}\right)$ and concentration thus computed $\left(\mathrm{C}_{\mathrm{TC}}\right)$. The symbols $\mathrm{D}, \mathrm{T}$, and $\mathrm{A}$ represent dunes, transition, and anti-dunes, and the numbers beside each point are values of the Chezy parameter, $\mathrm{C} / \sqrt{\mathrm{g}}$. A systematic scatter about the line of perfect agreement $\left(\mathrm{C}_{\mathrm{TM}}=\mathrm{C}_{\mathrm{TC}}\right)$ with the Chezy parameter is apparent. The large deviation in the lower concentration range can be partially explained by the factor $\left(\frac{\tau_{\mathrm{o}}^{\prime}}{\tau_{\mathrm{c}}}-1\right)$ used in the computational procedure. This factor should be the temporal mean of the integral of the positive values of $\frac{\tau_{0}^{\prime}}{\tau_{c}}-1$. The temporal mean, obviously, would be much larger than the value used when $\tau_{0}^{\prime}$ is almost equal to $\tau_{\mathrm{c}}$.

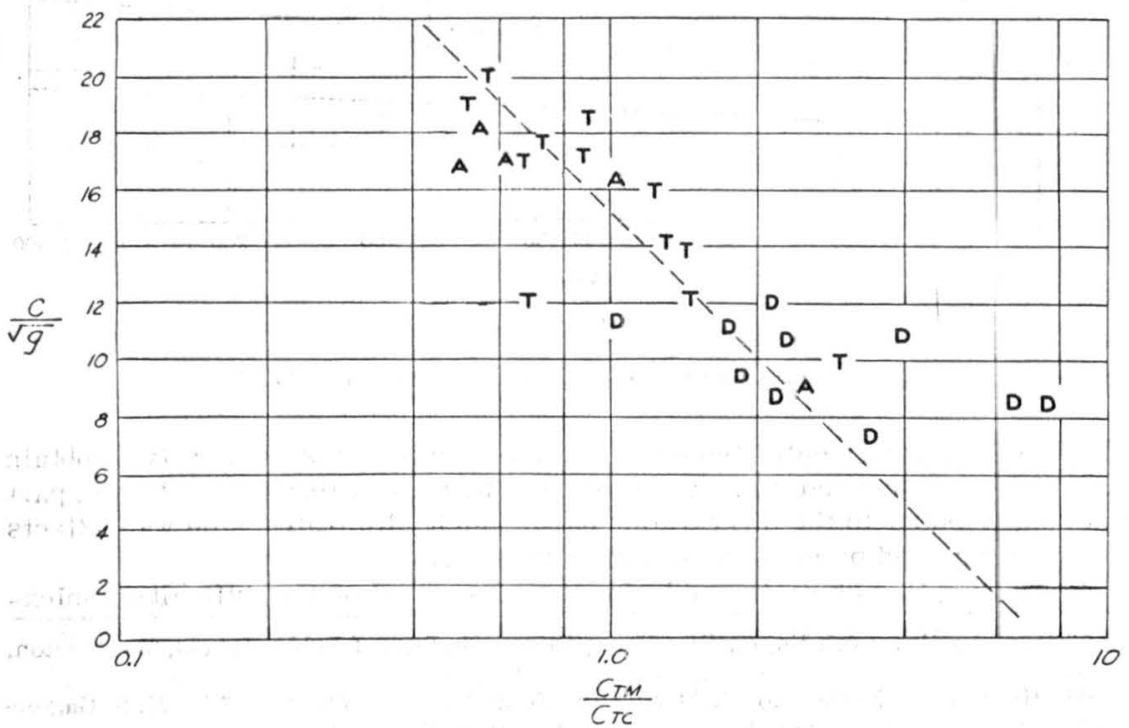

FIG. 23.-RATIO OF MEASURED TO COMPUTED CONCENTRATION 
In Fig. 23 a comparison is shown between the dimensionless Chezy parameter $\mathrm{C} / \sqrt{\mathrm{g}}$ and ratio of measured to computed concentration. Concentrations computed by Eq. 17 tend to be high as the roughness, or resistance, to flow is small (larger values of $\mathrm{C} / \sqrt{\mathrm{g}}$ ) and low as the roughness is great (smaller values of $\mathrm{C} / \sqrt{\mathrm{g}}$ ). It is not unreasonable that the chances for a particle to project itself into suspension are greater for a relatively rough than smooth bed.

DASEL E. HALLMARK, ${ }^{35}$ M. ASCE. - The authors are to be commended for this paper in afield where only meager data exists. Alluvial streams have presented a problem to civilizations for many centuries; and even in the present century communities have been destroyed by alluvial streams. ${ }^{36}$

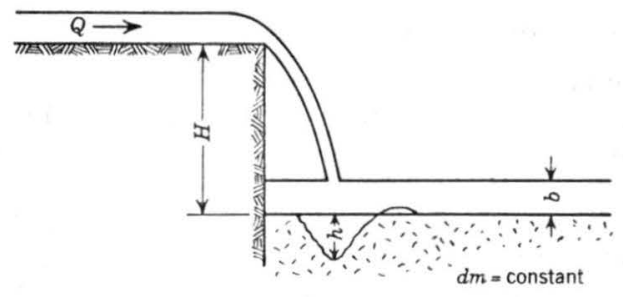

$\sigma_{w}=$ standard deviation of fall velocity

Note: $\sigma_{w}$ was only variable for these tests

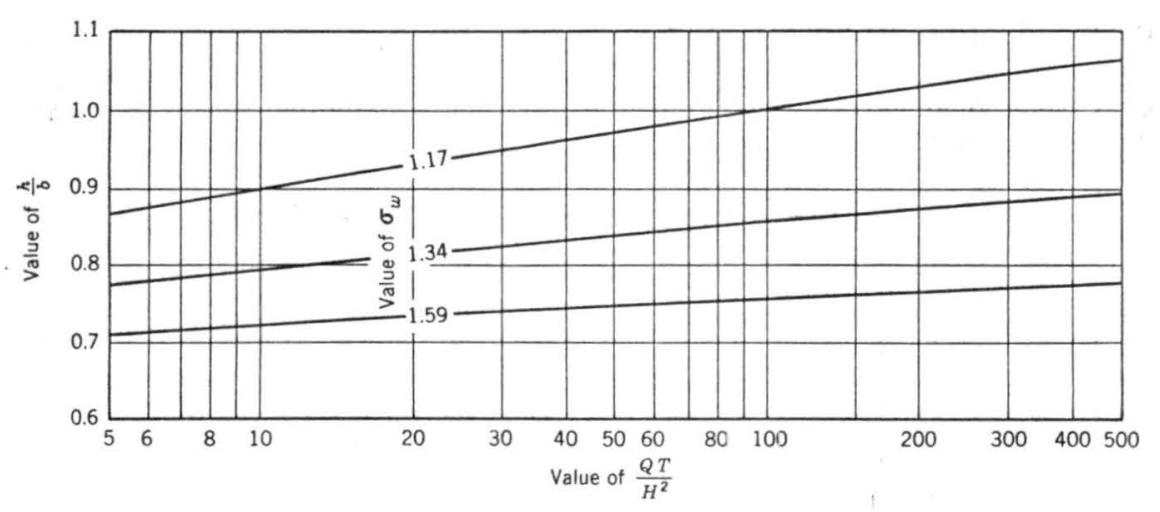

FIG. 24.-INFLUENCE OF $\sigma$ ON RATE OF SCOUR

One of the major enlightening features of the paper is the ability to obtain data that are so consistent as demonstrated in Figs.9, 10, and 11. This in part can be attributed to the large flume used, which eliminated side wall effects often encountered by most laboratory investigations.

In limiting this study to one bed material several of the difficult complex-

35 Highway Research Engr., Div. Hydr. Research, Bur. of Public Roads, Washington, D. C.

36 "Hydraulics Method to Fight Mud and Stone Carrying Streams," by M. S. Gagoshidze, Hydrotechnic and Soil Improvement Magazine, No. 9, Moscow, 1958. 
ities are minimized. The relative standard deviation of the size distribution of the bed material $\sigma$ of a given median fall diameter $\mathrm{d}$ influences movement of this is illustrated in Fig. 24 in which the rate of scour parameter $\frac{\mathrm{h}}{\mathrm{b}}$ on the ordinate versus time parameter $\frac{\mathrm{QT}}{\mathrm{H}^{2}}$ clearly defines different rates of movement. The explanation of this phenomenon is in the sorting process of the fine partithe bed considerably. This is borne out by localized scour study 37 in which the $d$ was nearly constant and $\sigma$ was varied over a considerable range. Graphically cles from the bed material, leaving larger particles which become interlocked and more resistant to motion. This sorting and interlocking process also is

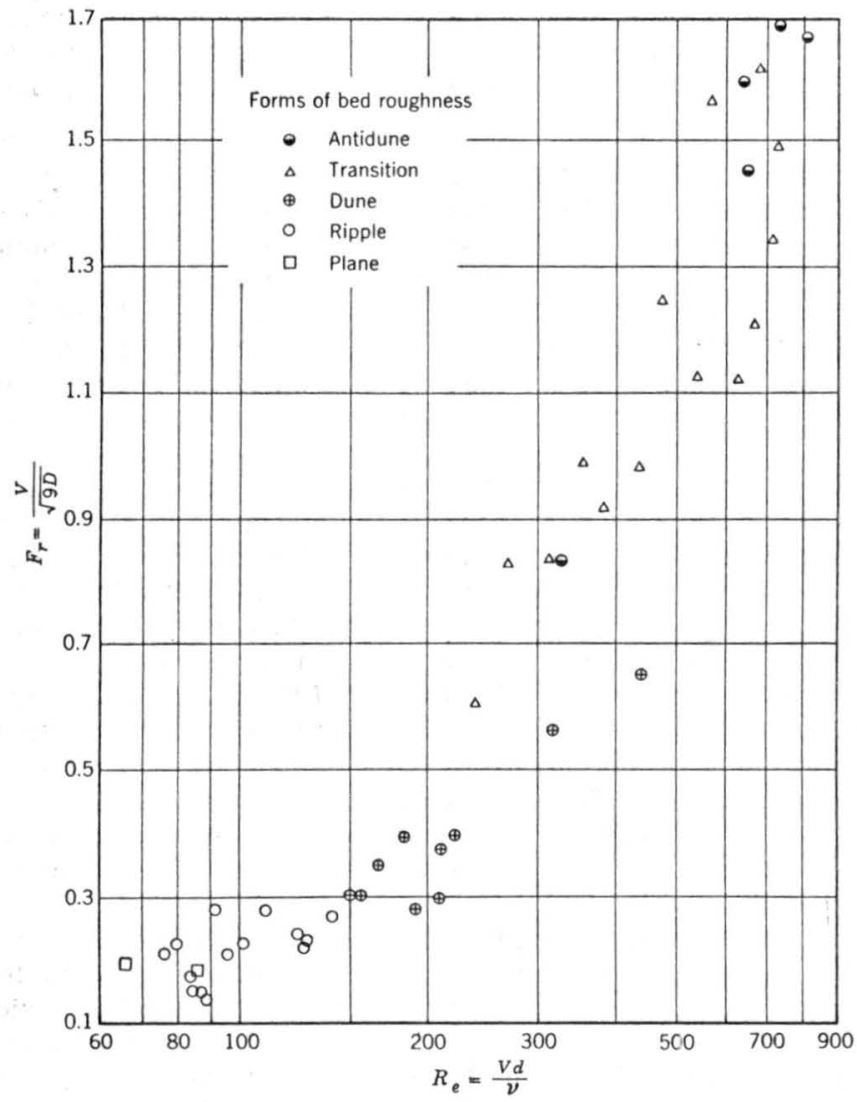

FIG. 25.-VARIATION OF $F_{\mathrm{r}}$ WITH $\mathrm{R}_{\mathrm{e}}$

37 "Influence of Particle Size Gradation on Scour at Base of Free Overfall," by Dasel E. Hallmark, thesis presented to Colorado State Univ., Ft. Collins, Colo., in 1955, in partial fulfilment of the requirements for the degree of Masters of Science. 
visible in streams where the bed material is well graded.

In the laboratory data presented here one would expect this phenomenon to appear in the ripple and dune formations. In fact, a plot of $F_{r}$ versus $R_{e}$ (Fig. 25 ) indicates that there is a definite relation between the type of bed roughness and the size of the bed material. In the low $F_{r}-R_{e}$ range the viscous forces in the Reynolds number are important factors; where as in the higher Froude numbers the relation of kinetic to gravitational forces predominate. Fig. 25 supports the discussion by the authors of the Froude number for classification of the bed roughness.

One of the perplexing elements in alluvial hydraulics is the tractive or shear force $\tau$ on the bed, $\gamma \mathrm{D} \mathrm{S}$. It is often used to make the data fall into a more consistent pattern but is it justifiable? With the major break-throughs in alluvial hydraulics in the last decade a better understanding of the shear force that is exerted on the bed and the force with which the bed opposes shear as related to median size $d$ and standard deviation $\sigma$ is becoming increasingly more important.

THOMAS MADDOCK, JR。 38 F。ASCE, and W。B. LANGBEIN, 39 F. ASCE.Messrs.Simons and Richardson have presented unusually detailed results of a careful study of the behavior of water and sediment in an $8-\mathrm{ft}$ flume. As the authors note, their set of data contain the broadest range of flow conditions since those of Gilbert in 1914. Thus, these data are a considerable contribution to knowledge of the hydraulics of channels with movable beds. The authors are to be greatly commended for the care with which the work was undertaken and the clarity with which they describe what takes place in a flume of this size under different conditions of flow。

Data presented by Simons and Richardson are particularly of interest because of the unusual number of observations at very low rates of transport, that is $<20 \mathrm{ppm}$ or $.002 \%$ by weight of water. (This is roughly about $1.2 \mathrm{cu} \mathrm{ft}$ of sand for each cfs day. At this rate, a stream flowing 100,000 cfs would move less than $5,000 \mathrm{cu}$ yd of sand per day. Such a load certainly would not be a burden on the stream). It is to be noted that as previous investigators have shown, particularly Rubey, 40 in his analysis of the Gilbert data, and Casey, 41 the shear velocity, as described by $(\gamma \mathrm{D} \mathrm{S})^{1 / 2}$ is not a constant but is a variable at the beginning of motion of the bed.

As a matter of fact, the Simons and Richardson data lead to the inescapable conclusion that there is no such thing as a critical or threshold shear in the sense that such a value is a constant for a given size and gradation of bed material. Rather, it would seem, there are ranges of threshold shears for each flume, size, and, perhaps, composition of material. This range appears to be a function of the possible variation in depth, as well as the possible range in slope of the water which can be made to flow without introducing sidewall effects. This is by no means a new conclusion but it is one which seems to be overlooked most frequently. Casey 41 made the following observation: "If the originally smooth bottom becomes riffled, then for constant discharge and slope

38 Hydr. Engr., Geol. Survey, U.S. Dept. of the Interior, Washington, D.C.

39 Hydr. Engr., Geol. Survey, U.S. Dept. of the Interior, Washington, D.C.

40 “The Force Required to Move Particles on a Stream Bed," by William W. Rubey, U. S. Geol. Survey Prof. Paper 189E, 1938.

41 "Ueber Geschiebebewegung, Mitteilung der Preuss," by Hugh J. Casey, Versuchsanstalt f. Wasserbau v. Schiffbau (VWS) Berlin, 1935, Heft 19. 
the water surface is raised; and thus the tractive force is increased. The movement of the grains is, however, opposed by the greater resistance of the increasing bed roughness. The mean stream velocity decreases with increasing depth, the sorting becomes irregular and the sand movement decreases or vanishes."

While it may be true that there is a critical shear velocity at the beginning of motion on an artificially smoothed bed, such beds never exist in nature. Once deformed they can never again naturally become smooth. This is the reason why ripples are always found on a streambed, once flow has receded, if the sediment load of the stream declines more rapidly, relatively speaking, than the discharge.

The corollary to such a conclusion is, of course, that each value of shear velocity has a specific mean velocity which must accompany it. There is a certain value of the friction factor $\frac{\gamma \mathrm{R} \mathrm{S}}{\rho \mathrm{V}^{2}}$ which must go along with each shear velocity. Thus " $\mathrm{n}$ " of the Manning equation would become a dependent variable.

At this point we are faced again with a question. If we would assume that roughness is wholly controlled by the bed material, this conclusion would be satisfactory. But hydraulic engineers for years have been judging the value of " $\mathrm{n}$ " at a given location for use in the Manning equation, by the appearance of the channel, and with a fair degree of success, too. Just what happens to the relationships at the beginning of motion once artificial roughness is introduced is unknown or unsure.

The Simons and Richardson data reveal a clear association of slope and depth at the beginning of (or at very low rates of) movement. Thus, the highest values of $\gamma \mathrm{D} \mathrm{S}$ are associated with the lowest depths. Point 12 on Fig. 9 represents a discharge with depth of but $0.29 \mathrm{ft}$. Because of the relatively great width-depth ratios, it is doubtful if much higher values of $\gamma \mathrm{DS}$ would be associated with the beginning of movement in this flume. A narrower flume might yield different results.

TABLE 3.-COMPUTATIONS FOR FIGS, 26, 27 AND $28^{\mathrm{a}}$

\begin{tabular}{r|c|c|c|c|c|c|c}
\hline \hline $\begin{array}{r}\text { No. } \\
(1)\end{array}$ & $\begin{array}{c}\mathrm{sin} \% \\
(2)\end{array}$ & $\begin{array}{c}\mathrm{D} \\
(3)\end{array}$ & $\begin{array}{c}\sqrt{\mathrm{s}} \mathrm{D} \\
(4)\end{array}$ & $\begin{array}{c}\mathrm{V} \\
(5)\end{array}$ & $\begin{array}{c}\mathrm{V} \sqrt{\mathrm{S} \mathrm{D}} \\
(6)\end{array}$ & $\begin{array}{c}\mathrm{V}_{\mathrm{r}} \\
(\text { (random }) \\
(7)\end{array}$ & $\begin{array}{c}\mathrm{V} \sqrt{\mathrm{S} \mathrm{D}} \\
(8)\end{array}$ \\
\hline 14 & .015 & .61 & .09 & .81 & .073 & .70 & .06 \\
3 & .039 & .85 & .184 & 1.16 & .214 & 4.78 & .88 \\
11 & .049 & .35 & .13 & .70 & .091 & 2.04 & .26 \\
4 & .057 & .69 & .20 & 1.44 & .288 & 3.32 & .66 \\
10 & .088 & .33 & .17 & .75 & .13 & 2.99 & .51 \\
22 & .124 & 1.00 & .36 & 1.70 & .61 & 5.54 & 2.0 \\
40 & .301 & .81 & .49 & 3.32 & 1.63 & 5.38 & 2.64 \\
26 & .366 & .34 & .35 & 5.38 & 1.90 & .75 & .26 \\
36 & .446 & .19 & .29 & 2.05 & .59 & 1.16 & .34 \\
27 & .436 & .33 & .38 & 2.99 & 1.12 & 6.18 & 2.35 \\
38 & .619 & .50 & .57 & 5.38 & 3.08 & 1.70 & .96 \\
44 & .898 & .28 & .50. & 4.78 & 2.39 & 5.38 & 2.69 \\
43 & 1.01 & .43 & .66 & 6.18 & 4.08 & 2.80 & 1.85 \\
37 & .620 & .43 & .52 & 5.54 & 2.90 & 1.44 & .75 \\
35 & .494 & .25 & .35 & 2.80 & .98 & .81 & .28 \\
\hline
\end{tabular}

a Data from Table 1, not all tabulated herein. 


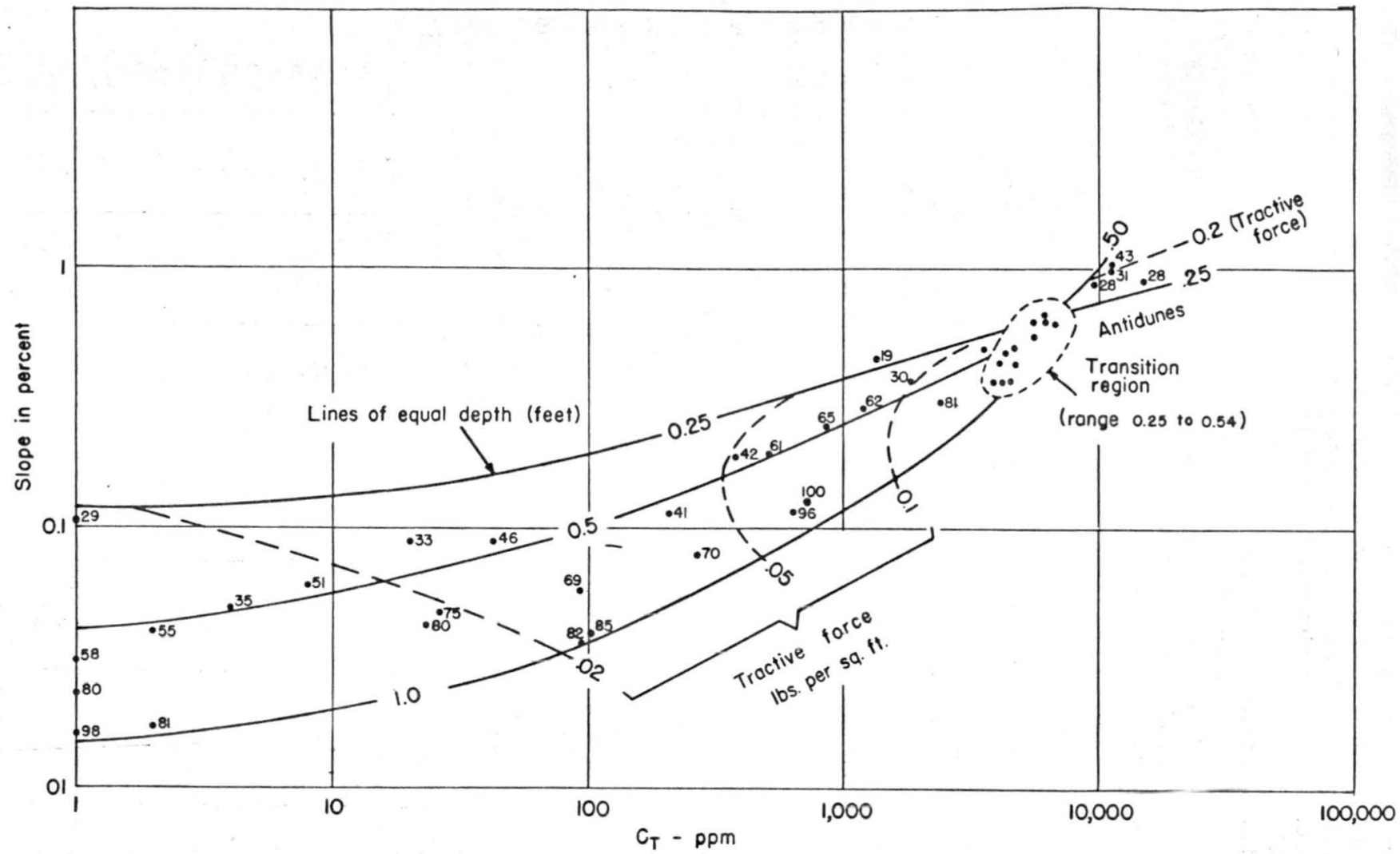

FIG. 26.-RELATIONSHIP OF CONCENTRATION, TO SLOPE, DEPTH, AND TRACTIVE FORCE 
The smallest values of shear at beginning, or low rates, of sediment movement are associated with the greatest depths. Here again flume limitations came into play since point 17 , the lowest value of $\gamma \mathrm{D}$ S after ripples developed, had a depth of $0.98 \mathrm{ft}$, which appears to be about as deep as Simons and Richardson cared to go.

Fig. 9 shows a trend in the relation between concentration and tractive force. However, the relationship surely must be more complex, depending upon the division in available energy between transport and frictional resistance. Fig。 26 shows the variation in concentration in terms of slope and depth (see Table $3)$.

Lines of equal tractive force that are also drawn upon Fig. 26 show the complex action of that factor on concentration. It is evident that the concentration is not uniquely related to the tractive force. The transport in this flume varies with each combination of depth and slope. For any given depth the concentration increases with slope, but note that the lines converge with increasing slope. There is evidence that the lines cross in the "transition region" so that in the antidune phase greater concentrations are associated with shallow depths. The region labeled "transition" on Fig。 26 contains those points which plot in the so-called "smooth" or transition region of Fig. 27. Seemingly, in this region the division of energy between transport and friction is unstable.

The authors' conclusions with respect to data presented in Fig。9 appear to be open to question. They state, "It is significant to note that a sudden decrease in $\tau_{\mathrm{O}}$ occurred at about $\mathrm{C}_{\mathrm{T}}=2,000 \mathrm{ppm}$ as the bed changed from dunes to plane bed or standing waves。” Point 36 on Fig. 9 represents a discharge of $3.15 \mathrm{cfs}$ with a depth of $0.19 \mathrm{ft}$. This is getting to the limit of feasible discharges in a flume because the accuracy of depth and slope measurements declines with low depths. Nonetheless, it would appear that with a lower discharge and a steeper slope, it would be possible to get transition flow with concentrations of about $1,000 \mathrm{ppm}$. On the other hand, point 40 on Fig。 9 represents a discharge of $21.41 \mathrm{cfs}$ with a depth of $0.81 \mathrm{ft}$. This appears to be the upper limit of the flume capacity. There seems to be no reason why a larger discharge on a flatter slope, were this possible, would not give a dune bed with sediment movement at concentrations in excess of $4,000 \mathrm{ppm}$.

It would seem more likely that the phenomenon pointed out by the authors represents flume characteristics. If discharge is the same, or nearly so (runs $38,39,40,43)$, there is little evidence of marked decrease in shear with increasing sediment load. Moreover, the break shown on Fig. 9 does not appear when the data are plotted as in Fig. 26.

Fig. 8 is of interest and even more so if sediment concentrations are plotted as athird variable. If this is done, it is clear that sediment load increases with increasing values of the Froude number. However, if two discharges have the same Froude number, the one with the largest slope has the greatest sediment concentration. The results of Simons and Richardson's work in effect confirm the work of Brooks. 42 Brooks' conclusions, which, at the time, were the subject of much discussion, now appear to be confirmed in their entirety, although not wholly by these experiments.

The authors approach the analysis of their data by a general statement of the mechanics of flow and dimensional analysis. In this study there were two

42 "Mechanics of Streams with Movable Beds of Fine Sand," by Norman H. Brooks, Transactions, ASCE, Vol. 123, 1958. 


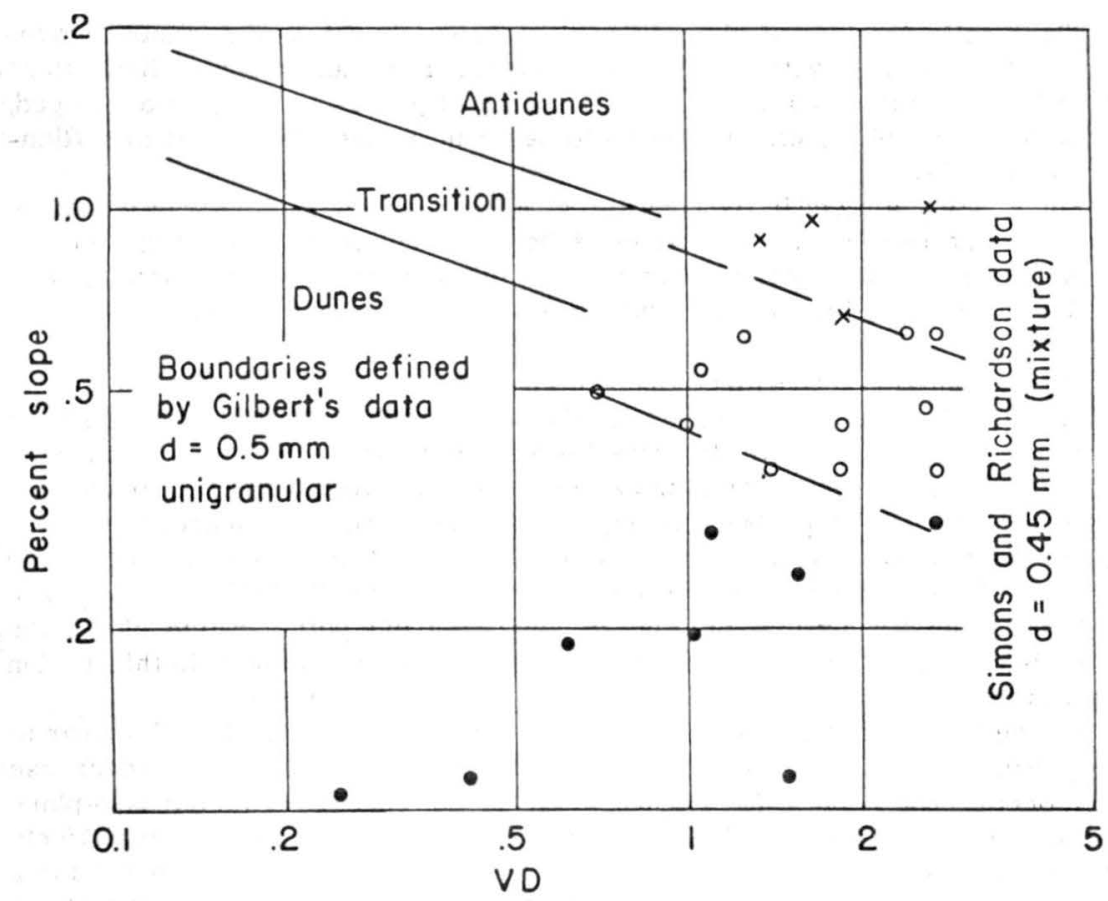

FIG. 27.-CRITERIA FOR REGIME OF TRANSPORT

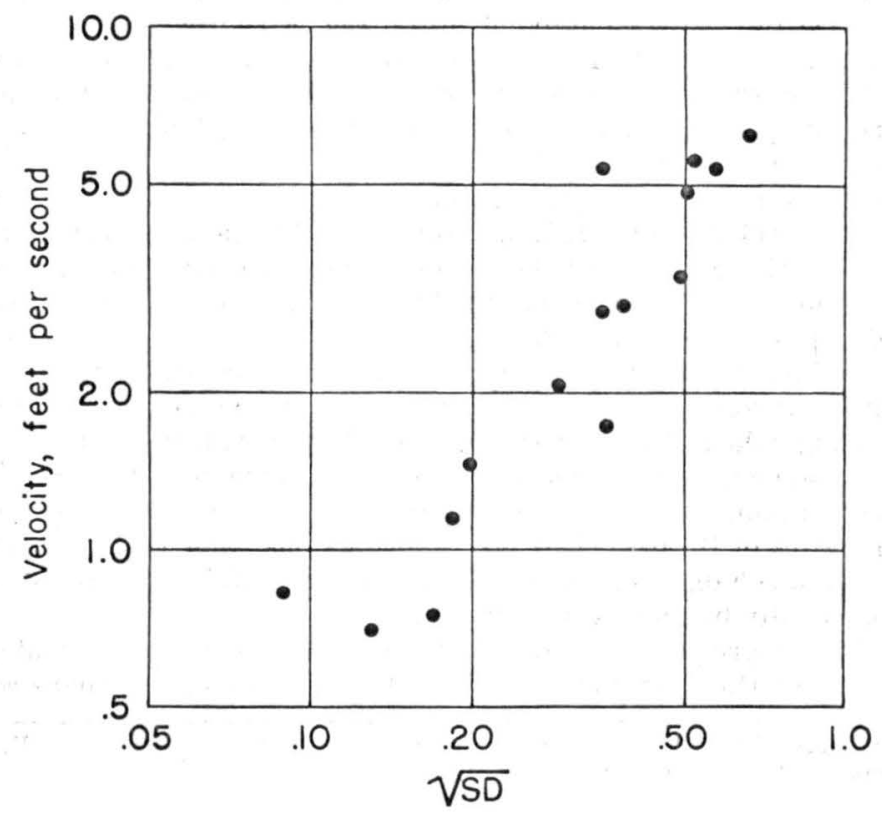

FIG. 28.-RELATION BETWEEN VELOCITY AND $\sqrt{\mathrm{SD}}$ 
independent variables--slope and discharge--and two pr possible three dependent variables, depth, total sediment concentration and possible size cistribution. All other variables, such as viscosity, specific weights, etc。, were essentially constant.

Therefore, the authors could improve their valued study by incorporating one of the few variables which can be measured, the total sediment concentration. Total sediment concentration is not an item in Eq. 5, where, as a matter of fact, most of the variables are irrelevant to this set of experimental data which deals with only one sand and one fluid. The authors appear to justify this omission by concluding that Figs. 8, 10, and 11 are an effective means of presenting inherent relations among some of the variables.

Fig. 8 is an attempt to order the modes of transport in relation to the velocity and depth without, however, developing a relationship. But the idea is perhaps similar to the treatment by Langbein. 43 Data (omitting those for " 3 dimensional" flow) from Simons and Richardson (Table 1) have been plotted (Fig。27) on an extension of Fig。 1 of the Langbein paper. The left side of Fig. 27 was defined by Gilbert's data, size $0.5 \mathrm{~mm}$ ungranular; the Simons ard Richardson data are for size $0.45 \mathrm{~mm}$, median diameter of a mixture. Considering the slightly finer grade and the effect of the mixture, the several data appear consistent with the older diagram, which, in terms of slope, perhaps merits consideration by the authors.

Fig, 10 is the kind of dimensionless diagram that also might be reconsidered because similar quantities appear on both axis. Eliminating the constant or near-constant quantities such as density, particle size, and viscosity, the diagram is actually a plot of $\mathrm{VV}_{*}$ against $\mathrm{V}_{*^{\circ}}$ Since $\mathrm{V}_{*}{ }^{2} \sqrt{\mathrm{S} \mathrm{D}}$, the diagram intrinsically is a plot of $V \sqrt{\mathrm{S} \mathrm{D}}$ against $\sqrt{\mathrm{S} \mathrm{D}}$. With this operation, it is possible to obtain relationships between random data, or to "improve" a poor relationship. For example, the authors say, in referring to Fig. 10, "It is of importance to note the precision with which the relation describes and systematically groups the various forms of bed roughness。” It is clear that the relation cannot be general. Obviously, it applies only to the single series of the experiment。

Fig. 28 shows the intrinsic relationship between $\mathrm{V}$ and $\sqrt{\mathrm{S} \mathrm{D}}$; the scatter obviously reflects the variations in the Chezy C.

Fig. 29 shows the same thing, but with $\sqrt{\mathrm{SD}}$ repeated in the ordinate. Note the "improvement" in the definition--an improvement that is misleading。

Fig。 30 is a plot of the same data, but the velocities were re-ordered so that they were entirely random. There is a definable trend, though there is no intrinsic relationship.

It should be made clear that the authors are not alone in their treatment. A more common illustration is offered by the sediment rating curve, which is a plot of discharge against the product of discharge and concentration.

Another type of artificial correlation results when products or quotients of variables are related against their sums or differences.Fig。11 is an example of the former, and Fig。 3 an example of the latter。

Fig. 11 is essentially a plot of $\frac{\mathrm{V}}{(\gamma \mathrm{D})^{1 / 2}} \mathrm{~S}^{3 / 2}$ against $\frac{\mathrm{V}^{2}}{\mathrm{~g} \mathrm{D}}+\mathrm{S}$. Such a pro-

cedure would lead to a conclusion that there was some inherent relationship,

$49{ }^{\alpha}$ Hydraulic Criteria for Sand Waves," by Walter B. Langbein, Transactions, AGU, Part II, 1942. 


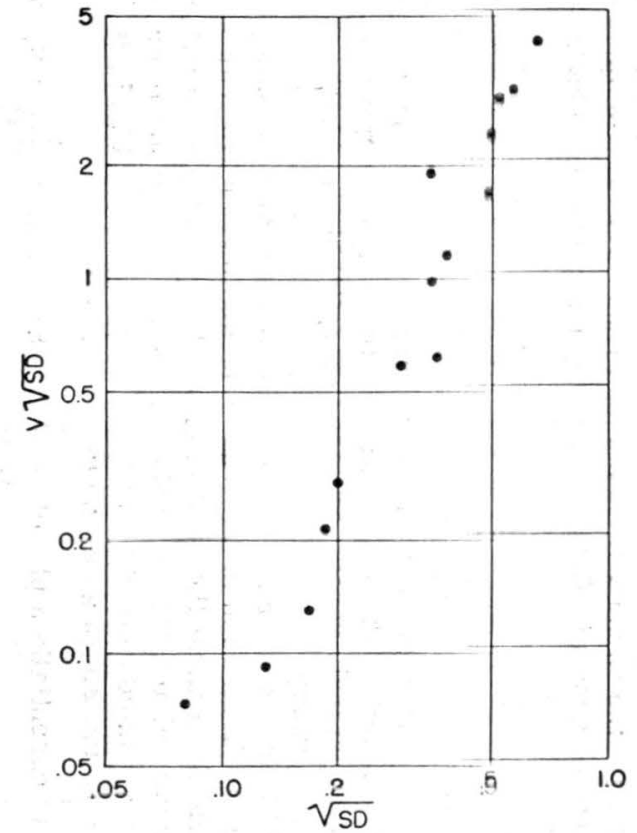

FIG. 29.-“IMPROVED” RELATIOIISHIP BETWEEN V $\sqrt{\mathrm{SD}}$ AND $\sqrt{\text { बा। }}$

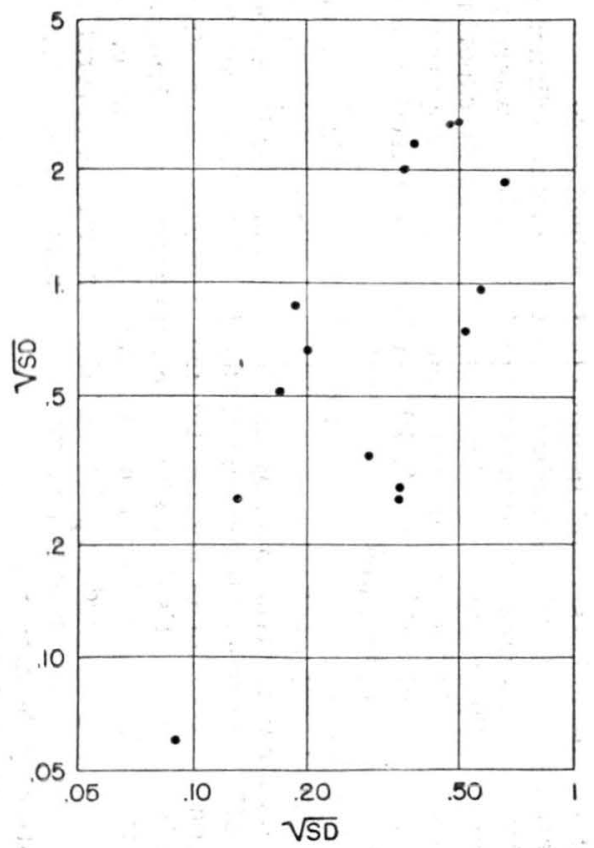

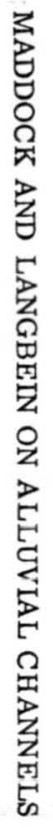

FIG. 30,-SPURIOUS RELATIONSHIP CREATED BETWEEN RANDOMLY RELATED $V$ AND $\sqrt{\mathrm{SD}}$ 


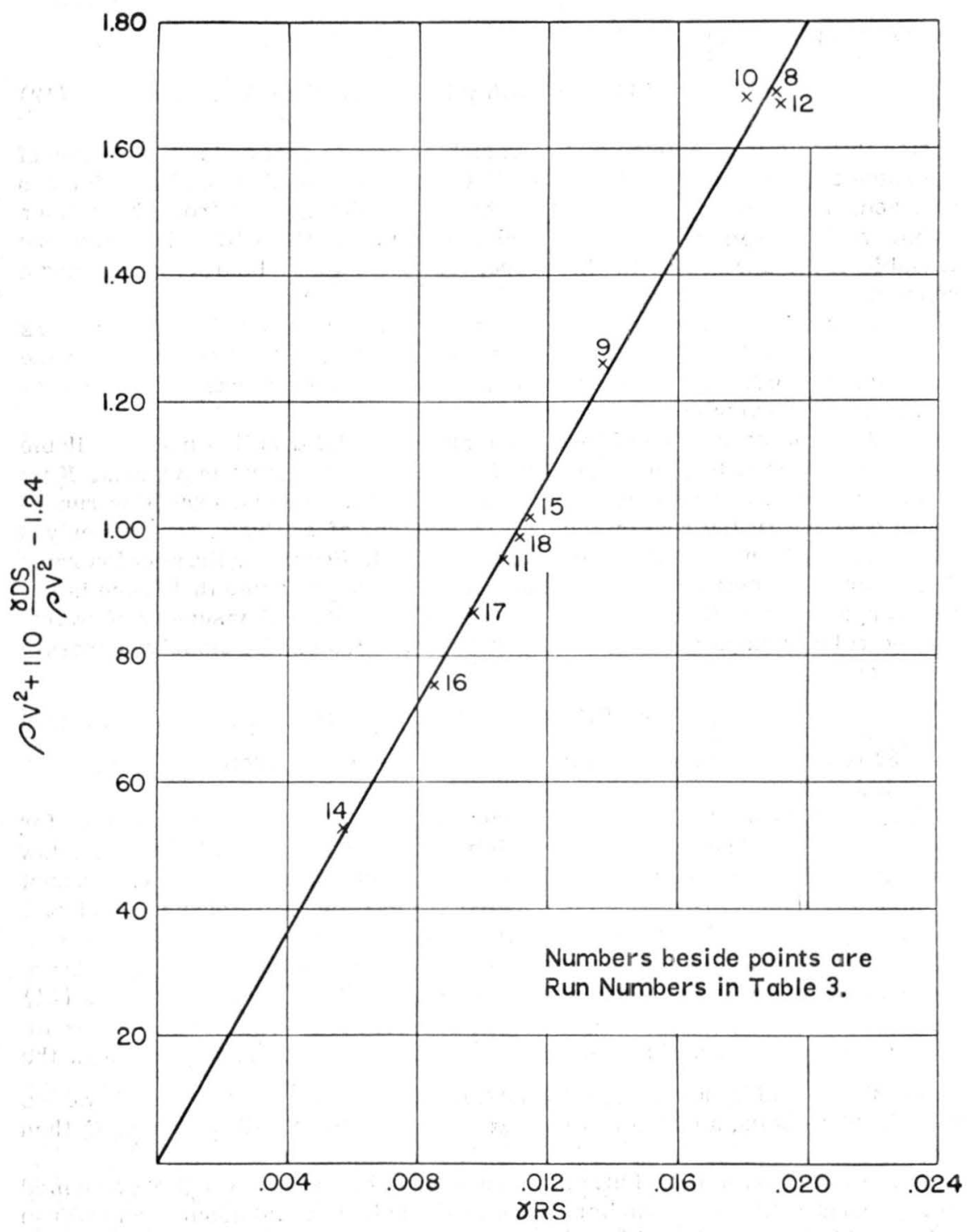

FIG. 31 
if, for example, the Manning and the Colebrook-White equations were plotted against each other for a limited range of data. There is a considerable danger that the relations which look so good on Fig. 11 may be overhopeful.

The approximate equation of the line on the graph of Fig. 31 is

$$
\rho \mathrm{V}^{2}+110 \frac{\gamma \mathrm{D} \mathrm{S}}{\rho \mathrm{V}^{2}}-1.24=89.7 \gamma \mathrm{D} \mathrm{S} \ldots \ldots \ldots \ldots
$$

Rearranging this equation, we get

$$
\frac{\gamma \mathrm{D} \mathrm{S}}{\rho \mathrm{V}^{2}}=.01126+.816 \gamma \mathrm{DS}-.00909 \rho \mathrm{V}^{2} \ldots \ldots \ldots
$$

Notice that this is a division of two variables on one side and a subtraction of the same two variables on the other. Yet there is no fundamental relationship involved. The best we can say is that the value which results from the division of one variable by the other can be closely approximated by subtracting one variable from another, with the proper coefficients, of course, and adding a constant。

Because it is frequently possible that the use of non-dimensional parameters may mislead one to produce invalid correlations, the writers see cianger in the use of dimensionless parameters where observations have been made of a limited number of variables.

Mention has been made of the unique amount of information made available by these studies at beginning, or very low rates, of sediment movement. If we take those 10 runs with no or very low rates of movement, excepting run 13 which does not fit the rest of the data in any type of analysis, we have only 3 variables, D, Q, and S, all of which are measured. Regarding the very low rates of sediment movement as being of no importance and assume that there is little change in the sediment composition or the density and viscosity of water.

The relationships existing among these variables can be closely expressed by the equation

$$
\mathrm{D}=.0166 \mathrm{Q}^{2}-165 \mathrm{~S}+.392 \ldots \ldots \ldots \ldots
$$

Fig。 32 is a graph of this equation。 Numbers beside the plotted points are the run numbers.

The correlation that exists in this equation is valid although the solution for $\mathrm{D}$, if $\mathrm{Q}$ and $\mathrm{S}$ are known, will give much better results for small slopes and low discharges than the solution for either of the other two variables. This cannot be helped because $\mathrm{D}$ is the most difficult of all variables to measure precisely.

The equation can be expressed in the form

$$
\frac{1}{\mathrm{~V}}=1.062 \mathrm{~V} \mathrm{D}+\frac{1}{\mathrm{VD}}(.392-165 \mathrm{~s}) \ldots \ldots \ldots
$$

The result of this relationship is that $\frac{1}{\mathrm{~V}}$ has little variation even though the term . 392 - $165 \mathrm{~S}$ is positive. Note, however, that when $\mathrm{Q}$ is constant, $\mathrm{V}$ varies with $\mathrm{S}$, there being a greater degree of variation for small values of $\mathrm{Q}$ than large.

It is to be doubted that this relationship would be found if $\mathrm{V} D$ were assumed to represent a Reynolds number. Who, at the outset, would assume an inverse relationship between $\mathrm{V}$ and $\mathrm{V} \mathrm{D}$ at the beginning of motion? Whether the relationship is meaningful in terms of classical hydraulics is something else 


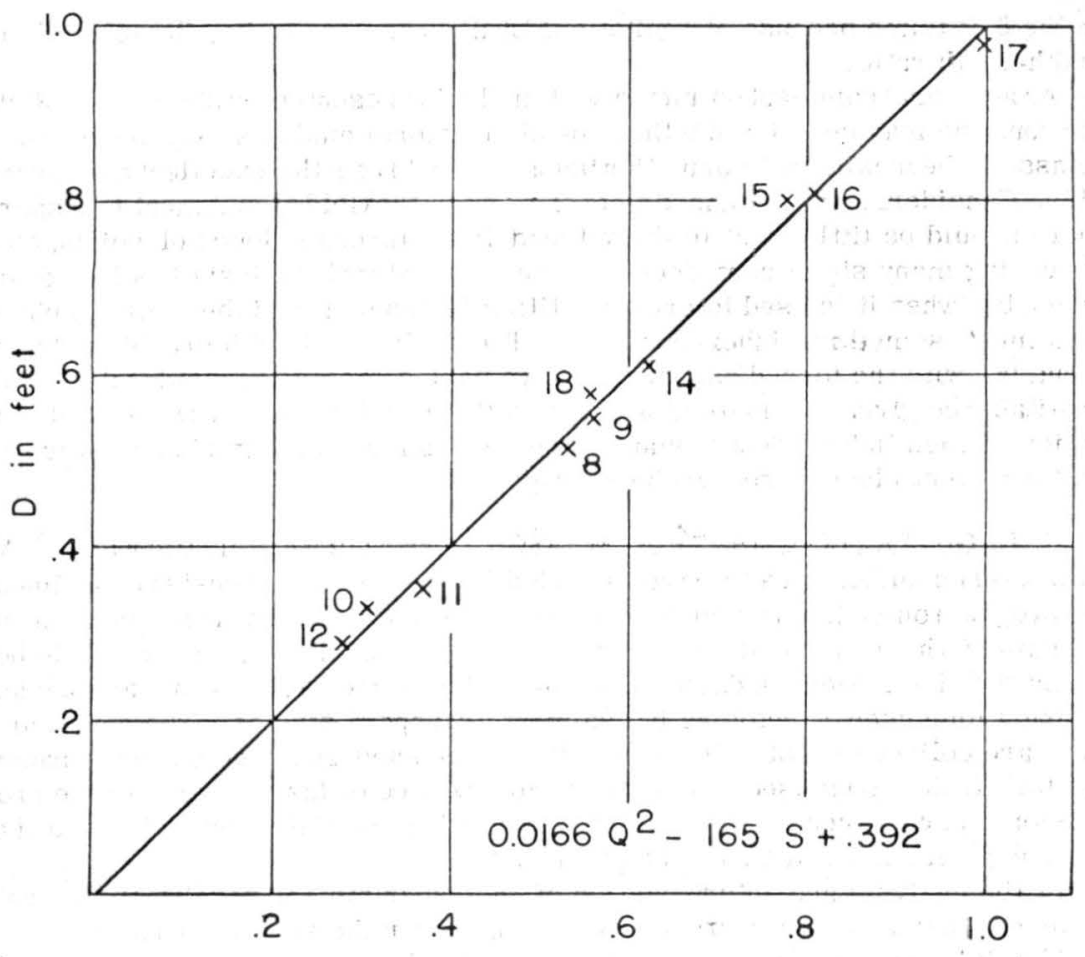

FIG. 32

again, but it is unquestionably true, as Eq。21 and Fig。26 indicate, that $\gamma$ D S is not a constant at the beginning of motion on the bed of a stream.

To summaxize the results of the Simons and Richardson studies, it seems that once a certain combination of discharge and slope are given, the bed of the 8 -ft flume, if it is originally smooth, will begin to deform. As deformation proceeds, the friction factor increases and the Chezy coefficient decreases. This adjustment will take place with no or extremely low amounts of sediment in motion after equilibrium is reached. With increasing discharge the sediment begins to move at increasing rates, until the dunes are washed out. During this stage the friction factor decreases and the Chezy coefficient increases with increasing discharge. With further increase in discharge, the sediment load increases rapidly, but the friction factor now increases and the Chezy coefficient declines.

It appears that differences in the bedconfiguration result in differing values of the shear velocity at beginning (or low rates) of sediment transport. There is a relation between mean velocity and discharge if slope is known, however, and without doubt other relations may be found with further study. The complete range of shear velocities under which sediment of the size and composition used by Simons and Richardson may begin to move cannot be measured 
in the 8 -ft flume because of limitations of discharge capacity, flume depth, or width-depth ratio.

As a general comment on methods of analysis presented by Simons and Richardson, one may question whether non-dimensicnal analysis may be relied on to assure the maximum information being derived from the excellent data available. Considering the advanced state of work in the field of sediment transport, there should be little need to draw trend lines through clouds of points, thus obscuring many significant details. Non-dimensional analysis has its advantages, but when it is used to create artificial groups of variables for graphical treatment, something inherent is lost. The fault is not with graphical treatment, but with the forced association of variables. Some reconsideration could profitably be given to a method of analysis that resolves the separable and joint action of each independent variable, and thus achieves the kind of results that this excellent piece of research deserves.

R。 HUGH TAYLOR, JR., ${ }^{44} \mathrm{~A}_{\circ} \mathrm{M}_{\text {。 }}$ ASCE, and NORMAN H。 BROOKS, 45 M。 ASCE. - The authors are to be commended for their comprehensive experimental program on sediment transport at the Coloracio State University under sponsorship of the U. S. Geological Survey. Their experiments are valuable because they have been conducted in an 8 -ft wide flume which is larger than any tilting flume used heretofore in sediment transport studies. The data which they are collecting, not only for the $0.45-\mathrm{mm}$ sand reported on in the paper, but for all the sizes used in their program, will be of lasting value to the profession. For the record the writers ask in what form the complete record of their experiments will finally be published.

In the analysis and interpretation of the experimental results there are a number of points which warrant discussion。 Under the section "Theory of Flow in Alluvial Channels," the authors have not actually presented a theory but only some dimensional analysis, leading to $\mathrm{Eq}$ 。6。 To apply dimensional analysis sensibility to the roughness problem requires selection of the pertinent variables; but furthermore one must be careful to assume the correct number of functional relationships. In other words there may be more than just one dependent variable, as several relations may have to be satisfied simultaneously.

For example, the writers believe that for natural rivers the bed-material sediment discharge $\left(Q_{S}\right)$ should be included as another independent variable, because field evidence shows that river behavior changes significantly with a change in $Q_{S}$ supplied to a reach. The transport relation is strongly interlocked with the flow relation, and neither one can be properly considered without the other. Thus in Eq. 1 variables such as B, V, and $\mathrm{S}$ cannot be considered to vary at will as independent variables, but are constrained by other unmentioned relations such as a transport equation. Hence a simple listing of the variables is not as important as a careful corsideration of the constraints, which at the present state of knowledge are none too clear.

However, one redundancy is apparent in Eq.6. Because the drag coefficient for the particles $C_{D}$ is the same as for spheres (because the fall diameter $d$ is used for the characteristic length), $C_{D}$ is a function of the particle Reynolds number, namely

44 U. S. Geol. Survey, W. M. Keck Lab. of Hydr. Water Resources, Calif. Inst. of Tech., Pasadena, Calif.

45 Assoc. Prof. of Civ. Engrg., W. M. Keck Lab. of Hydr. and Water Resources, Calif. Inst. of Tech., Pasadena, Calif. 


$$
C_{D}=f\left(\frac{w d}{\nu}\right) \ldots \ldots \ldots \ldots
$$

in which $f$ is the experimentally deter mined curve given in any elementary textbook. Rewriting,

$$
\begin{aligned}
& \frac{\mathrm{w} \mathrm{d}}{\nu}=\frac{\mathrm{w}}{\mathrm{V}} \frac{\mathrm{d}}{\mathrm{D}} \frac{\mathrm{V} \mathrm{D}}{\nu} \\
& =\left(\frac{\mathrm{w}}{\mathrm{V}}\right)\left(\frac{\mathrm{d}}{\mathrm{D}}\right)\left(\mathrm{R}_{\mathrm{e}}\right) \ldots \ldots \ldots \ldots \ldots \ldots
\end{aligned}
$$

The last three parameters in parenthesis are given in $\mathrm{Eq}, 6$, so $\mathrm{C}_{\mathrm{D}}$, a known function of the preceding product, is superfluous; that is, $\mathrm{C}_{\mathrm{D}}$ is already a dependent variable by another relation not expressed.

Finally, dimensional analysis should give dimensionless combinations which are convenient. Since the paper is on resistance to flow, a dimensionless friction factor such as the Darcy-Weisbach $f$ should be used instead of slope $S$ in Eq. 6.

Furthermore, in the tabulation of experimental values (Table 1) it would be most helpful if the authors would give the computed roughness coefficients, and $\mathrm{C} / \sqrt{\mathrm{g}}$-values, upon which the subsequent discussion in the text is based. The arrangement of data in Table 1 according to increasing slope values is not a sequence with increasing roughness or shear because of the variable depth.

Bed Forms. - In the list of forms of bed roughness, "Plant bed and water surface" has been placed under the "Rapid flow regime, $\mathrm{F}_{\mathrm{r}}>1$." While this may be true for their flume experiments (although none in the category are cited in Table 1) it should be made very clear that $F_{r}>1$ is not a necessary conditionfor existence of a plane or flat bed. When there is no strong coupling between the bed and water surface profiles (as there is for standing waves or antidunes), the Froude number is a minor or irrelevant parameter because of the absence of a local gravitational effect on the flow pattern. For the plane bed condition it is only necessary to have velocities near the bed of such magnitude that a dune, if one were to form, would be "sheared" off. The stability of the sand surface depends on the magnitude of the local fluid forces relative to the resistance of particles to motion, and should not be sensitive to depth. Since the Froude number does depend on depth, and does not depend on the sand characteristics, it is an illogical parameter for describing bed forms which are not coupled with surface waves.

This brings us to the crucial weakness of the authors' entire method of description of the various bed forms in alluvial channels under "Observed Flow Phenomena." In attempting to make their description appear more generalized they have used the dimensionless quantities $d / \sigma$ and $F_{r}$ as criteria for separation of the various types of bed forms (for example, "transition" occurs when $" \mathrm{~d} / \sigma^{\prime}>2$ and $\left.0.6<\mathrm{F}_{\mathrm{r}}<1.0 "\right)$. The citing of dimensionless values has merit, not a priori, but only if they are meaningful over a significant range of conditions. Because there is no physical reasoning to support the use of these parameters, and the cited values are easily proved to be lacking in generality, their use obscures the solution to the problem rather than clarifying it.

As indicated previously the Froude number has relevance only for the stand- $\}$ ing wave and antidune cases. It means very little to say that ripples change to dunes at $\mathrm{F}_{\mathrm{r}}=0.28$; the authors would make their point more clearly by stating that dunes begin at a mean velocity of about $1.40 \mathrm{fps}$ for their experiments. 
With change to another flow system of a different depth but with the same sand, the velocity at the point where ripples become dunes is more likely to be about the same actual value cited above than a new value computed from $F_{r}=0.28$.

Consider now the parameter $\mathrm{d} / \sigma^{\prime}$, the ratio of the grain size to the so-called thickness of the laminar sublayer. When the bed is covered with ripples, dunes, or other form resistance, $\sigma^{\prime}$ lacks physical interpretation, but still can be computed by the relation

$$
\sigma^{\prime}=\frac{11.6 \nu}{v_{*}} \ldots \ldots \ldots \ldots \ldots \ldots
$$

Consequently

$$
\mathrm{d} / \sigma^{*}=\frac{\mathrm{dV}_{*}}{11.6 \nu} \ldots \ldots \ldots \ldots \ldots
$$

Now for example the authors state that motion begins when $d / \sigma^{\prime}$ was between 0.48 and 0.53 . By Shields' graph 46 the initiation of motion could begin at values of this parameter ranging from say 0.2 to 50 or more depending on the properties of the particles and of the fluid. (By comparison $\tau_{0} / \Delta \gamma_{S} d$ ranges from 0.035 to 0.07 as a function of $\left.\mathrm{d} / \sigma^{\prime}\right)$. Whether the boundary is hydrodynamically smooth or rough (as determined by the value of $\mathrm{d} / \sigma^{\prime}$ ) is irrelevant; the question involves the balance of forces on the particles.

The features which the authors call ripples have been called dunes in the past by the writers in describing laboratory experiments at the California Institute of Technology 47,48 (CIT). The larger features called dunes by the authors have not beenobserved at CIT, because of depths limited to $0.5 \mathrm{ft}$ or less, and widths of $0.875 \mathrm{ft}$ or $2.79 \mathrm{ft}$ respectively in two flumes. They may je related, however, to what has been described as sand waves, which were features with long flat tops, and not three-dimensional in plan as shown by Fig. Ł. Apparently there is no essential difference between ripples and dunes other than size, but it is curious that there is no gradual gradation from ripples to dunes. Still much larger dune-type features have been observed in rivers (as by Carey and Keller 49 on the Mississippi River). Perhaps for a given sand only certain ranges of dune (or ripple) heights and wave lengths are possible, with appearance of the large set(s) suppressed by inadequate depth or width. If this is so, it makes the roughness analysis and modeling of alluvial channels a very troublesome problem, which cannot be resolved by laboratory work alone.

The general description of antidunes and standing waves agrees well with recent research at CIT by John F. Kennedy 50,51 on the mechanics of these

46 “Sediment Transportation," by C. B. Brown, Engineering Hydraulics, ed. H. Rouse, Wiley, New York, 1950, p. 790.

47 “Mechanics of Streams with Movable Beds of Fine Sand," by N. H. Brooks, Transactions, ASCE, Vol. 123, 1958, pp. 526-594.

48 "Laboratory Studies of the Roughness and Suspended Load of Alluvial Streams," by V. A. Vanoni and N. H. Brooks, Sedimentation Laboratory, Calif. Inst. of Tech., Pasadena, Calif., Report E-68, 1957.

49 “Systematic Changes in the Beds of Alluvial Rivers," by W. C. Carey and M. D. Keller, Proceedings, ASCE, Vol. 83, No. HY 4, August, 1957.

50 “Stationary Waves and Antidunes in Alluvial Channels," by J. F. Kennedy, thesis presented to the Calif. Inst. of Tech., Pasadena, Calif., in 1960, in partial fulfilment for the degree of Doctor of Philosophy.

51 "Study of Relations between Transportation of Sediment and Hydraulic Characteristics of Streams," by J. F. Kennedy, Keck Lab. of Hydr. and Water Resources, Calif. Inst. of Tech., Pasadena, Calif., Report KHWR-6, in press. 
waves, sponsored by the Agricultural Research Service. It may be noted that antidune behavior is considerably influenced by the grain size, as well as the velocity. For example, Kennedy found that for $0.23 \mathrm{~mm}$ sand, the friction factor $f$ consistently rose as $F_{r}$ increased, due to heavy wave breaking, but that for $0.55 \mathrm{~mm}$ sand, $\mathrm{f}$ decreased as $\mathrm{V}$ increased because the amplitude of antidunes decreased, and wave breaking was less important than for the more easily transported $0.23 \mathrm{~mm}$ sand. Also for $0.55 \mathrm{~mm}$ sand, a flat bed regime was found following antidunes with increasing velocity (at $\mathrm{F}_{\mathrm{r}} \approx 2$ ); but for $0.23 \mathrm{~mm}$ sand this regime was not found.

In Fig. 8 there are a number of runs listed as "Standing Waves" (Runs 28, $31,33,34,35,37,38,39,41$ ), but in Table 1 these are all listed as "Transition." Clarification of the bed configuration is needed for these runs.

Analysis of Roughness by Authors.-At the end of the section "Analysis of Data," the authors present Fig. 11 (Eq. 9) which, it is claimed, can be used to compute $\mathrm{C} / \sqrt{\mathrm{g}}$ (or simply $\sqrt{8 / \mathrm{f}}$ ). Since $\mathrm{C} / \sqrt{\mathrm{g}}$ does not appear explicitly, one may instead seek $\mathrm{S}$ by trial and error, given depth, velocity, and sand and water properties. It must be noted that this curve is by no means general, but applies only for the particular sand and flume used by the author.

To see how well Fig. 11 allows the slope to be determined, trial-and-error solutions for $\mathrm{S}$ were attempted for several of the reported runs, assuming everything known by S. Fig. 33 shows the curve of Fig. 11, together with two other curves, each of which is obtained by assuming arbitrary values of $\mathrm{S}$ while using the depths and velocities reported for the runs indicated (runs 12 and 40). The assumed values range from 0.1 to 10 times the observed slope. For definitive trial-and-error solutions, of course, these curves should have well defined intersections with the given function. Unfortunately this is not the case. The trial curves shown represent a variation of a hundredfold in assumed Svalues and still lie within the belt of scattering of the data points upon which the function is based. Several other runs were tried, with similar results. It must therefore be concluded that Fig. 11 is of no help in the estimation of slope (or friction factor). The indiscriminate juggling of relationships may thus, as in this case, lead to relations more nearly approaching disguised mathemaical identities than physical laws.

That the same conclusion holds for Fig. 10 is evident when it is noted that each of the variables contains slope to the one-half power. Thus the "trial" curves are straight lines which slope upward to the right at $45^{\circ}$ and which likewise have rather unsatisfactory intersections with the zone within which the data lie.

An Alternate Analysis of Roughness.-In clear-water flow in pipes or in open channels with rigid boundaries, the slope of the energy grade line may be determined by means of the Darcy-Weisbach friction factor, f, which is a wellestablished function of the Reynolds number and of the relative roughness (and is usually expressed in a pipe friction diagram). If the flow is in an alluvial channel, however, the problem is complicated by the presence of additional causes of energy dissipation, such as the turbulence in the wakes of dunes and ripples on the moveable bed. Hence Einstein and others have chosen to approtion the total boundary shear stress $\tau_{0}$ into a part, $\tau{ }_{0}{ }_{0}$ due to grain roughness and the additional part, $\tau{ }^{\prime \prime}$, due to form drag, so that $\tau_{0}=\tau^{{ }_{0}}+\tau^{\prime \prime}{ }_{0}$. Since $\tau_{0}=\gamma \mathrm{r} \mathrm{S}$, this partition requires some partition either of the hydraulic radius or of the slope (or of both). If the hydraulic radius is partitioned, following 


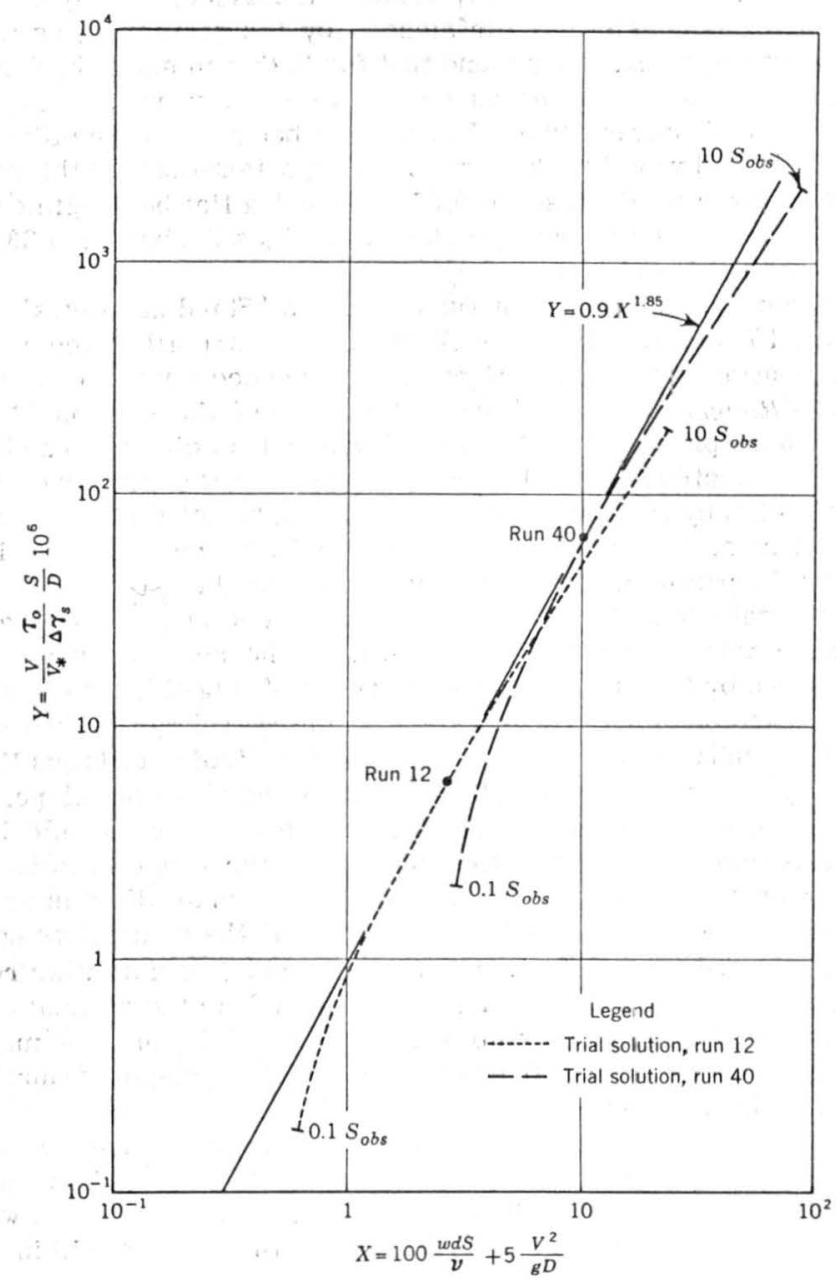

FIG. 33.-AUTHORS' FIG. 11, SHOWING IMPOSSIBILITY OF TRIAL-AND-ERROR SOLUTIONS FOR SLOPE

Einstein and Barbarossa, 52 the results are two virtual channels of the same slope and flow velocity but of different geometries, giving rise to a certain amount of intuitional difficulty. If, on the other hand, the slope is partitioned, as Meyer-Peter and Müller 53 proposed, one can write $S=S^{\prime}+S^{\prime \prime}$, and visu-

52 “River Channel Roughness," by H. A. Einstein and N. L. Barbarossa, Transactions, ASCE, Vol, 117, 1952, p. 1121-1146.

53 "Formulas for Bed-Load Transport," by E. Meyer-Peter, and R. Muller, Internatl. Assoc. for Hydr. Research, Second Meeting, Stockholm, Sweden, 1948, pp. 39-65. 
alize $S^{\prime}$ as that energy slope necessary for the given flow to overcome the resistance due to the grain resistance on a flat bed, where $S^{\prime \prime}$ would be the additional energy slope necessary to enable the flow to overcome the form drag caused by the bed configuration.

This being the case, the ratio of the true slope to that corresponding to the grain drag only $\left(\mathrm{S} / \mathrm{S}^{\prime}\right)$ would be a simple measure of the energy dissipation arising out of the alluvial nature of the stream, as related to that expected in clear-water flow over a flat bed. Furthermore, to the extent that most of the additional dissipation arises from form $\mathrm{drag}$, $\mathrm{S} / \mathrm{S}$ ' could be a useful description of the bed configuration itself. Since the Darcy-Weisbach friction factor, $f$, for open channel flow is defined as

$$
\mathrm{f}=\frac{8 \mathrm{~g} \mathrm{r} \mathrm{s}}{\mathrm{v}^{2}} \ldots \ldots \ldots \ldots \ldots \ldots
$$

in which $\mathrm{r}$ is the hydraulic radius, and $\mathrm{V}$ is the mean channel velocity, then a corresponding friction factor, related to the grain resistance only, may be defined as

$$
\mathrm{f}^{\prime}=\frac{8 \mathrm{~g} \mathrm{r} \mathrm{S}}{\mathrm{v}^{2}} \ldots \ldots \ldots \ldots \ldots \ldots
$$

Hence,

$$
\frac{\mathrm{S}}{\mathrm{S}^{\dagger}}=\frac{\mathrm{f}}{\mathrm{f}^{\prime}} \ldots \ldots \ldots \ldots \ldots \ldots \ldots
$$

and thus the ratio $\mathrm{f} / \mathrm{f}^{\prime}$ has the same physical significance as $\mathrm{S} / \mathrm{S}^{\prime}$.

According to the definition of $\mathrm{S}^{\prime}, \mathrm{f}^{\prime}$ is simply the friction factor for clear flow over a flat bed with grain roughness only. Hence a reliable value of $f^{\prime}$ may readily be found from the Moody pipe-friction diagram, using $4 \mathrm{r}$ in place of the pipe diameter, and taking the equivalent sand roughness $\epsilon$ to be the mean grain size of the bed material. (Some investigators say that the equivalent roughness is bigger than the mean size (for example, the $65 \%$-size is advocated by Einstein 52); this may well be true, and further research is needed on this point, but it is of minor importance here). Namely,

$$
f^{\prime}=\Phi\left(R_{e}, \frac{\epsilon}{4 r}\right) \ldots \ldots \ldots \ldots
$$

Thus to compute the value of the ratio $\mathrm{f} / \mathrm{f}^{\prime}$ from measured data one has only to divide the $f$ of Eq. 26 by the $f^{\prime}$ from the pipe friction diagram.

Ideally one would expect $f / f^{\prime}$ to be near unity when the stream bed is flat, and much higher when the bed is dune-covered. In the situation where suspended load dampens the turbulence, one could even expect values of $f / f^{\prime}$ to be less than one. 48 These expectations are very clearly demonstrated by the authors' data. Table 4 shows the values of $\mathrm{f}, \mathrm{f}^{\prime}$, and $\mathrm{f} / \mathrm{f}^{\prime}$ computed from their data (Table 1). It will be seen that a value of $f / f^{\prime}=2$ very neatly separates the runs with bed forms (for example, dunes or ripples) from those either without bed forms or with only the gradual sinusoidal variations of the type associated with standing waves or antidunes.

There are two advantages which may be realized in the use of the $\mathrm{f} / \mathrm{f}^{\prime}$ parameter. The first is in the matter of terminology, and the second is in the problem of predicting roughness. 
The present situation with respect to terminology for description of bed configurations is unsatisfactory. A list of all the terms which have been applied in the literature is a long one, and in current use one can find a laboratory calling a ripple the same form that another calls a dune, while the latter uses the term "dune" to refer to something else again. Rather than depending solely on an agreement on terminology as a necessary step in the quantitative analysis of roughness, it would seem that a more fruitful approach would be to use a numerical quantity which can be objectively determined. In such a case the use of curves for alluvial open-channel discharge (Liu and Hwang, 54 for example) would not require both a prediction of the bed forms to be expected and also a knowledge of what particular term had been used to describe them.

TABLE 4.-FRICTION FACTORS AND $\frac{f}{/ f^{\prime}}$ FOR AUTHORS' DATA

\begin{tabular}{|c|c|c|c|c|c|c|c|c|c|}
\hline $\begin{array}{c}\text { Run } \\
\text { No. } \\
(1)\end{array}$ & $\begin{array}{c}f \\
(2)\end{array}$ & $\begin{array}{l}f^{\prime} \\
(3)\end{array}$ & $\begin{array}{l}f / f \\
(4)\end{array}$ & $\begin{array}{l}\text { Form of Bed } \\
\text { Roughness a } \\
\text { (5) }\end{array}$ & $\begin{array}{l}\text { Run } \\
\text { No. } \\
(6)\end{array}$ & $\begin{array}{c}\mathrm{f} \\
(7)\end{array}$ & $\begin{array}{r}f^{\prime} \\
(8)\end{array}$ & $\begin{array}{l}\mathrm{f} / \mathrm{f}^{\prime} \\
(9)\end{array}$ & $\begin{array}{c}\text { Form of Bed } \\
\text { Roughness } \\
\text { (10) }\end{array}$ \\
\hline 14 & .0308 & .0208 & 1.48 & Plane & 20 & .0927 & .0193 & 4.80 & Dunes \\
\hline 17 & .0514 & 0189 & 2.70 & Ripples & 23 & .0537 & $.01 \& 7$ & 2.87 & Dunes \\
\hline 16 & .0471 & .0196 & 2.40 & Ripples & 24 & .1288 & .0192 & 6.71 & Dunes \\
\hline 13 & .0367 & .0238 & 1.54 & Plane & 40 & .0474 & .0177 & 2.68 & Dunes \\
\hline 15 & .0630 & .0195 & 3.23 & Ripples & 39 & .0204 & .0190 & 1.07 & Transition \\
\hline 18 & .0684 & .0210 & 3.24 & Ripples & 26 & .0101 & .0211 & 0.48 & Transition \\
\hline 2 & .0435 & .0190 & 2.29 & Ripples & 28 & .0274 & .0207 & 1.32 & Transition \\
\hline 3 & .0528 & .0187 & 2.82 & Ripples & 29 & .0740 & .0223 & 3.32 & Transition \\
\hline 9 & .0657 & .0210 & 3.12 & Ripples & 31 & .0244 & .0201 & 1.21 & Transition \\
\hline 1 & .0479 & .0191 & 2.50 & Ripples & 27 & .0384 & .0213 & 1.80 & Transition \\
\hline 5 & .0435 & .0191 & 2.28 & Ripples & 36 & .0508 & .0252 & 2.02 & Transition \\
\hline 11 & .0830 & .0237 & 3.50 & Ripples & 41 & .0222 & .0190 & 1.17 & Transition \\
\hline 4 & .0420 & .0192 & 2.19 & Dunes & 30 & .0527 & .0226 & 2.33 & Transition \\
\hline 8 & .0802 & .0212 & 3.78 & Ripples & 35 & .0380 & .0230 & 1.65 & Transition \\
\hline 7 & .0585 & .0192 & 3.04 & Dunes & 34 & .0267 & .0220 & 1.21 & Transition \\
\hline 10 & .1223 & .0240 & 5.11 & Ripples & 33 & .0187 & .0222 & 0.84 & Transition \\
\hline 6 & .0816 & .0216 & 3.77 & Ripples & 38 & .0244 & .0194 & 1.26 & Transition \\
\hline 12 & .1018 & .0243 & 4.20 & Ripples .. & 37 & .0201 & .0200 & 1.00 & Transition \\
\hline 19 & .0624 & .0215 & 2.91 & Dunes & 32 & .0228 & .0206 & 1.11 & Antidune \\
\hline 21 & .0907 & .0178 & 5.09 & Dunes & 45 & .0926 & .0220 & 4.21 & Antidune \\
\hline 22 & .0886 & .0177 & 5.01 & Dunes & 44 & .0267 & .0217 & 1.22 & Antidune \\
\hline 25 & .0850 & .0211 & 4.00 & Dunes & 42 & .0256 & .0215 & 1.19 & Antidune \\
\hline & & & & & 43 & .0266 & .0198 & 1.34 & Antidune \\
\hline
\end{tabular}

a From Table 1.

Because the principal reason for wanting to know what bed form will be found under given conditions is so that the friction factor can be estimated, it is useful to have a means of estimating the friction factor directly. In connect with a roughness relation, moreover, it would seem unnecessary to distinguish between those features the authors call "ripples" and those they call "dunes." (While these situations are clearly different with respect to transport, they are similar as far as roughness is concerned). It is therefore suggested that an objective, numerical quantity is a necessary part of the description of a bed configuration, and that the value of $f / f^{\prime}$ is a measure suitable to this purpose.

54 “Discharge Formula for Straight Alluvial Channels," by H.-K. Liu and S.-Y. Hwang, Proceedings, ASCE, Vol. 85, No. HY 10, October, 1959, pp. 65-98. 


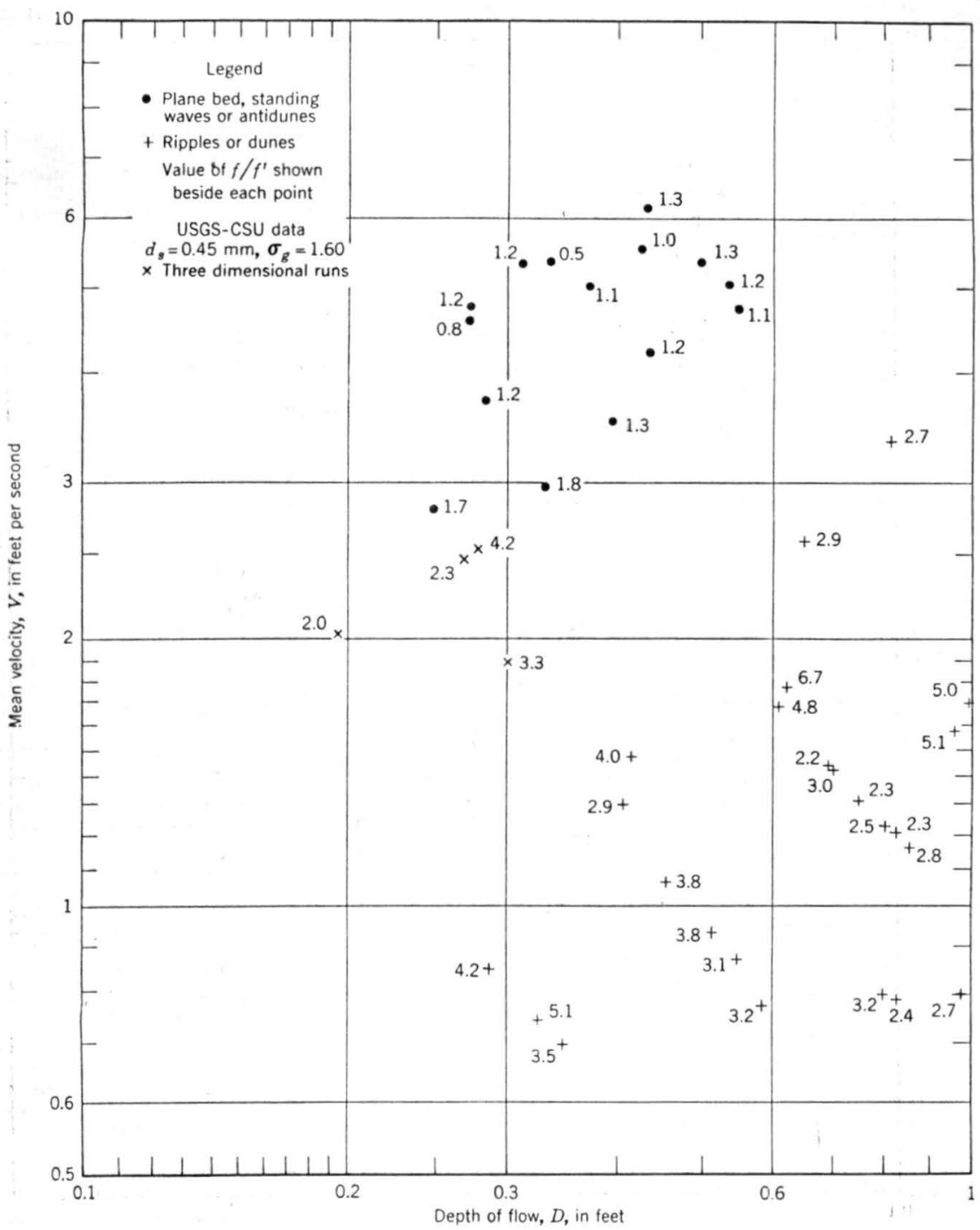

FIG. 34.-VARIATION OF $\mathrm{f} / \mathrm{f}$ ? WITH VELOCITY AND DEPTH FOR $0.45 \mathrm{~mm}$ SAND IN CSU FLUME ACCORDING TO AUTHORS' DATA 


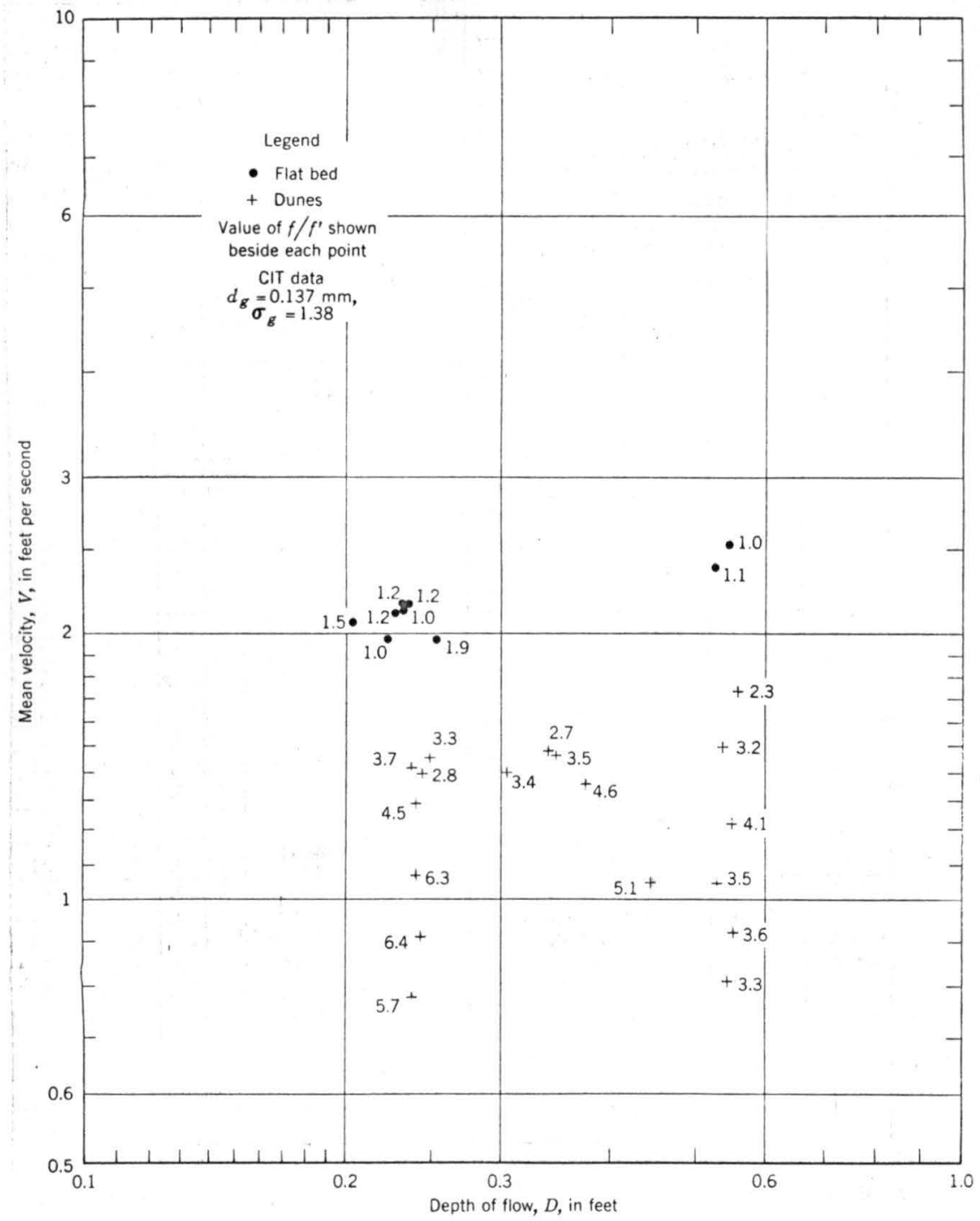

FIG. 35.-VARIATION OF $\mathrm{f} / \mathrm{f}^{\prime}$ WITH VELOCITY AND DEPTH FOR $0.14 \mathrm{~mm}$ SAND IN CIT FLUME 
It is hardly necessary to say that such a value in itself is an incomplete description, in the same way that the verbal description, in itself, is also incomplete.

TABLE 5.-DATA FROM RUNS ON CALIFORNIA INSTITUTE

OF TECHNOLOGY SAND NO. 4

\begin{tabular}{|c|c|c|c|c|c|c|}
\hline $\begin{array}{l}\text { Run } \\
\text { No. }\end{array}$ & $\begin{array}{c}\text { Velocity } \\
\text { V fps }\end{array}$ & $\begin{array}{l}\text { Depth } \\
\mathrm{D} \mathrm{ft}\end{array}$ & f & $f^{\prime}$ & $f_{/ f}$ & $\begin{array}{l}\text { Bed Con- } \\
\text { figuration }\end{array}$ \\
\hline \multicolumn{7}{|c|}{ (a) Vanoni and Brooks b,c } \\
\hline $2-9$ & 0.77 & 0.238 & .124 & .0216 & 5.74 & Dunes \\
\hline $2-3$ & 0.90 & 0.243 & .133 & .0208 & 6.39 & Dunes \\
\hline $2-8$ & 1.07 & 0.240 & .129 & .0205 & 6.29 & Dunes \\
\hline $2-1$ & 1.28 & 0.240 & .090 & .0201 & 4.48 & Dunes \\
\hline $2-7$ & 1.40 & 0.237 & .074 & .0201 & 3.68 & Dunes \\
\hline $2-6$ & 1.44 & 0.249 & .064 & .0196 & 3.27 & Duries \\
\hline $2-17 D^{a}$ & 1.39 & 0.302 & .067 & .0196 & 3.42 & Dunes \\
\hline $2-17 \mathrm{~F}^{\mathrm{a}}$ & 2.07 & 0.203 & .029 & .0193 & 1.51 & Flat \\
\hline $2-2$ & 2.13 & 0.233 & .0235 & .0192 & 1.22 & Flat \\
\hline $2-12$ & 0.80 & 0.541 & .061 & .0183 & 3.34 & Dunes \\
\hline $2-5$ & 1.04 & 0.528 & .063 & .0178 & 3.54 & Dunes \\
\hline $2-10$ & 1.22 & 0.549 & .072 & .0175 & 4.12 & Dunes \\
\hline $2-11$ & 1.49 & 0.536 & .055 & .0170 & 3.24 & Dunes \\
\hline $2-13 D^{a}$ & 1.72 & 0.553 & .038 & .0169 & 2.25 & Dunes \\
\hline $2-16 \mathrm{~F}^{\mathrm{a}}$ & 2.39 & 0.524 & .0185 & .0168 & 1.10 & Flat \\
\hline $2-4$ & 2.53 & 0.544 & .0170 & .0164 & 1.04 & Flat \\
\hline \multicolumn{7}{|c|}{ (b) Nomicosc } \\
\hline $\mathrm{H}-2$ & 2.13 & 0.233 & .0215 & .0207 & 1.04 & Flat \\
\hline $\mathrm{H}-3$ & 1.97 & 0.223 & .022 & .0211 & 1.04 & Flat \\
\hline $\mathrm{H}-7 \mathrm{a}$ & 1.38 & 0.243 & .059 & .0213 & 2.77 & Dunes \\
\hline \multicolumn{7}{|c|}{ (c) Kennedyd } \\
\hline $3-1$ & 0.91 & 0.550 & .068 & .0187 & 3.63 & Dunes \\
\hline $3-4$ & 1.14 & 0.441 & .096 & .0187 & 5.13 & Dunes \\
\hline $3-2$ & 1.35 & 0.373 & .086 & .0189 & 4.55 & Dunes \\
\hline $3-7$ & 1.45 & 0.345 & .067 & .0190 & 3.51 & Dunes \\
\hline $3-5 D^{a}$ & 1.47 & 0.340 & .052 & .0192 & 2.71 & Dunes \\
\hline $3-5 F^{a}$ & 1.97 & 0.254 & .036 & .0192 & 1.87 & Flat \\
\hline $3-6$ & 2.15 & 0.233 & .023 & .0193 & 1.19 & Flat \\
\hline $3-6 A$ & 2.13 & 0.235 & .023 & .0193 & 1.19 & Flat \\
\hline $3-6 \mathrm{~B}$ & 2.21 & 0.228 & .023 & .0193 & 1.19 & Flat \\
\hline
\end{tabular}

${ }^{\mathrm{a}} \mathrm{D}=$ dune section in run with long sand wave. $\mathrm{F}=$ flat section in run with long sand wave. No side-wall correction made.

b “Mechanics of Streams with Movable Beds of Fine Sand," by N. H. Brooks, Transactions, ASCE, Vol. 123, 1958, pp. 526-594.

c "Laboratory Studies of the Roughness and Suspended Load of Alluvial Streams," by V. A. Vanoni and N. H. Brooks, Sedimentation Laboratory, Calif. Inst. of Tech., Pasadena, Calif., Report E-68, 1957.

d' "Study of Relations between Transportation of Sediment and Hydraulic Characteristics of Streams," by J. F. Kennedy, Keck Laboratory of Hydraulics and Water Resources, Calif. Inst. of Tech., Pasadena, Calif., Report KHWR-6, in press.

The second advantage which the use of $\mathrm{f} / \mathrm{f}^{\prime}$ may offer is in predicting the roughness which may be expected for given flow conditions. A number of interesting ideas are suggested by Figs. 34 and 35 , which show $\mathrm{f} / \mathrm{f}^{\prime}$ as a function 
of depth and velocity. Fig. 34 uses data for the authors' experiments, $d=0.45$ $\mathrm{mm}$, (runs 13 and 14 have been omitted because there is no transport and the flat bed was artificially prepared). Fig. 35 uses data from experiments (2, 3, 6 ) made at the California Institute of Technology on a finer sand (geometric mean, $\mathrm{dg}=0.137 \mathrm{~mm}$ ). (Tables 4 and 5 respectively.) First, it will be noted that the variation of $\mathrm{f} / \mathrm{f}$ ' seems fairly regular, especially when it is remembered that as a percentage of the actual friction factor a difference between $f / f^{\prime}$ values of 2 and 3 is much greater than between $f / f^{\prime}$ values of 6 and 7 . Second, it is interesting to note that the separation between dune-type bed configurations and flat configurations occurs at about the same $f / f^{\prime}$ value in both sands.

The directness and simplicity with which $\mathrm{f}$ may be estimated for a given depth and velocity may be illustrated by the following example. Suppose it were desired to estimate the friction factor for a flow over the authors' sand if the depth were $0.8 \mathrm{ft}$ and the velocity were $2.5 \mathrm{fps}$. From Fig. $34, \mathrm{f} / \mathrm{f}^{\prime}$ would be about 3 , and a rough (dune or ripple) bed would be expected. Taking the mean diameter for the effective roughness height and assuming $\nu=10-5 \mathrm{sq} f \mathrm{ft}$ sec, the relative roughness, $\epsilon /(4 \mathrm{r})$, is .00055 , and $R_{\mathrm{e}}=4 \mathrm{r} \mathrm{V} / \nu=940,000$; for these values the pipe friction diagram gives $f^{\prime}=.05$, approximately. The slope can be determined by substituting directly into the definition of f, Eq. 26; in this example, the result is about $\mathrm{S}=.0015$.

Further research on the roughness problem is urgently needed. It may be hoped that continued flume studies like the authors' and more field investigations will make a comprehensive and logical roughness analysis possible in the future.

LUCIEN M. BRUSH, JR, 55 M. ASCE. - This paper should be of interest to geologists as well as hydraulic engineers. Of importance to engineers is the accumulation of knowledge concerning resistance through controlled flume studies. The present-day inability to predict resistance in alluvial channels frequently has led to the inadequate design of channels and has greatly hindered progress in the field of sediment transportation. Geologists should find the description of bed forms and their associated sedimentary structures useful in attempting to evaluate past environments. Certain features of both the hydraulic and geologic implications of this paper deserve additional comment and will thereby form the basis of the discussion.

Geologic Ramifications.--One of the aims of geologic investigations of sedimentary rocks is to infer the past history or environment of deposition. Admittedly this is difficult to do because the original fluid is no longer present in rocks. However, it is not uncommon to have sedimentary structures preserved in the rocks and these structures are often identical to the ones shown by the authors for dunes in Fig. 2. If it is assumed that physical processes involving the flow of water over alluvial channels obey the same laws of physics today as in the geologic past, much may be inferred from sedimentary structures found in rocks. For example, the basic sedimentary structure shown by the authors in Fig. 2 for dunes consists of thin horizontal strata of fine sediment overlain by coarser sediment arranged in parallel strata inclined at an angle approximately equal to the angle of repose of the sand. Geologists frequently encounter this structure in sedimentary rocks and denote it as planar

55 Research Engr., Iowa Inst. of Hydr. Research, and Assist. Prof., Dept. of Mechanics and Hydr., State Univ. of Iowa, Iowa City, Iowa. 
cross-stratification or torrential cross-bedding. For rather poorly founded reasons, geologists usually associate this structure with torrents (high velocity streams on steep slopes) found in arid regions. Obviously, this interpretation is subject to question, because dunes and their associated structures are shown by the authors and others to vanish as the Froude number approaches one. Thus, planar cross-stratification would be the rule (subcritical flow) rather than the exception (supercritical flow) for flow in alluvial channels and would hardly be typical of high-velocity streams on steep slopes.

The preceding example is just one of many that may be derived from studies of dune structures and their associated hydraulic environment. For example, a statistical study of the spatial orientation of the planes of inclined strata would allow estimates to be made of the local, as well as the mean-flow direction of the stream. Furthermore, although the authors have not made this clear, the underlying horizontal layer of fine sediment is absent if there is no appreciable amount of suspended load present. The authors have failed to show the details of the bedding structures associated with ripples but it has been found by the writer that the ripple structure also consists of inclined strata similar to those formed by dunes. The mineralogical content of the underlying horizontal layer, which represents at least a part of the suspended load, and the mineralogical content of the inclined strata, which represent the bed load, are also of geological importance because proper identification of these minerals would enable deductions to be made as to the source areas of the sediment being transported by the streams.

Obviously, a complete and detailed reconstruction of the hydraulic characteristics of a stream is, most probably, beyond reach, but many possibilities appear encouraging and others remain to be explored. The authors have not incorporated the quantitative aspects of dune and ripple geometry into their analysis. Thus, one cannot tell whether or not the bed configuration as represented by sedimentary structures might yield still more information that the geologist could use in attempting to reconstruct the past.

Hydraulic Considerations. - The failure of the authors to employ parameters describing the dune geometry and to use them in subsequent plotting detracts somewhat from the problem at hand, but in all fairness it must be recognized that a detailed description and classification of bed regimes is a step in the right direction and that the paper serves to reemphasize the need for additional studies of dunes, in particular, their geometry and limiting size for various flow conditions and particle size distributions.

The relationship shown by Fig. 10 is by far the most important of those given regardless of the scattering of some of the points and overlapping of some of the regimes. In fact, if this relationship should stand up for different particle size distributions, the need of worrying about regimes would be reduced vastly because all the pertinent flow characteristics usually needed for design purposes would be available. For example, given $\mathrm{d}, \gamma_{\mathrm{S}}, \gamma$, and $\nu$ and assuming any two of the remaining variables, slope, discharge, and depth are known, the remaining variable may be obtained by using Fig. 10. F'urthermore, as is shown by the authors, the relationship is directly related to boundary-layer theory. Additional studies, of course, will be necessary to substantiate the validity of this relationship for different particle size distributions.

In contrast, the significance of Fig. 11, which may be expressed by the equation shown on the figure, is difficult to determine despite the fact that the relationship has much less scatter than the usual plots involving sediment. The 
authors' use of the Froude number as a term in the abscissa is difficult to understand in that more than half of the runs were made for subcritical flow. In addition, it is extremely difficult to grasp any physical significance to the combinations of the basic parameters used by the authors other than their dimensional homogeneity. If the authors could show a rational analytical development leading at least part way to this result, Fig. 11 would assume more meaning.

Although progress in alluvial channel roughness has been extremely slow, the authors have obtained data which should be of extreme usefulness to everyone in the field, both because of the wide range covered during the experiments and because the model channel is nearly stream-size in scale. Ultimately, the geometric details of the bed configuration must also be included in the analysis, and it is hoped that the authors will be successful in performing this task.

DARYL B. SIMONS, 56 M. ASCE, and E. V. RICHARDSON, ${ }^{57}$ A. M. ASCE. - The points brought out in the discussions are of considerable wor th in evaluating the data presented, planning future research including coordination of effort with other interested researchers, and avoiding some of the pitfalls of analysis where large numbers of interrelated variables are involved.

Collection of Data.-Several points regarding data-collection procedures and possible errors introduced by the measuring techniques used were raised by Blench.

Measurement of Discharge.-Will the type of orifice meter used in this study, which was calibrated using water, accurately meter a water-sediment mixture? Based on R. Durand's experimental work, 58 the applicability of this type of meter was indirectly confirmed. For the whistle-type orifice meter, he concluded that sediment has a negligible effect on the calibration curve developed for clear water provided the sediments were in complete suspension. Further theoretical work was done 59 by Nobuhiro Yotsukura on the effect of suspended sediment on the calibration of the side-contracted orifice. He concluded that the maximum error in measurement of discharge of sedimentladen flow would be approximately $5 \%$ for concentrations of sediment of $20 \%$ to $25 \%$ by volume. The maximum total concentration of sediment was only $0.6 \%$ by volume in this study.

The Method of Introducing Sediment into the Flume.-In all of the experimental work reported by the writers the sand has been recirculated. In general, this method was found to be very satisfactory. However, with very small concentrations of sediment (ripples) it takes a long time for a run to come into equilibrium. Also, if sand is stored anywhere in the system during a run, another problem arises; that is, on the subsequent run, the stored sand from the preceding run may be flushed into the flume, and, because the flushing usually occurs rapidly, a sand wave results which recirculates through the system, gradually dampening with time. It was found necessary to eliminate waves thus created shortly after their formation by shutting down, screeding

56 Hydr. Engr., Geol. Survey, U. S. Dept. of the Interior, Fort Collins, Colo.

57 Hydr. Engr., Geol. Survey, U. S. Dept. of the Interior, Fort Collins, Colo.

58 "Basic Relations of the Transport of Solids in Pipes," by R. Durand, Proceedings, Minnesota Internatl. Hydr. Convention, IAHR and ASCE, 1953.

59 "Effect of Bentonite Suspensions on Sand Transport in Four-Inch Pipe," by Nobuhiro Yotsukura, thesis presented to Colorado State University, at Fort Collins, Colo., in 1961, in partial fulfilment of the requirements for the degree of Doctor of Philosophy. 
out the waves, and then restoring the desired flow conditions. By this means, the problem of recirculating sediment is easily handled. For dunes and other forms of bed roughness that occur at larger velocities and with larger rates of bed material transport, no such problem exists.

Method of Measuring Total Bed Material Load. - Various methods of measuring total load were carefully studied before selecting the techniques used. However, certain problems were involved. It is necessary to measure the sediment load over a relatively long period of time, averaging the results to assure accuracy. For example, referring to Fig. 36, it can be seen that continuous sampling (a sample every $5 \mathrm{~min}$ ) for as long as two hours may be required in the case of dunes for which transport varies considerably and ra-

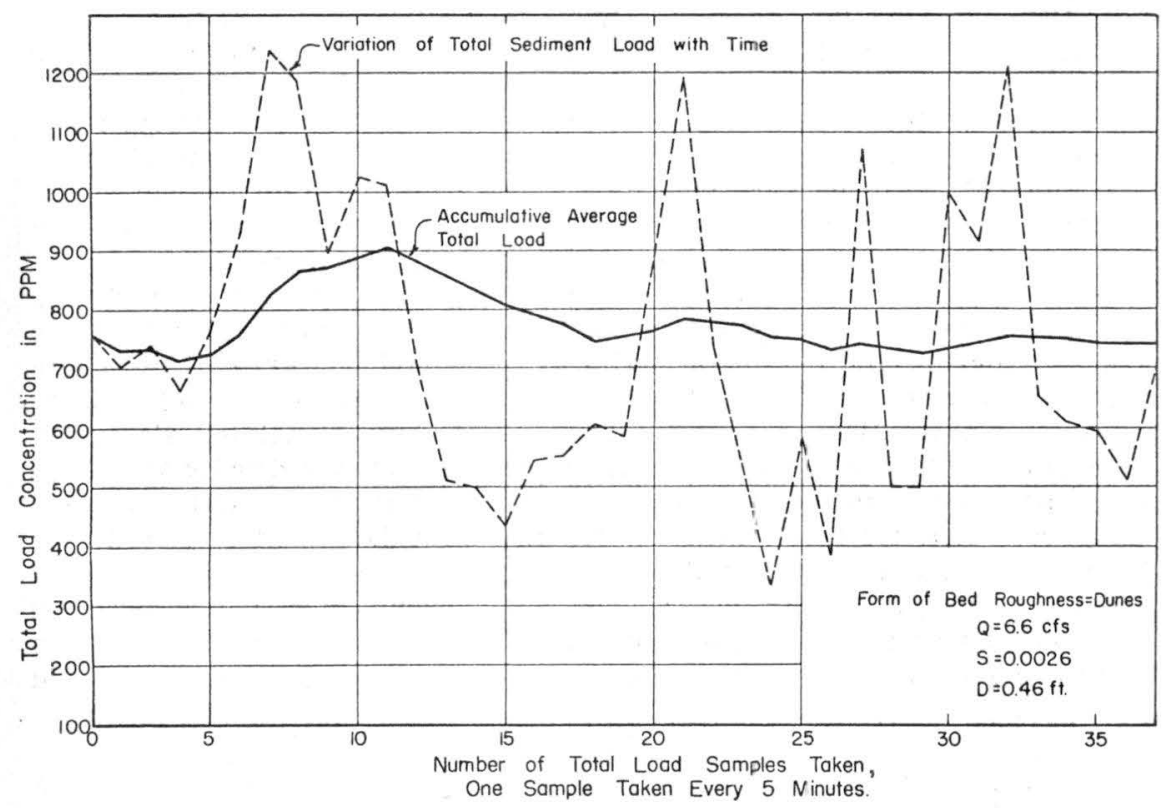

FIG. 36.-VARIATION OF CONCENTRATION OF TOTA_ BED-MATERIAL LOAD WITH NUMBER OF SAMPLE OF BED-MATERIAL LOAD

pidly with time and space before the results of one more sample will not appreciably affect the cumulative average.

Measurement of Depth.-The measurement of depth was also mentioned in the discussions. The depths determined by (1) taking the average of many individual depth measurements down the center line of the flume with flow, and (2) screeding the bed and measuring the depth after completing the run were found to be essentially the same. However, the measurement of depth needs to be seriously considered in greater detail. The effective depth is not actually known when one is striving for a particular answer. For example, in studying resistance to flow, it may be necessary to correct the depth for the separation zones downstream of the crests of the ripples and dunes. That is, 
the effective depth may be less than the measured depth and the effective velocity may be larger than the measured average velocity.

Temperature Variation.-Considering the temperature of the water-sediment complex at which these runs were conducted, Laursen and Zernial correctly point out in Fig. 17 that part of the runs were completed in the summer and part were completed in the winter without temperature control. Consequently, for those runs made in the winter, the temperature was relatively smaller, the viscosity of the water was larger, and the fall velocity of the bed material was smaller. Hence, in some respects, if it is assumed that fall velocity is a significant variable, essentially two different bed materials were being considered. This difficulty of varying fall velocity has been eliminated in subsequent studies by adding a temperature-control unit to the flume tail box. Unfortunately, this does little to eliminate the variation in temperature and fall velocity of the bed material that occurred during the collection of these data.

Analysis of Data.-The principal variables that the writers believe affect resistance to flow were cited and briefly discussed using dimensional analysis. Most of the discussers pointed out that the complex dimensionless parameters, whose relationships are shown in Fig. 11 practically reduce to a plot of $\mathrm{S}$ versus $\sqrt{\mathrm{S}}$. This mistake on the part of the writers emphasizes the importance of the proper use of dimensional analysis as a tool and the danger of relating complex dimensionless parameters when some of the variables are repeated in both parameters without reducing the interrelation between the parameters to its simplest form.

Another precautionary remark with respect to dimensional analysis is that, often, independent variables such as viscosity and mass density are left in the dimensionless terms used in the correlation work in spite of the fact that these variables are held essentially constant throughout the tests. To do this is misleading to the casual reader because he usually assumes all three variables occurring in the parameter have actually been varied systematically in the study. Consequently, it may be more enlightening to use only the variables that were actually varied in the empirical treatment; that is, perhaps it would be more realistic to use the product VDinstead of $\frac{\mathrm{V} \mathrm{D}}{\nu}$ when the viscosity is not varied, because, ultimately, when data are collected and studied in which the viscosity is actually varied, a very different relationship may result. This point was also emphasized by Maddock and Langbein.

Taylor and Brooks stated that $\mathrm{C}_{\mathrm{D}}$ is redundant in Eq. 6 because $\mathrm{C}_{\mathrm{D}}=$ $\phi\left(\frac{\mathrm{w} d}{\nu}\right)$ and $\mathrm{w}, \mathrm{d}$, and $\nu$ are included in other dimensionless terms occurring in the equation. This is true if $\mathrm{d}$ in Eq. 1 is the fall diameter as determined using the Visual Accumulation apparatus. However, if $d$ is the nominal diameter, then $C_{D}$ is not redundant in Eq. 6 because the shape factor of the partical $\left(f_{S}\right)$ has been omitted, $C_{D}=\phi\left(\frac{w d}{v}, f_{S}\right)$. Taylor and Brooks, Blench, and Maddock and Langbein also indicate that $Q_{S}$, the bed material discharge, should be included as an independent variable in the dimensional analysis. With respect to this, the writers believe that it should be deleted because, in the flume experiments and in many natural rivers in which the flow is in equilibrium, the sediment load must be dependent on the same variables as the depth. However, there are many examples in which the flow is not in equilibrium and 
a sediment discharge is imposed on a stream, canal or reach, from an outside source. Then, the sediment discharge is an independent variable and should be included in Eq. 1.

Examples in which a sediment load may be imposed on a stream and should be included in the analysis as an independent variable are (1) a canal diverting water and a variable sediment load from a river, (2) downstream of the junction of two streams, or (3) downstream of a bifurcation. In Eq. 1, another dependent variable could be selected instead of depth; for example, $\mathrm{C}_{t}$ denotes the concentration of total bed material load, $\mathrm{C}_{\mathrm{S}}$ refers to the concentration of contact load, $d_{S}$ is the representative size of suspended bed-material load, and so forth. In addition, any one of the foregoing variables may be substituted for any one of the independent variables in the functional relation. Hence, a large number of arrangements of variables is possible, but not all of the arrangements are of equal significance and utility. Therefore, the variables to be used in the dimensional analysis must be selected with considerable thought and care. However, it is only through repeated trials, plotting of data, analysis, and serendipity that the most significant arrangement of variables will be determined.

Forms of Bed Roughness. - The forms of bed roughness observed by the writers using the $0.45 \mathrm{~mm}$ sand were illustrated in Fig. 2. For smaller sizes of bed material or for larger depths than those investigated using the $0.45 \mathrm{~mm}$ sand, a plane bed with movement will develop after dunes and before standing waves and antidunes. With this form of bed roughness, resistance to flow is minimum, although little less than for standing waves or antidunes. As pointed out by Taylor and Brooks, a plane bed may form after dunes when $\mathrm{F}_{\mathrm{r}}<1$; in fact, the finer the bed material, the smaller the $\mathrm{F}_{\mathrm{r}}$ at which plane bed after dunes appears. Consequently, in subsequent articles presented by the writers, the forms of bed roughness have been divided into an upper and lower regime of flow. These regimes of flow are based on form of bed roughness, resistance to flow, and sediment transport rate instead of the magnitude of $\mathrm{F}_{\mathrm{r}} .60$

Considering the formation of ripples, Blench pointed out that, with a bed material having a diameter of $1 \mathrm{~mm}$, the ripple form of roughness would not develop after beginning of motion. Instead, the bed remained essentially flat. However, as the tractive force and sediment transport increased, dunes formed. These observations made by Blench are consistent with those made by the writers and others. ${ }^{61}$ Based on the writers' experiments, when d50 was greater than $0.60 \mathrm{~mm}$, ripples did not form when movement of the bed material began; in fact, a plane bed persisted until the rate of transport of sediment reached approximately $20 \mathrm{ppm}$. Then, as the slope or depth or both were increased, the sediment transport rate increased and dunes formed. It should also be noted that the Russian scientist V. S. Knoroz, 62 reported that ripples or dunes always formed after beginning of motion using sands with median diameters up to $1.48 \mathrm{~mm}$. He attributed the plane bed after beginning of mo-

60 "Forms of Roughness in Alluvial Channels," by Daryl B. Simons and E. V. Richardson, Proceedings, ASCE, Vol. 87, No. HY 3, May, 1961, pp. 87-105.

61 "Research Publication," by C. C. Inglis, Irrig. Research Sta., No. 13, Poona, India.

62 « The Effect of the Channel Maco-Roughness on its Hydraulic Resistance,” by V. S. Knoroz, Inst. Gidrotekaniki, Vol. 62, 1959, pp. 75-95; translated by Ivan Mitten, Geol. Survey, U. S. Dept. of the Interior, Denver, Colo. 
tion and prior to the formation of ripples or dunes reported by other experimenters to an inadequate length of period of flow.

The question was raised by Taylor and Brooks, "Is there any essential difference between ripples and dunes or should both forms of roughness be discussed and accepted as one form of roughness?" The writers believe that there is a distinct difference between ripples and dunes. The ripples are of approximately the same form, amplitude, and spacing for all sand sizes of bed material investigated thus far for which ripples form (sizes ranging from 0.2 $\mathrm{mm}$ to $0.45 \mathrm{~mm}$ ). Whereas with dunes the spacing and shape are intimately related to the fall velocity of the bed material. For bed materials of small fall velocities, the spacing of the dunes is large and the dunes are less angular, resulting in a smaller resistance to flow than for dunes formed of bed material with larger fall velocities. In addition, with ripples as a form of bed roughness, there is a definite relative roughness effect. That is, the ratio of the amplitude of ripple to depth decreases as depth is increased. In fact, ripples have not been observed that have average amplitudes much greater than $0.1 \mathrm{ft}$ and their maximum length is usually less than $1 \mathrm{ft}$ to $1.5 \mathrm{ft}$. Whereas with dunes, as depth of flow is increased. the amplitude of the dunes increases.

The so-called standing sand and water waves that are in phase and the antidunes as illustrated in Figs. 5 and 6 have been observed and studied in flumes and have been observed in many sand channel streams. 63,64 With standing sand and water waves and antidunes, the resistance to flow is relatively small and, as mentioned by Taylor and Brooks, the resistance to flow increases with an increase in antidune activity. In addition, Taylor and Brooks point out that, by further increasing the energy input to the flow, they were able to change the antidune condition to a flat bed similar to that observed after dunes, but presumably carrying more sediment. In their case, a bed material of medium diameter of $0.55 \mathrm{~mm}$ was used. The writers, on the other hand, have never observed the change from antidune conditions to a plane bed as energy input to the system is increased. However, the writers have noted a different type of antidune which they have arbitrarily called a chute and pool type of antidune. ${ }^{60}$ In a short flume it is possible that one might only see the chute portion of the phenomena described, which is essentially a plane or flat bed. As this type of antidune flow develops, assuming a flume of sufficient length to accommodate several chutes and pools, resistance to flow continues to increase. In fact, the average velocity of flow may be considerably smaller than for normal antidune flow in spite of the steeper slope; however, sediment transport increases markedly. This latter type of flow phenomena may be the same as Blench's shock antidune.

Resistance to Flow. - Several interesting relations involving resistance to flow were presented by the discussers. In Figs. 18, 19, and 20, Laursen and Zernial relate $C \sqrt{\mathrm{g}}$ to $2 \mathrm{D} / \mathrm{h}$ and show how points defined by these values scatter with respect to Nikuradses' line relating $C / \sqrt{g}$ and $r_{0} / k$. The results involving Barton and Lin and Laursen and Lin's data, Figs. 19 and 20, show less scatter than the writers' data presented in Fig. 18. The reason for this has been made obvious by Laursen and Zernial. That is, all of the runs used to

63 "Discontinuous Rating Curves for Pigeon Roost and Cuffawa Creeks in Northern Mississippi,” by B. R. Colby, USAA, ARS, 1960.

64 “Depth Discharge Relations in Alluvial Streams," by D. R. Dawdy, Water-Supply Paper 1498-C, Geol. Survey, U. S. Dept. of the Interior, Washington, D. C., 1961. 
establish Figs. 19 and 20 involved principally ripple and dune bed forms whereas Fig. 18 is based on runs in which the bed form ranged from plane bed near beginning of motion to antidunes. If the broader range of flow conditions had been investigated in the other studies, scatter similar to that in Fig. 18 would have resulted in Figs. 19 and 20. Other factors that complicate development of a useful relation to this form are (1) the inability to determine a meaningful value of $\mathrm{h}$ for standing waves and antidunes and the difficulty of measuring $\mathrm{h}$ for ripples and dunes, (2) the effect of the rolling sediment at the sand water interface on resistance to flow (in general, the writers' investigations indicate that resistance to flow is slightly smaller for a given bed roughness with movement of bed material than without movement of bed material), and (3) the difficulty of determining the velocity of flow as it is related to the amplitude and spacing of the bed forms. Knoroz 62 presented equations for predicting the height $\mathrm{h}$ and spacing 1 of dunes. Unfortunately, these dimensions in his equations are based on the velocity of the flow.

Based on the results of Figs. 18,19, and 20, Laursen and Zernial point out that partical roughness seems to increase with increasing coarseness of sand. This was verified by laboratory experiments conducted by the writer; however, the gradation of the bed material must also play an important role. The grain roughness for sand of uniform gradation is greater than for a widely graded sand with the same median diameter. This point is inferred by the results of Halmarks' study, Fig. 24. Also, as pointed out in the preceding section, the form roughness increased with size of sand when the bed form was dunes. The relation presented by Maddock and Langbein, Fig. 32, which involves those runs for which sediment discharge was very small, shows an excellent relation between $\mathrm{D}, \mathrm{Q}$, and $\mathrm{S}$. However, as they recognize, one cannot expect such a relation to hold for a large range of $\mathrm{Q}, \mathrm{S}$, and $\mathrm{D}$ and certainly not for runs involving larger sediment-transport rates and a variety of forms of bed roughness. This type of relation indicates that it might be possible to establish significant relations between $\mathrm{D}, \mathrm{S}, \mathrm{Q}, \mathrm{d}$, and rate of sediment transport for each form of bed roughness where mode of sediment transport does not vary appreciably.

In accordance with Einstein's suggestion to check previous theories and formulas for resistance to flow, $\frac{\mathrm{V}}{\mathrm{V}_{*} "}$ and $\psi^{\prime}$ were computed and plotted for both the $0.45 \mathrm{~mm}$ sand and the $0.28 \mathrm{~mm}$ sand, Fig. 37. Einstein's river curve fits the data fairly well except at the two extremes. For small values of $\psi^{\prime}$ corresponding to plane beds, standing waves and antidunes, the points plot well below Einstein's river curve. For large values of $\psi^{+}$corresponding to ripples and plane bed near beginning of sediment movement, the points plot well above Einstein's river curve.

The relation presented by Taylor and Brooks in Figs. 34 and 35 distinctly separate the upper from the lower flow regimes. However, it does not separate ripples from dunes, which would be desirable. Also, the relation depends on knowing the velocity which, more often than not, is the principal unknown quantity. The suggestion of separating the resistance to flow on the basis of slope of the energy grade line, which as they noted has been suggested by others, instead of on the basis of two virtual channels, has merit and has been tried by the writers. However, considerable more data must be studied with a large range of sand sizes in order to determine the suitability of this method. 


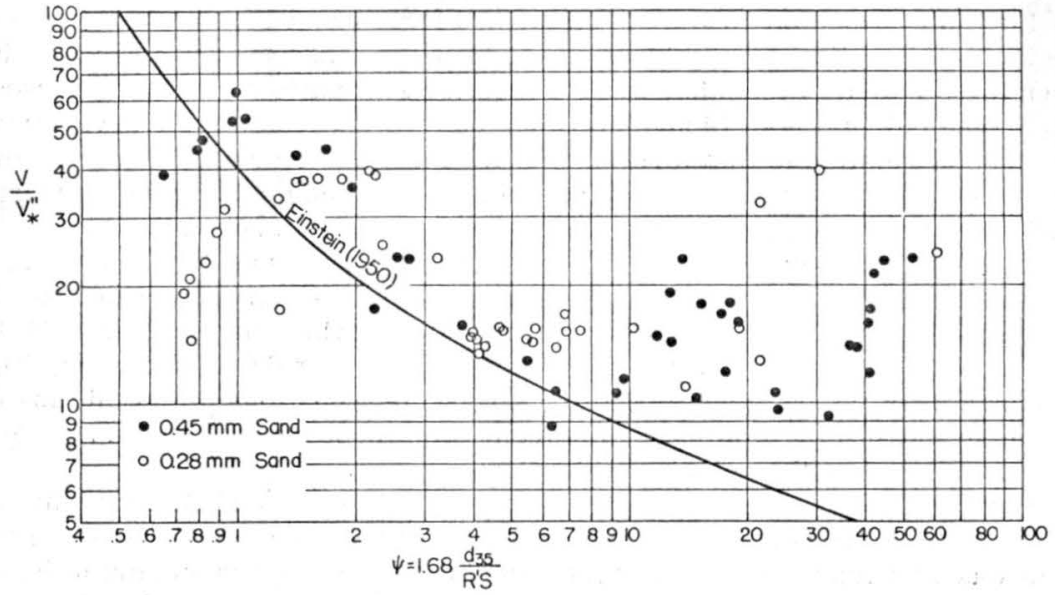

FIG. 37.-FRICTION V" DUE TO CHANNEL IRREGULARITIES

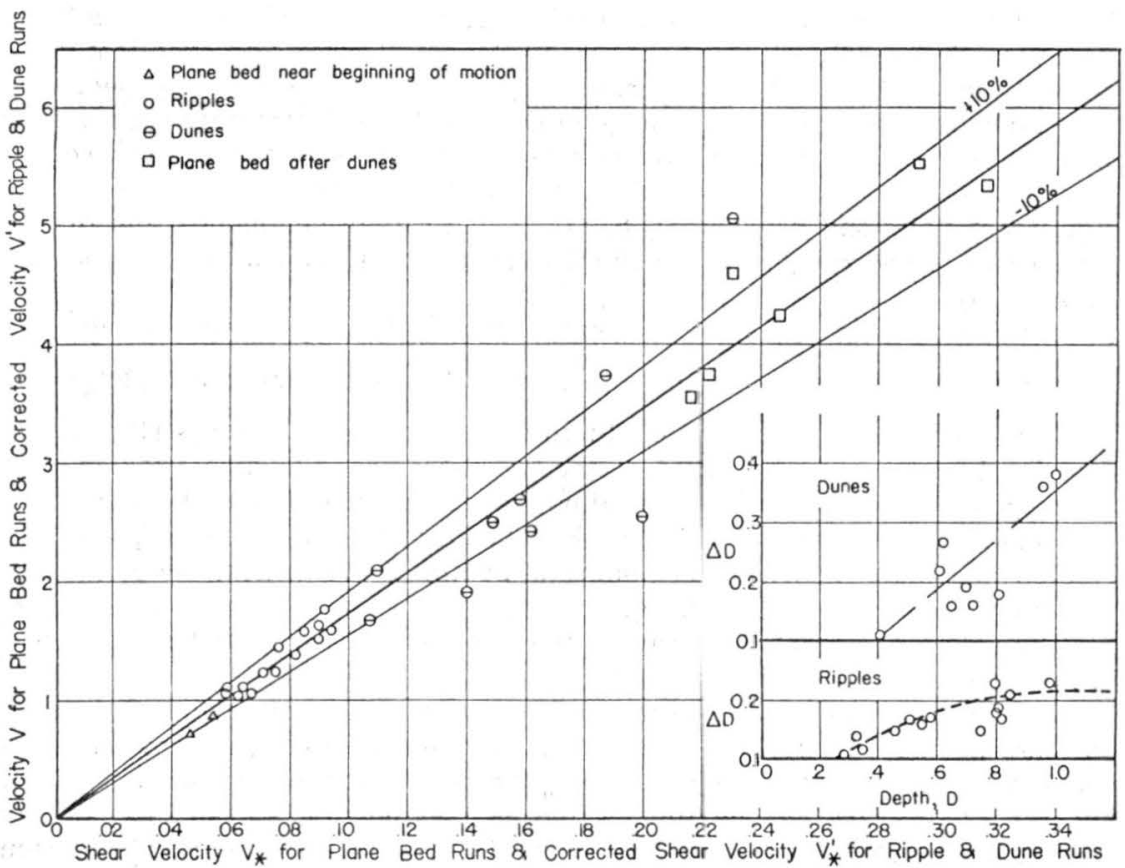

FIG. 38.-RELATION OF V AND V' TO $V_{*}$ AND V ${ }_{*}^{\prime}$, RESPECTIVELY, FOR $.45 \mathrm{~mm}$ SAND 
In addition, this procedure does not properly account for viscous effects unless this is done with respect to the determination of form of bed roughness.

Further study of the data by the writers suggests a method of relating the magnitude of the separation zone downstream of ripples and dunes to the resistance to flow. This has been done by correcting the measured depth $D$ by the increase in depth $\Delta D$ resulting from the separation zones. First, a mean relation between $\mathrm{V}$ and $\mathrm{V} *$ was established for the plane bed runs, neglecting the difference in resistance to flow and relative roughness with and without sediment movement for the plane bed. The resulting relation is essentially a straight line that passes through the origin, Fig. 38. With ripples and dunes, the points showing the relation between $\mathrm{V}$ and $\mathrm{V} *$ (not plotted) fall well below this line, indicating that resistance to flow is greater. If it is assumed that this variation is related to the magnitude of the separation zones and the spacing of such zones downstream of the crests of the ripples or dunes, it might be further assumed that, if velocity and depth were corrected to eliminate the separation zones, (that is, depth decreased and velocity increased), the new plot of velocity versus shear velocity based on corrected depth and velocity should fall approximately on the line representing plane bed conditions.

The utilization of records of bed roughness verified that such was essentially true. Hence, for the ripple and dune runs, corrected depths, $D^{\prime}=$ $(D-\Delta D)$, and corrected velocities, $V^{\prime}=(V D) / D^{\prime}$, were determined such that the relation between $V^{\prime}$ and $V_{*}{ }^{\prime}=\sqrt{g D^{\prime} S}$ were plotted on the line for a plane bed, Fig. 38. The values of $\Delta \mathrm{D}$ thus obtained were then related to $\mathrm{D}$ as indicated, Fig. 38. Hence, knowing form of bed roughness and average depth, the correction to depth $\Delta \mathrm{D}$ can be estimated from the line relating $\Delta \mathrm{D}$ and $\mathrm{D}$ to determine $D^{\prime}$. Knowing $D^{\prime}$ and $S$, the modified shear velocity $V_{*}^{\prime}=\sqrt{g D^{\prime} S}$ can be computed and the corresponding value of the corrected velocity, $\mathrm{V}^{\prime}$, can be read from the relation between $V^{\prime}$ and $V_{*}{ }^{\prime}$. The last step involves determining the average velocity from the relation $\mathrm{V}=\mathrm{V}^{\prime} \mathrm{D}^{\prime} / \mathrm{D}$.

The points plotted on Fig. 39 for ripples and dunes relate $\mathrm{V}^{\prime}$ and $\mathrm{V}_{*}$ ' values as predicted, knowing the form of bed roughness and depth of flow. It can be seen that for ripples the average velocity can be predicted within $\pm 10 \%$. For dunes the relation is not as reliable, but other plots of laboratory and field data are more encouraging. Using the $0.23 \mathrm{~mm}$ bed-material data, a further refinement for the $\triangle D-D$ relation for dunes can be obtained by including slope as a third variable. For plane bed before the formation of ripples and following dunes, there is no correction $\triangle \mathrm{D}$ and knowing depth $\mathrm{D}$ and slope $\mathrm{S}$, the velocity $\mathrm{V}$ can be directly estimated. This implies that, for all plane bed conditions with a given sand, the resistance to flow is practically constant.

The $\triangle \mathrm{D}$-versus-D correlation is different fo: ripples than dunes. With ripples the correction term is approximately the height of the ripples, whereas, with dunes it is some fraction of the dune height. Of interest is Knoroz statement 62 that the separation zone for ripples or dunes is approximately 10 times their amplitude. Also, Knoroz stated that for ripples the separation zone extended from crest to crest, but not for dunes. If the separation zone extends downstream $10 \mathrm{~h}$ (work in the wind tunnel reported in 1961 showed that the separation zone downstream from a vertical flat plate was 12 times its height, 65$)$ then the separation zone does extend from crest to crest for ripples

65 "Separation Flow Downstream of a Plate Set Normal to a Plane Boundary," by H. S. Nagubushaniah, thesis presented to Colorado State University, at Fort Collins, Colo., in 1961, in partial fulfilment of the requirements for the degree of Doctor of Philosophy. 
but not for dunes. Excluding the transition zone, in which prior conditions and the unsteady nature of the flow effect form roughness, the resistance to flow and form roughness are a function of fluid properties, sediment, flow, and channel characteristics. A unique relation for resistance to flow must exist. Until such a relation is determined separating the resistance to flow into that resulting from grain and form roughness on the basis of slope, hydraulic radius, measured or estimated bed configuration or depth is a useful crutch that will continue to be used. However, determining resistance to flow by this method is not much more accurate than can be obtained from experience assuming the form of bed roughness is known in the beginning.

Sediment Transport. - It was not the writers' intent to delve into the problem of sediment transport at this particular time. However, considerable interest has been exhibited by the discussers along these lines. For example, Maddock and Langbein point out that $\mathrm{C}_{\mathrm{t}}$ was one of the variables that was

TABLE 6.-BASIC VARIABLES FOR ADDITIONAL RUNS, $0.45 \mathrm{~mm}$ SAND

\begin{tabular}{r|r|r|r|r|r|r|l}
\hline \hline Run & $\begin{array}{c}\text { S2 10, } \\
\text { in feet } \\
\text { per foot }\end{array}$ & $\begin{array}{c}\text { Q, in } \\
\text { cfs }\end{array}$ & $\begin{array}{c}\text { D, in } \\
\text { feet }\end{array}$ & $\begin{array}{c}\text { V, in } \\
\text { fps }\end{array}$ & $\begin{array}{c}\mathrm{T}, \text { in } \\
\text { oC }\end{array}$ & $\begin{array}{c}\mathrm{C}_{\mathrm{T}}, \text { in } \\
\text { ppm }\end{array}$ & $\begin{array}{c}\text { Form of bed } \\
\text { roughness }\end{array}$ \\
\hline 85 & 0.047 & 7.11 & 0.78 & 1.13 & 12.7 & 12 & Ripples \\
46 & 0.084 & 14.54 & 1.11 & 1.64 & 13.1 & 181 & Dunes \\
47 & 0.042 & 9.59 & 0.75 & 1.60 & 11.5 & 23 & Dunes \\
48 & 0.052 & 15.26 & 1.23 & 1.55 & 11.5 & 60 & Dunes \\
49 & 0.173 & 21.32 & 1.33 & 2.00 & 11.0 & 588 & Dunes \\
\hline 93 & 0.072 & 7.20 & 0.62 & 1.45 & 14.7 & 100 & Dunes \\
82 & 0.248 & 8.16 & 0.64 & 1.60 & 23.2 & 562 & Dunes \\
51 & 0.236 & 8.11 & 0.62 & 1.62 & 13.1 & 1130 & Dunes \\
94 & 0.237 & 11.30 & 0.81 & 1.74 & 13.5 & 487 & Dunes \\
83 & 0.200 & 15.58 & 0.91 & 2.14 & 16.2 & 588 & Dunes \\
\hline 100 & 0.790 & 21.42 & 0.51 & 5.28 & 13.3 & 8550 & Plane \\
81 & 0.634 & 21.35 & 0.55 & 4.85 & 10.7 & 4490 & Standing Wave \\
84 & 0.740 & 15.36 & 0.41 & 4.67 & 15.0 & 7110 & Antidune \\
\hline \hline
\end{tabular}

carefully measured and that perhaps it should have been worked into the analysis to a greater extent. Along the same lines, Einstein emphasized that the data should have been used more to check existing theories, considering both resistance to flow and sediment transport. Similarly, Blench suggests that the data should have been plotted in accordance with the Meyer-Peter-Müller and Einstein relations to determine whether or not there is agreement between the writers' data, Gilbert's data, and data from the major irrigation canals of India.

Referring to Table 6, data from a second series of runs, using the $0.45 \mathrm{~mm}$ bed material, are presented. The total bed-material load was carefully measured for this series of runs. In keeping with the foregoing suggestions, the total bed-material load for these runs has been computed using the Einstein method. ${ }^{66}$ In using Einstein's method, the actual velocity was used and $\mathrm{R}^{\prime}$. was

66 «The Bed Load Function for Sediment Transportation in Open Channel Flows, ”y H. A. Einstein, Technical Bulletin 1026, U. S. Dept. of Agric., Washington, D. C., 1950. 
used and $\mathrm{R}^{\prime}$ was determined directly using the method proposed by Vanoni and Brooks. 67

The computed bed material discharge for the $0.45 \mathrm{~mm}$ sand is given in Table 7; Fig. 39 shows the relationship between the total bed-material load as computed by the Einstein procedure and measured total bed-material load. The computed sediment discharge is less than the actual measured amount for dunes. For the plane, standing wave, and antidune bed roughnesses, the computed amount is higher than actually measured in almost all cases. In all cases the size distributions of the computed load did not compare with the size distributions of the measured load.

TABLE 7.-MEASURED SEDIMENT DISCHARGE AND COMPUTED SEDIMENT DISCHARGE BY EINSTEIN'S METHOD

\begin{tabular}{|c|c|c|c|c|c|c|c|c|c|}
\hline Run No. & $\mathrm{V}_{*}{ }^{\prime}$ & $\mathrm{R}^{\prime}$ & $\mathrm{V} / \mathrm{V}_{*}{ }^{n}$ & $\psi^{\prime}$ & $\phi_{\mathrm{T}}$ & Bed form & $\begin{array}{c}\mathrm{Q}_{\mathrm{C}} \\
\mathrm{T} / \mathrm{D}\end{array}$ & $\begin{array}{l}\mathrm{Qm}_{\mathrm{T}} \\
\mathrm{T} / \mathrm{D}\end{array}$ & $\begin{array}{c}\text { Per- } \\
\text { centage } \\
\text { of } \\
\text { meas- } \\
\text { ure- } \\
\text { ment } \\
\end{array}$ \\
\hline 85 & 0.0583 & .224 & 12.3 & 20.5 & 0.0091 & Ripples & 0.031 & 0.23 & 13.5 \\
\hline 46 & 0.0832 & .256 & 10.85 & 10.05 & 0.285 & Dunes & 2.53 & 7.5 & 33.7 \\
\hline 47 & 0.0762 & .43 & 24.4 & 12.0 & 0.023 & Dunes & 1.06 & 0.592 & 179.0 \\
\hline 48 & 0.0752 & .338 & 12.7 & 14.1 & 0.096 & Dunes & 0.486 & 2.37 & 20.5 \\
\hline 49 & 0.107 & .205 & 8.0 & 6.08 & 1.33 & Dunes & 11.0 & 33.8 & 32.6 \\
\hline 93 & 0.074 & .236 & 15.4 & 12.7 & 0.076 & Dunes & 1.08 & 1.91 & 56.5 \\
\hline 82 & 0.090 & .1015 & 7.75 & 8.58 & 0.336 & Dunes & 4.67 & 9.40 & 49.7 \\
\hline 51 & 0.0915 & .110 & 8.22 & 8.3 & 0.46 & Dunes & 3.98 & 11.9 & 33.5 \\
\hline 94 & 0.0967 & .122 & 7.60 & 7.48 & 0.57 & Dunes & 5.59 & 14.6 & 38.2 \\
\hline 83 & 0.1125 & .197 & 10.0 & 5.50 & 0.96 & Dunes & 18.75 & 24.6 & 76.2 \\
\hline 100 & 0.272 & 0.291 & 22.4 & 0.94 & 19.1 & Plane & 596. & 487. & 122. \\
\hline 81 & 0.248 & 0.302 & 21.4 & 1.13 & 10.15 & $\begin{array}{c}\text { Standing } \\
\text { Waves }\end{array}$ & 402 . & 258. & 157. \\
\hline 84 & 0.246 & 0.254 & 23.9 & 1.15 & 11.5 & Antidunes & 415. & 295. & 141. \\
\hline
\end{tabular}

Referring to Einstein's $\phi-\psi$ curve, 66 the flume data fit the theoretical curve very well for lower regime flow conditions. For upper regime flow conditions, the values of $\phi$ are larger than the theoretical curve indicates that they should be, causing the curve to deflect sharply upward. In fact, for violent antidune activity, values of $\phi$ climbed so rapidly with respect to the decrease in magnitude of $\psi$ that $\phi$ is essentially independent of $\psi$. Subsequent work by Bishop indicates that these trends are typical for a wide range of sizes of bed material. His study also showed that the values of $A_{*}$ and $B_{*}$ given by Einstein 66 are not constant but are related to the size of bed material.

Referring to Fig. 40, the results of applying the Meyer-Peter-Müller formulas to the $0.45-\mathrm{mm}$ data are presented. 68 The points representing the com-

67 "Laboratory Studies of the Roughness and Suspended Load of Alluvial Streams," by V. A. Vanoni and N. H. Brooks, Report No. E 68, California Inst. of Tech., Pasadena, Calif., 1957.

68 "Investigation of Meyer-Peter, Müller Bed Load Formulas,” by J. R. Sheppard, Bur. of Reclam., U. S. Dept. of the Interior, Denver, Colo. 


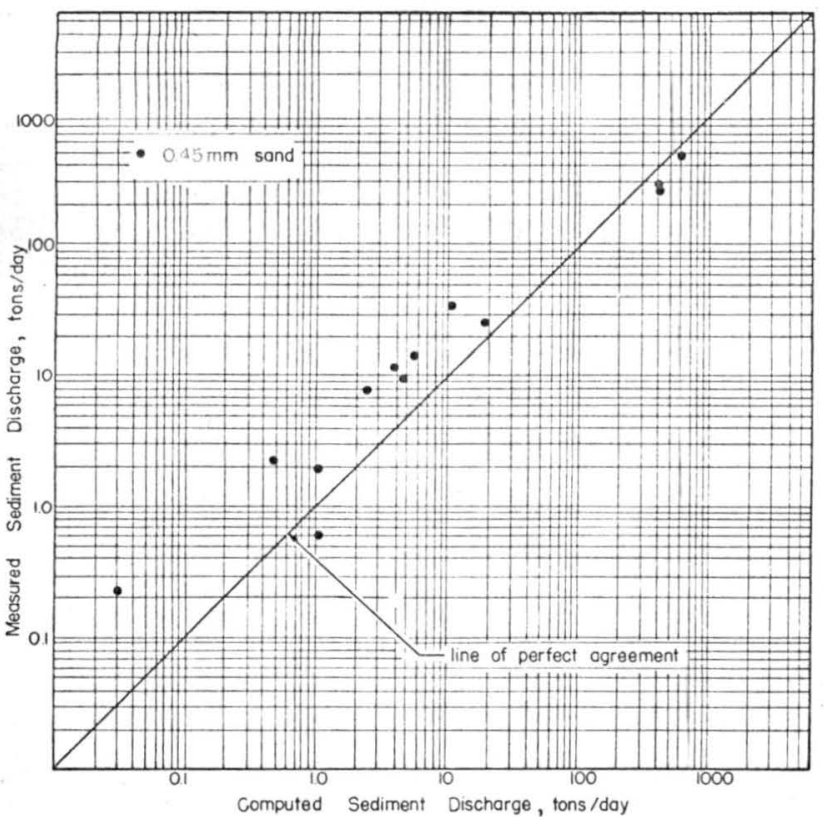

FIG. 39.-MEASURED SEDIMENT DISCHARGE COMPARED TO SEDIMENT DISCHARGE COMPUTED BY EINSTEIN'S METHOD

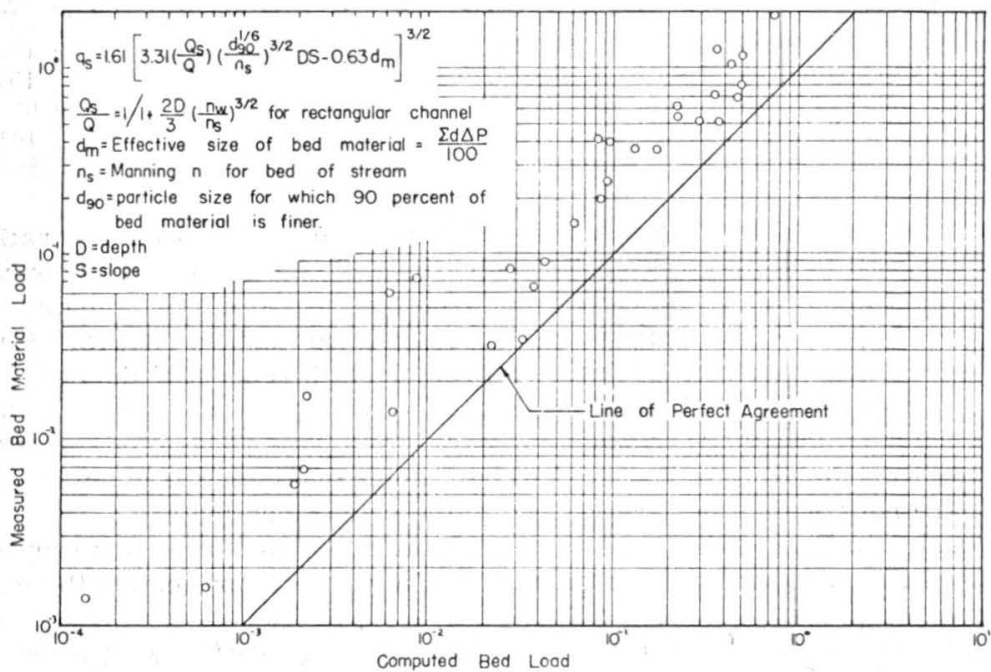

FIG. 40.-RELATION OF MEASURED TOTAL BED-MATERIAL DISCHARGE TO BED LOAD COMPUTED BY MEYER-PETER-MÜLLER EQUATION 
puted bed load versus measured bed material load plot nearly parallel to and above the line of perfect agreement. For the data to scatter about the line of perfect agreement, the average suspended load, which would be added to the computed bed load to determine the bed-material load, would have to be approximately $65 \%$ of the bed-material load. The average suspended load from approximate measurements is $30 \%$ to $40 \%$ of the bed-material load when the bed roughness is ripples, dunes, plane bed or standing waves indicating that the computed bed load may only be approximately one-half of the true bed load. However, when antidunes develop the suspended bed-material load is approximately equal to the total bed-material lcad and adding the computed bed load to this suspended load would indicate a larger than actual bed material load.

The plot of V2/D versus concentration of total load presented by Blench is interesting and gives a good relationship for both laboratory data and field data. In a study of the Rio Grande, Culbertson and Nordin of the Geological Survey, United States Department of Interior (written communication), obtained a good relation between bed material transport and $\mathrm{V} 2 / \mathrm{D}$.

It is worth noting that it is usually possible to get a fairly good relationship between concentration of bed-material load and velocity. The exception occurs when antidune activity is so violent that, as slope of channel is increased, velocity of flow decreases. Under these circumstances, the concentration of bed-material load becomes independent of average stream velocity.

Referring to Fig. 15 presented by Blench, he points out that the change to antidunes probably will occur at $\mathrm{F}_{\mathrm{b}}$ greater than 80 in all cases. The writers believe, based on their experiments, that the magnitude of $\mathrm{F}_{\mathrm{b}}$ at which antidunes develop, is a function of the size of the bed material. With fine sand the antidune flow would occur at smaller values of $F_{b}$ and for coarse sand and gravel antidunes will not occur unless $F_{b}$ is larger than Blench indicated.

The writers pointed out the existence of a break in the shear versus concentration of total load relationship, Fig. 9. This jreak signifies that the regime of flow has changed. Blench has also found that a break in the shearconcentration relation exists and that a similar break occurs in the slopetotal load relationship. However, it is doubtful that the latter type of discontinuity would be found in field situations because slope remains essentially constant as stage changes. That is, the change in regime is brought on by the change in depth not by change in slope. There is also a break in the stagedischarge relation brought on by the change in resistance to flow as regime changes. Referring to the same type of relation, Laursen and Zernial point out that the discontinuity between shear and total bed-material load can be eliminated by modifying the shear term to $\tau_{0}^{\prime}$ which is defined as

$$
\tau_{\mathrm{O}}^{\prime}=\frac{\mathrm{V}^{2} \mathrm{~d}^{1 / 3}}{30 \mathrm{D} 1 / 3} \quad \ldots \ldots \ldots \ldots \ldots
$$

in which $\tau_{0}^{\prime}$ is an approximation of the particle shear. The writers' observations are consistent with the foregoing; that is, that the discontinuity is usually caused by the change in form roughness.

In Fig. 22, Laursen and Zernial relate total bed-material load, as computed by Laursen's method, and measured total bed material load. The writers have found Laursen's method of evaluating total bed material load to be quite reliable for both laboratory and field conditions. Laursen and Zernial point out 
that the large deviation in the lower concentration range can be partly explained by the factor $\left(\tau_{\mathrm{O}}^{\prime} / \tau_{\mathrm{c}}\right)$ used in the computational procedure. Another factor that could be partly responsible for the deviation in this low concentration range is the presence of measurable quantities of light-weight material, mica, in the bed material. There is not a sufficient amount of this material to affect the conditions at larger shear values and larger transport rates, but it could have some bearing on the actual magnitude of measured total bedmaterial load within the low concentration range.

Several interesting points pertaining to sediment transport were revealed by Maddock and Langbein. They state that, with a very small concentration of bed-material load, the sediment is no burden to the stream. The writers agree that little energy is actually spent in transporting the sediment compared to the total energy of the stream. Even with a concentration of bed-material load on the order of $20,000 \mathrm{ppm}$ to $30,000 \mathrm{ppm}$ only $2 \%$ to $3 \%$ of the stream's energy is required to transport it. On the other hand, it must be kept in mind that even with small concentrations of sediment various types of form roughness develop. These can double the resistance to flow in the stream.

Maddock and Langbein took issue with the following statements made by the writers: (1) that 1,000 ppm of bed-material load is approximately an upper limit when the bed roughness is dunes, (2) that the lower limit of concentration of bed-material load in the transition zone is approximately $2,000 \mathrm{ppm}$. More specifically, they stated that it should be possible to find situations in which the bed roughness is dunes and the corresponding concentration of bed material is on the order to $4,000 \mathrm{ppm}$. Similarly, they state that it should be possible to establish a transition condition with concentrations of bed material as small as 1,000 ppm.

Studying field data and other laboratory data in which the bed roughness was known to be dunes, the writers have not found any situations in which the rate of bed-material transport exceeded approximately $1,200 \mathrm{ppm}$. The reason for this is that, to preserve dunes as the form of bed roughness as depth is increased, slope must decrease, the magnitude of the shear stress exerted by the fluid on the bed remains essentially constant, and bed-material transport is not appreciably changed. Considering the transitionzone that connects lower regime and upper regime flow, the lower limit of transition zone bed material transport should coincide approximately with the upper limit of bed material transport when the bed form is large dunes. Consequently, although the writers have not been able to do so, they agree that it may be possible to set up flow within the transition range in which the concentration of bed material is as small as $1,000 \mathrm{ppm}$.

In addition, the writers wish to acknowledge that with the limited number of variables that were considered, more attention probably should have been given to including concentration of bed-material load in their analyses. Certainly it has been demonstrated that more can be done along these lines; however, considerable additional data covering a range of sizes of bed material, gradation of bed material, and covering a range of apparent viscosities is necessary to be able to improve appreciably the existing theories of sediment transport. 